Universidade de São Paulo

Instituto de Astronomia, Geofísica e Ciências Atmosféricas

Departamento de Astronomia

Luís Henrique Sinki Kadowaki

\title{
Reconexão magnética em discos de acreção e seus efeitos sobre a formação e aceleração de jatos: um estudo teórico-numérico
}

São Paulo 

Luís Henrique Sinki Kadowaki

\section{Reconexão magnética em discos de acreção e seus efeitos sobre a formação e aceleração de jatos: um estudo teórico-numérico}

Dissertação apresentada ao Departamento de Astronomia do Instituto de Astronomia, Geofísica e Ciências Atmosféricas da Universidade de São Paulo como parte dos requisitos para a obtenção do título de Mestre em Ciências.

Área de Concentração: Astronomia

Orientadora: Prof. ${ }^{a}$ Dr. ${ }^{a}$ Elisabete M. de Gouveia Dal Pino

São Paulo 

À minha querida Andreza, com todo amor e carinho. 



\section{Agradecimentos}

À minha orientadora Prof. ${ }^{a}$ Dr..$^{a}$ Elisabete M. de Gouveia Dal Pino, por uma orientação dedicada, exemplar e paciente.

À minha família, cujos sacrifícios levaram-me a este momento tão especial.

Aos meus amigos: Rogério, Daniel, Kadu, Guilherme e Andressa, por todos os momentos em que estudamos juntos e, principalmente, por todos os momentos de descontração.

Aos meus colegas e amigos de grupo: Fernanda, Márcia, Reinaldo e Grzegorz, por todas as contribuições realizadas a partir de discussões muito construtivas sobre as simulações.

Aos meus amigos do IAG e IFUSP, por quem sinto grande admiração.

À minha querida Andreza, por todo o seu amor e dedicação. Sua paciência e carinho nos momentos mais difíceis me ajudaram a continuar sempre em frente com os meus objetivos.

À CAPES e CNPq, pelo apoio financeiro. 



\section{Resumo}

Jatos e discos de acreção associados a objetos galácticos e extragalácticos tais como, microquasares (i.e., buracos negros de massa estelar presentes em alguns sistemas binários estelares), núcleos ativos de galáxias (NAGs) e objetos estelares jovens (OEJs), frequentemente exibem eventos de ejeção de matéria quase periódicos que podem fornecer importantes informações sobre os processos físicos que ocorrem nas suas regiões mais internas. Entre essas classes de objetos, os microquasares com emissão transiente em raios-X vêm sendo identificados em nossa Galáxia desde a última década, e tal como os NAGs e quasares distantes, alguns desses sistemas também produzem jatos colimados com velocidades aparentemente superluminais, não deixando dúvidas de que se tratam de um gás ejetado com velocidades relativísticas. Um exemplo amplamente observado em comprimentos de onda do rádio aos raios-X é o microquasar GRS 1915 + 105 (e.g., Dhawan et al., 2000), que foi o primeiro objeto galáctico a exibir evidências de um jato com movimento aparentemente superluminal (Mirabel e Rodríguez, 1998, 1994).

Um modelo para explicar a origem dessas ejeções superluminais, bem como a emissão rádio sincrotrônica em flares não muito diferentes dos que ocorrem na coroa solar, foi desenvolvido por de Gouveia Dal Pino e Lazarian (2005), onde é invocado um processo de reconexão magnética violenta entre as linhas de campo magnético que se erguem do disco de acreção e as linhas da magnetosfera da fonte central. Em episódios de acreção onde a razão entre a pressão efetiva do disco e a pressão magnética diminui para valores menores ou da ordem de 1 e as taxas de acreção se aproximam da taxa crítica de Eddington, a reconexão pode tornar-se violenta e libera grandes quantidades de energia magnética em pouco tempo. Parte dessa energia aquece o gás, tanto da coroa quanto do disco, e parte acelera as partículas a velocidades relativísticas por um processo de Fermi de primeira 
ordem, pela primeira vez estudado em zonas de reconexão magnética por esses autores, produzindo um espectro sincrotronico de lei de potência com índice espectral comparável às observações.

Neste trabalho realizamos um estudo complementar, iniciado por Piovezan (2009), no qual generalizamos o modelo acima descrito para o caso dos NAGs. Nesse estudo, constatamos que a atividade de reconexão magnética na região coronal, na base de lançamento do jato, pode explicar a origem das ejeções relativísticas, dos microquasares aos NAGs de baixa luminosidade (tais como galáxias Seyfert e LINERS). A potência liberada em eventos de reconexão magnética em função das massas dos buracos negros dessas fontes, de $5 M_{\odot}$ a $10^{10} M_{\odot}$, obedece a uma correlação que se mantém por todo esse intervalo, abrangendo $10^{9}$ ordens de magnitude. Essa correlação implica em uma dependência quase linear (em um diagrama log-log), aproximadamente independente das características físicas locais dos discos de acreção dessas fontes. Além do mais, ela é compatível com o chamado "plano fundamental", obtido empiricamente, que correlaciona a emissão rádio e raios-X dos microquasares e NAGs às massas dos seus buracos negros (veja Merloni et al., 2003). Assim, o modelo de de Gouveia Dal Pino e Lazarian (2005) oferece uma interpretação física simples para a existência dessa correlação empírica, como devida à atividade magnética coronal nessas fontes. Já os quasares e NAGs mais luminosos não satisfazem à mesma correlação, possivelmente porque a densidade ao redor da região coronal nessas fontes é tão alta que "mascara" a emissão devida à atividade magnética. A emissão rádio nesses casos deve-se, possivelmente, a regiões mais externas do jato supersônico, onde ele já expandiu o suficiente para tornar-se opticamente fino e visível, e onde os elétrons relativísticos são possivelmente produzidos em choques (veja também de Gouveia Dal Pino et al., 2010a,b).

Paralelamente, investigamos a formação de eventos de reconexão magnética através de simulações magnetohidrodinâmicas axissimétricas (2.5D-MHD), da interação entre o campo magnético poloidal ancorado no disco de acreção viscoso (satisfazendo ao modelo padrão de Shakura e Sunyaev, 1973) e a magnetosfera dipolar da fonte central em rotação. Para esse fim, consideramos condições iniciais semelhantes às dos OEJs. Nos testes preliminares aqui realizados, a reconexão magnética das linhas ocorre em presença de uma resistividade numérica, que não é intensa o bastante para determinar um processo de reconexão a taxas da ordem da velocidade de Alfvén, ou seja, ela é essencialmente "lenta". 
Ainda assim, pudemos identificar alguns dos efeitos previstos pelo modelo de reconexão magnética rápida aqui estudado. Por exemplo, verificamos que a frequência e a intensidade com que eventos de reconexão magnética podem ocorrer é sensível tanto à topologia inicial do campo magnético do sistema quanto às taxas de acreção do disco (como previsto pelo modelo de de Gouveia Dal Pino e Lazarian, 2005), de modo que tais eventos ocorrem de forma mais eficiente em regimes de alta taxa de acreção. Finalmente, além da investigação sobre o desenvolvimento de eventos de reconexão magnética, pudemos também examinar a partir das simulações a formação natural de funis de acreção, os quais são colunas de acreção que conduzem gás do disco para a superfície da fonte central através das linhas do campo magnético. Os resultados desse estudo foram comparados com as observações de funis de acreção de objetos estelares jovens. 



\section{Abstract}

Jets and accretion disks associated with galactic and extragalactic objects such as microquasars (i.e., stellar-mass black holes occurring in some binary stellar systems), active galactic nuclei (AGNs) and young stellar objects (YSOs), often exhibit quasi-periodic ejections of matter that may offer important clues about the physical processes that occur in their inner regions. Among these classes of objects, microquasars with transient emission in X-rays have been identified in our Galaxy since the last decade and like AGNs and distant quasars, some of them also produce collimated jets with apparent superluminal speeds, leaving no doubt that we are also dealing with ejected gas with relativistic velocities. One example widely investigated from radio wavelengths to X-rays is the microquasar GRS $1915+105$ (e.g., Dhawan et al., 2000), which was the first Galactic object to show evidence of a jet with apparent superluminal motion (Mirabel e Rodríguez, 1998, 1994).

A model to explain the origin of the superluminal ejections and the synchrotron radio emission in flares which are not very different from those occurring in the solar corona, was developed by de Gouveia Dal Pino e Lazarian (2005), where they invoked a process of violent magnetic reconnection between the magnetic field lines that arise from the accretion

disk and the lines of the magnetosphere of the central source. In accretion episodes where the ratio between the effective disk pressure and magnetic pressure decreases to values smaller than the unity and the accretion rate approaches the critical Eddington rate, the reconnection may become violent and releases large amounts of magnetic energy in a short time. Part of this energy heats the coronal and the disk gas and part accelerates particles to relativistic velocities through a first-order Fermi-like process, which was investigated for the first time in magnetic reconnection by these authors and results a synchrotron radio power-law spectrum that is compatible to the observations. 
In the present work we conducted a complementary study, initiated by Piovezan (2009), which generalize the model described above for the case of AGNs. We found that the activity due to magnetic reconnection in the coronal region, at the base of the launching jet, can explain the origin of relativistic ejections from microquasars to low luminous AGNs (LLAGNs, such as Seyfert galaxies and LINERs). The power released by magnetic reconnection events as a function of the black hole masses of these sources, between $5 M_{\odot}$ and $10^{10} M_{\odot}$, obeys a correlation that is maintained throughout this interval, spanning $10^{9}$ orders of magnitude. This correlation implies an almost linear dependence (in a log-log diagram), which is approximately independent of the physical properties of the accretion disks of these sources. Moreover, it is compatible with the so-called "fundamental plane" obtained empirically, which correlates the radio and X-rays emission of microquasars and AGNs with the masses of their black holes (see Merloni et al., 2003). Thus, the model of de Gouveia Dal Pino e Lazarian (2005) provides a simple physical interpretation for the existence of this empirical correlation as due to coronal magnetic activity in these sources. More luminous AGNs and quasars do not seem to obey the same correlation, possibly because the density around the coronal region in these sources is so high that it "masks" the emission due to the magnetic activity. The radio emission in these cases is possibly due regions further out of the supersonic jet, where it has already expanded enough to become optically thin and visible and where the relativistic electrons are probably accelerated in shocks (see also de Gouveia Dal Pino et al., 2010a,b).

In addition, we investigated the development of magnetic reconnection events through axisymmetric magnetohydrodynamic simulations (2.5D-MHD) of the interaction between the poloidal magnetic field that arises from the viscous accretion disk (which satisfies the standard model of Shakura e Sunyaev, 1973) and the dipolar magnetosphere of the rotating central source. To this aim, we considered initial conditions which are compatible to those of YSOs. In the preliminary tests conducted here, magnetic reconnection occurs in the presence of numerical resistivity only, which is not intense enough to determine a process of reconnection with rates of the order of the Alfvén speed, i.e., it is essentially "slow". Nevertheless, we were able to identify some of the effects predicted by the model of "fast" magnetic reconnection studied here. For example, we found that the frequency and strength with which events of magnetic reconnection can occur is sensitive to both 
the initial topology of the magnetic field of the system and the accretion disk rates (as predicted by the model of de Gouveia Dal Pino e Lazarian, 2005), so that such events occur more efficiently under high accretion rates. Finally, besides the investigation of the development of magnetic reconnection events, we could also examine in our numerical studies the natural formation of funnel flows which are accretion columns that transport gas from the accretion disk to the surface of the central source along the magnetic field lines. The results of these studies were compared with the observations of funnel flows in young stellar objects. 



\section{Lista de Figuras}

1.1 Esquema em escala de cinco microquasares em nossa Galáxia. A distância entre o Sol e Mercúrio (0,4 UA) é mostrada na parte superior desse painel. A cor da estrela secundária é um indicador da sua temperatura superficial. Adaptado de Remillard e McClintock (2006). . . . . . . . . . . . . . .

1.2 Exemplo dos três estados ativos do microquasar GRO J1655-40. Da esquerda para direita são ilustrados, respectivamente, os estados TS, HS e SPLS. A linha vermelha corresponde ao espectro de energia modelado com uma componente térmica e a linha tracejada azul a uma lei de potência. Já a linha pontilhada corresponde à linha de emissão Fe K $\alpha$ alargada relativisticamente. Figura adaptada de Remillard e McClintock (2006). . . . . . . .

1.3 Observações em rádio e raios-X do microquasar GRS1915+105 obtidas entre 14 de Outubro e 8 de Novembro de 1997. No diagrama superior é apresentada a emissão em raios-X "mole" na banda 2-12 keV (triângulos vermelhos) e "dura" na banda 20-100 keV (círculos azuis). Já no painel do meio é apresentada a emissão rádio (em Jansky) em 13 e 3,6 cm (círculos vermelhos e triângulos azuis, respectivamente). No painel inferior é apresentado o índice espectral da emissão não-térmica em rádio. Todos os diagramas estão em função do tempo. Os estados plateau e flare estão representados, respectivamente, à direita e à esquerda da linha vertical preta. Figura adaptada de Dhawan et al. (2000). . . . . . . . . . . . . . . . . 
1.4 Exemplos de rádio galáxias do tipo FR I (à acima) e FR II (à baixo). A primeira corresponde ao mapa em rádio da galáxia M84, do aglomerado de Virgo; e a segunda corresponde ao quasar 3C 175. Nessa última, a posição do quasar coincide com a localização da fonte compacta brilhante. O jato, por sua vez, estende-se da fonte compacta ao lóbulo de um dos lados. Objetos FR II possuem lóbulos muito brilhantes, provavelmente, produzidos pela ejeção do plasma relativístico nos choques formados pelo impacto supersônico entre o jato e o meio intergaláctico. Figuras adaptadas de Peterson (1997) . . . . . . . . . . . . . . . .

1.5 Similaridades morfológicas e diferenças de escala entre NAGs/quasares (à esquerda) e microquasares (à direita). Figura retirada de Mirabel e Rodríguez

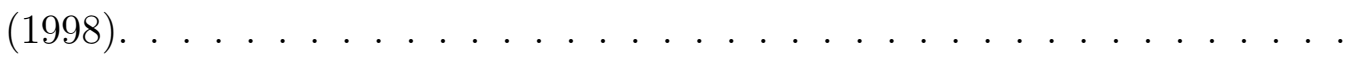

1.6 Plano fundamental dos microqusares e NAGs. Neste gráfico, $M$ é a massa do buraco negro central, $L_{R}$ é a luminosidade da emissão rádio, e $L_{X}$ a luminosidades em raios-X do sistema. Figura extraída de Merloni et al.

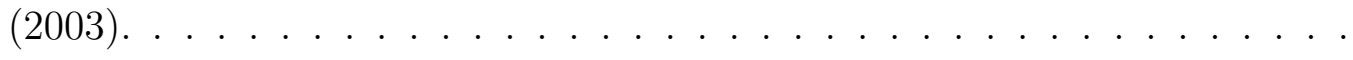

1.7 O diagrama esquemático acima mostra a evolução temporal da taxa de acreção para OEJs de baixa massa. A linha pontilhada corresponde à taxa de acreção segundo um dos primeiros cenários de formação estelar (Shu, 1977). A linha tracejada representa aproximadamente os resultados das simulações numéricas mais realísticas de formação de estrelas. A linha contínua mostra algumas características adicionais observadas, como os outbursts do tipo FU Ori e as estrelas T Tauri clássicas. Figura extraída de Schulz (2005). 47

1.8 Figura esquemática da estrutura de acreção magnetosférica em estrelas $T$ Tauri. Figura extraída de Camenzind (1990). . . . . . . . . . . . . . .

2.1 À esquerda é apresentado o esquema da configuração do campo magnético aproximadamente dipolar da fonte central e do campo poloidal que se ergue do disco de acreção, permeando a coroa logo acima deste. O raio $R_{X}$ corresponde à região onde o disco é truncado. À direita é destacada a região da zona neutra Y onde ocorrem os eventos de reconexão. Figuras adaptadas de de Gouveia Dal Pino e Lazarian (2005). . . . . . . . . . . . . . . . . 54 
2.2 À esquerda, esquema da zona de reconexão segundo o modelo de SweetParker; no centro, segundo o modelo de Petscheck; à direita, segundo o modelo de Lazarian e Vishniac (1999). Adaptado de Lazarian (2005). . . 55

2.3 Esquema da zona de reconexão. Figura extraída de Piovezan (2009). . . . . 61

2.4 Potência magnética em função da massa do buraco negro central. As estrelas correspondem às luminosidades em rádio dos microquasares GRS 1915+105, XTE J1859+226 e XTE J1550-564. Os círculos, triângulos e quadrados correspondem, respectivamente, às luminosidades em rádio de jatos nucleares produzidos por LINERs, galáxias Seyfert e quasares (obtidos de Kellermann et al., 1998; Nagar et al., 2005). As barras de erro das oito fontes mais luminosas e massivas indicam uma redução por um fator 100 devido ao relativistic beaming (Rybicki e Lightman, 1986), que provavelmente afeta a emissão dos jatos relativísticos (Kellermann et al., 1998). A cor de cada uma das barras correspondem à variação do espaço de parâmetros para diferentes intervalos de comprimento dos arcos magnéticos $(l): 0 R_{X}<l<3 R_{X}$ em preto, $3 R_{X}<l<10 R_{X}$ em cinza claro, e $10 R_{X}<l<333 R_{X}$ em cinza escuro. Veja o texto para mais detalhes. . . . . . . . . . . . . . . . . . . . 70

3.1 Perfil inicial do domínio (veja seção 3.3 adiante) com a grade computacional, em linhas amarelas, que demonstram a boa resolução obtida nas regiões mais internas do domínio. . . . . . . . . . . . . . . . .

3.2 Desenho esquemático para as condições de fronteira eqüissímetrica e axissimétrica. As setas azuis e vermelhas correspondem, respectivamente, às componentes poloidais da velocidade e do campo magnético. As linhas contínuas representam os valores dentro do domínio computacional e as tracejadas correspondem aos valores nas células fantasmas. . . . . . . . 
3.3 Perfil inicial do sistema disco-fonte central. O gráfico superior corresponde à configuração de campo magnético dos modelos I e II, onde é admitido um campo estelar puramente dipolar da ordem de $1,5 \mathrm{kG}\left(B_{*}=2,5\right.$ e $\left.B_{d}=0\right)$. Já o gráfico inferior corresponde à configuração magnética dos modelos III e IV, onde é admitida a presença tanto do campo dipolar da fonte central quanto do campo poloidal do disco de acreção $\left(B_{*}=2,5\right.$ e $\left.B_{d}=0,002\right)$, sendo esse último da ordem de 1 G. As linhas brancas correspondem ao campo conectado à fonte central, enquanto que as linhas amarelas representam o campo magnético poloidal do disco. As linhas foram interpoladas a partir do campo magnético de forma arbitrária, somente para demonstrar o seu comportamento em um determinado instante. As cores de fundo correspondem ao logaritmo da densidade em unidades do código; e as setas brancas correspondem à orientação dos campos. . . . . . . . . .

3.4 Perfis de rotação no plano equatorial do sistema, obtidos em $t=0,2 P_{*}$, e normalizados em função da velocidade angular da fonte central $\left(\Omega_{*}=0,1\right)$. A linha tracejada corresponde a um perfil de rotação puramente Kepleriano, enquanto que a linha contínua corresponde ao perfil adotado para os modelos I e III $(\xi=1)$. A linha tracejada e pontilhada corresponde aos modelos II e IV, onde admitimos um perfil 50\% menor que aquele aplicado ao primeiro grupo $(\xi=0,5)$. Em ambas as simulações, o disco é truncado em torno de

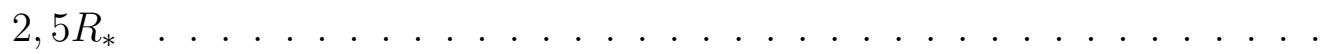

3.5 Perfil das simulações do modelo I $\left(B_{d}=0\right.$ e $\left.\xi=1\right)$ em $t=0,3 P_{*}, t=1,6$ $P_{*}, t=3,2 P_{*}$ e $t=5,6 P_{*}\left(P_{*}=2 \pi t_{0} / \Omega_{*}\right)$. As linhas brancas correspondem ao campo magnético da fonte central e foram interpoladas a partir do campo magnético de forma arbitrária. As cores de fundo correspondem ao logaritmo da densidade em unidades do código. . . . . . . . . . . . . . 92

3.6 Perfil das simulações do modelo II $\left(B_{d}=0\right.$ e $\left.\xi=0,5\right)$ em $t=0,3 P_{*}$, $t=0,6 P_{*}, t=0,9 P_{*}$ e $t=1,3 P_{*}$. Aqui, as linhas amarelas correspondem ao campo magnético reconectado e que não está mais ligado a fonte central. 
3.7 Perfil do modelo II em $t=0,3 P_{*}$ e $t=1,3 P_{*}$. Os gráficos representam o perfil de densidade sobreposta por vetores que correspondem à orientação do campo de velocidades; e a distribuição da intensidade do campo magnético do sistema (ambas em escala logarítmica). No último gráfico é possível discernir a região de reconexão. . . . . . . . . . . . . . .

3.8 Evolução temporal da taxa de acreção medida na superfície da fonte central em $R=R_{*}$ (linha contínua) e no disco de acreção em um raio arbitrário $R=4 R_{*}$ (linha tracejada). O gráfico superior corresponde às taxas de acreção do modelo I e o gráfico inferior às taxas do modelo II. . . . . . . . . .

3.9 Forças projetadas, em $t=0,9 P_{*}$, ao longo da linha de campo localizada no funil de acreção. A figura à esquerda corresponde ao modelo I e à direita ao modelo II. O gradiente de pressão é representado pela linha tracejada, a força gravitacional pela linha contínua e a força centrífuga pela linha pontilhada e tracejada. Uma força positiva empurra o material ao longo da linha de campo, da estrela para o disco. $D$ corresponde ao comprimento da linha que vai da fonte central $(D=0)$ ao plano médio do disco. . . . . . . . . . 100

3.10 Comportamento da velocidade poloidal $\left(v_{p}\right)$, da densidade $(\rho)$, da velocidade angular $(\Omega)$ e da temperatura (em Kelvin), em $t=0,9 P_{*}$, ao longo da linha de campo localizada no funil de acreção. A figura à esquerda corresponde ao modelo I e à direita ao modelo II. $D$ corresponde ao comprimento da linha que vai da fonte central $(D=0)$ ao plano médio do disco. . . . . . . 100

3.11 Perfil das simulações do modelo III $\left(B_{d}=0,002\right.$ e $\left.\xi=1\right)$ em $t=0,3 P_{*}, t=$ $1,6 P_{*}, t=3,2 P_{*}$ e $t=5,6 P_{*}$. As linhas brancas correspondem ao campo magnético conectado à fonte central e as linhas amarelas ao campo poloidal do disco (desconectado da fonte central). As cores de fundo correspondem ao logaritmo da densidade em unidades do código. . . . . . . . . . . . . . . 102

3.12 Perfil das simulações do modelo IV $\left(B_{d}=0,002\right.$ e $\left.\xi=0,5\right)$ em $t=0,3 P_{*}$, $t=0,6 P_{*}, t=0,9 P_{*}$ e $t=1,3 P_{*}$. As cores correspondem às mesmas da figura 3.11 . 
3.13 Perfil do modelo III em $t=5,6 P_{*}$. O painel superior apresenta o perfil de densidade, em escala logarítmica, sobreposta por vetores que correspondem à orientação do campo de velocidades. Esses vetores revelam a presença de um fraco vento que ejeta matéria do disco de acreção próximo à região de reconexão. No painel inferior é apresentada a distribuição da intensidade de campo magnético do sistema em escala logarítmica, onde é possível discernir uma superfície de baixa magnetização, correspondente à reconexão (ou ao lençol de corrente). . . . . . . . . . . . . . . . . . . . 105

3.14 Perfil do modelo IV em $t=1,3 P_{*}$. O painel superior apresenta o perfil de densidade, em escala logarítmica, sobreposta por vetores que correspondem à orientação do campo de velocidades. No painel inferior é apresentada a distribuição da intensidade de campo magnético do sistema em escala logarítmica, onde é possível discernir a região de reconexão (ou ao lençol de corrente). Essa, por sua vez, apresenta um forte gradiente de $\boldsymbol{B}$, que se anula no lençol de corrente. . . . . . . . . . . . . . . . . . . . . 106

3.15 Evolução temporal da taxa de acreção medida na superfície da fonte central (linha contínua) e no disco de acreção (linha tracejada) em um raio arbitrário, $R=4 R_{*}$. O gráfico superior corresponde às taxas de acreção do modelo III e o gráfico inferior às taxas do modelo IV. . . . . . . . . . . . . 107

3.16 Forças projetadas, em $t=0,9 P_{*}$, ao longo da linha de campo localizada no funil de acreção. A figura à esquerda corresponde ao modelo III e à direita ao modelo IV. O gradiente de pressão é representado pela linha tracejada, a força gravitacional pela linha contínua e a força centrífuga pela linha pontilhada e tracejada. Uma força positiva empurra o material ao longo da linha de campo, da estrela para o disco. $D$ corresponde ao comprimento da linha que vai da fonte central $(D=0)$ ao plano médio do disco. . . . . . 108

3.17 Comportamento da velocidade poloidal $\left(v_{p}\right)$, da densidade $(\rho)$, da velocidade angular $(\Omega)$ e da temperatura (em Kelvin), em $t=0,9 P_{*}$, ao longo da linha de campo localizada no funil de acreção. A figura à esquerda corresponde ao modelo III e à direita ao modelo IV. $D$ corresponde ao comprimento da linha que vai da fonte central $(D=0)$ ao plano médio do disco. 
3.18 Perfil das simulações do modelo I em $t=1,6 P_{*}$. Os dois gráficos superiores correspondem ao caso com resfriamento e os dois últimos ao caso sem resfriamento, onde é visível o processo de expansão devido o aquecimento nas regiões mais internas do disco de acreção. A densidade encontra-se em unidades do código e a temperatura em Kelvin. Ambas são representadas em escala logarítmica. . . . . . . . . . . . . . . . . . . . . . . . 110

A.1 Dois elementos de fluído em órbitas vizinhas conectadas por uma mola fraca. A mola exerce uma força de tensão restauradora sobre o sistema resultando em um transporte de momento angular para fora do disco Balbus e Hawley (1998)

B.1 Padrão de ondas gerado pela solução local do problema de Riemann nas interfaces das células em $i-1 / 2$ e $i+1 / 2$. Figura obtida de Toro (2009). . 144

B.2 Posição das componentes do campo magnético ( $B$ e $b$ ) e das demais variáveis $(p)$ no espaço bidimensional e tridimensional. As quantidades centrais são representadas pelos círculos verdes e as quantidades localizadas nas faces pelos quadrados vermelhos. Na formulação CT, a força eletromotriz $(\Omega)$ é definida nas bordas da célula, representada pelos losangos azuis. Figura obtida do manual do usuário do código PLUTO (http://plutocode.to.astro.it).146 



\section{Lista de Tabelas}

1.1 Tabela comparativa entre NAGs/Quasares e microquasares. . . . . . . . . 43

3.1 Parâmetros fixos das simulações. . . . . . . . . . . . . . . . . . . . . . 87

3.2 Parâmetros livres e modelos da simulações. . . . . . . . . . . . . . . . . . . 88

B.1 Sistemas de coordenadas adotada pelo PLUTO. . . . . . . . . . . . . . . . 142

C.1 Medidas da emissão em rádio para os jatos nucleares, na escala de parsecs, para galáxias Seyfert e LINERs. . . . . . . . . . . . . . . . . . . . . 147 



\section{Sumário}

1. Introdução . . . . . . . . . . . . . . . . . . . . . . . . . . . . . . . . . . . 29

1.1 Sistemas estelares binários com buracos negros (ou microquasares) . . . . . 32

$1.1 .1 \quad$ Espectro em raios-X . . . . . . . . . . . . . . . . 34

1.1.2 Emissão simultânea em rádio e raios-X . . . . . . . . . . . . . 36

1.2 Núcleos Ativos de Galáxias . . . . . . . . . . . . . . . . . . . . . . . . 38

1.2.1 Propriedades em rádio e jatos relativísticos . . . . . . . . . . . . . 40

1.2.2 Similaridades com microquasares e o plano fundamental . . . . . . 41

1.3 Objetos Estelares Jovens . . . . . . . . . . . . . . . . . . . . 45

1.3.1 Taxas de acreção . . . . . . . . . . . . . . . 46

1.3.2 Atividade magnética . . . . . . . . . . . . . . . . . 47

2. Estudo analítico de eventos de reconexão magnética . . . . . . . . . . . . . . . . 51

2.1 Cenário de reconexão de de Gouveia Dal Pino e Lazarian . . . . . . . . . . 51

2.1.1 Formação da magnetosfera de um buraco negro . . . . . . . . . . . 51

2.1.2 Origem do campo magnético poloidal do disco . . . . . . . . . . . 52

2.1.3 Formação de um evento de reconexão magnética . . . . . . . . . . . 53

2.2 Eventos de reconexão em microquasares . . . . . . . . . . . . . . 56

2.2.1 Parâmetros do disco de acreção . . . . . . . . . . . . . . 57

2.2.2 Parâmetros da coroa magnetizada . . . . . . . . . . . . . . 59

2.2.3 Taxa de energia magnética liberada na reconexão magnética . . . . 61

2.2.4 Aceleração de partículas e emissão em rádio . . . . . . . . . . . . 63

2.2.5 Análise do espaço de parâmetros para microquasares . . . . . . . . 65 
2.2.6 Emissão em raios-X e a transição entre as fases do SPLS . . . . . . 66

2.3 Generalização do modelo para NAGs . . . . . . . . . . . . . . . . . 67

2.3.1 Taxa de energia magnética e análise do espaço de parâmetros para os NAGs . . . . . . . . . . . . . . . . . . . 68

2.3.2 Resultado da generalização do modelo de reconexão magnética violenta: dos microquasares aos NAGs . . . . . . . . . . . . 69

2.4 Reconexão magnética em objetos estelares jovens . . . . . . . . . . . . . 71

2.4.1 Taxa de energia magnética e análise do espaço de parâmetros . . . 72

2.5 Discussões . . . . . . . . . . . . . . . . . . . . . . . . . 74

3. Simulações magnetohidrodinâmicas axissimétricas de reconexão magnética em discos de acreção . . . . . . . . . . . . . . . . . . . . . . . 77

3.1 Equações magnetohidrodinâmicas e o método computacional . . . . . . . . 78

3.2 Domínio Computacional . . . . . . . . . . . . . . . . . 80

3.3 Condições iniciais no domínio e os termos de viscosidade e resfriamento . . 80

3.4 Condições de contorno (ou de fronteira) . . . . . . . . . . . . . 83

3.5 Unidades de referência e dimensionalização das unidades . . . . . . . . . . 85

3.6 Análise e resultados das simulações . . . . . . . . . . . . . . . 87

3.6.1 Simulações com campo magnético puramente dipolar (modelos I e II) 90

3.6.2 Simulações com campo magnético dipolar da fonte central e campo poloidal do disco $($ modelos III e IV) . . . . . . . . . . . . . . . 101

3.7 Efeitos do termo de resfriamento nas simulações . . . . . . . . . . . . . 107

3.8 Discussões . . . . . . . . . . . . . . . . . . . . . . . . . . . . . . . . . . . . . 109

4. Conclusões e Perspectivas . . . . . . . . . . . . . . . . . . . . . 113

Referências . . . . . . . . . . . . . . . . . . 117

Apêndice

A. Alguns conceitos e equações fundamentais de discos de acreção . . . . . . . . . . 129

A.1 Instabilidade magneto-rotacional f . . . . . . . . . . . . . . . . . 129

A.2 Potência de acreção do disco . . . . . . . . . . . . . . . . . . . 130 
A.3 Discos Keplerianos . . . . . . . . . . . . . . . . . . . . . . . 132

A.4 Parametrização $\alpha$ do disco . . . . . . . . . . . . . . . . . . . . . . 136

B. Método Numérico e o código PLUTO . . . . . . . . . . . . . . . . . . . . . . . 139

B.1 Estrutura do código . . . . . . . . . . . . . . . . . . . . 140

B.2 Solução numérica . . . . . . . . . . . . . . . . . . . . . . . 141

B.3 Soluções de Riemann . . . . . . . . . . . . . . . . . . . . . . . . . . . . . . 143

B.4 Termos fontes e termos dissipativos . . . . . . . . . . . . . 145

B.5 Divergência de $\boldsymbol{B}$ e a técnica de divisão de campo . . . . . . . . . . . . . 145

C. Tabela da emissão rádio observada em NAGs . . . . . . . . . . . . . . . . . . . 147 

Capítulo 1

\section{Introdução}

Observam-se fluxos de matéria com diferentes graus de colimação emergindo de uma grande variedade de sistemas astrofísicos, desde os mais colimados e potentes, como os jatos relativísticos que são produzidos por buracos negros supermassivos em núcleos ativos de galáxias (NAGs); até os menos potentes, como ventos e jatos supersônicos associados a objetos estelares jovens (OEJs) em regiões de formação estelar em nossa própria Galáxia. Em escalas intermediárias entre esses dois casos extremos, encontram-se, também, evidências de jatos relativísticos associados a sistemas estelares binários que hospedam estrelas de nêutrons ou buracos negros de massa estelar como a componente primária. Esses últimos são também usualmente denominados de microquasares (veja Mirabel e Rodríguez, 1998). Esses fluxos representam verdadeiros canais através dos quais massa, energia, momento angular e campo magnético são ejetados das fontes progenitoras. Portanto, são reconhecidos como excelentes laboratórios para o estudo de processos físicos associados a essas fontes, as quais frequentemente são inacessíveis observacionalmente. Em consequência, foram realizados nas últimas décadas intensos estudos, tanto analíticos quanto numéricos, sobre os mecanismos de formação desses fluxos com o objetivo de compreender a origem, estrutura e evolução desses sistemas (veja de Gouveia Dal Pino, 2005, e referências lá contidas).

Em particular, os jatos astrofísicos apresentam fortes indícios da existência de um mecanismo universal de produção, aceleração e colimação, já que apresentam características morfológicas que atuam independente das escalas dimensionais e energéticas ${ }^{1}$. Todas as

\footnotetext{
${ }^{1}$ Os jatos de NAGs possuem comprimentos típicos de $10^{6} \mathrm{pc}\left(1 \mathrm{pc}=3,086 \times 10^{18} \mathrm{~cm}\right)$; e objetos centrais com massas da ordem de $10^{6-9} M_{\odot}\left(1 M_{\odot}=2 \times 10^{33} \mathrm{~g}\right)$ e luminosidades no intervalo de $10^{43-48} L_{\odot}$ $\left(1 L_{\odot}=3,826 \times 10^{33} \mathrm{erg} / \mathrm{s}\right)$. Já os jatos de OEJs e de microquasares, apresentam dimensões típicas de 1 pc; e massas e luminosidades da fonte central da ordem de $1-10 M_{\odot}$ e $10^{4}-10^{39} L_{\odot}$, respectivamente.
} 
classes de jatos, por exemplo: (a) propagam-se por distâncias significativas, mantendo-se altamente colimados; (b) apresentam frequentemente uma ejeção bipolar, isto é, são ejetados em duas direções diametralmente opostas à fonte progenitora; (c) originam-se em objetos compactos; (d) apresentam ao longo de sua extensão uma cadeia de nós internos brilhantes separados por distâncias relativamente regulares entre si; (e) frequentemente terminam em lobos de emissão térmica no caso dos jatos de OEJs, e não-térmica contínua sincrotrônica no caso dos jatos relativísticos, os quais são interpretados como superfícies de trabalho onde os jatos chocam-se supersonicamente com o gás do meio ambiente; (f) e apresentam evidências de movimentos ondulatórios e precessantes com relação à direção preferencial em que se propagam (e.g., de Gouveia Dal Pino, 2005).

O mecanismo mais aceito atualmente para explicar a origem dos jatos foi proposto na década de 80 por Blandford e Payne (1982) (veja também Lovelace, 1976; e o modelo revisado em Spruit, 1996). Esse modelo parte da ideia de que um disco de acreção em rotação, ao redor da fonte central, fornece o material gasoso que escapa através das linhas de campo magnético que se erguem para a coroa, via aceleração magneto-centrífuga ${ }^{2}$. Nesse processo, o gás carrega o excesso de momento angular do disco, ao mesmo tempo em que forma um jato supersônico. Em contrapartida, ainda existem questões em aberto já que esse modelo não explica como ocorre a formação dos campos magnéticos no disco e na coroa que o envolve, nem como esse campo interage com as linhas magnéticas ancoradas à fonte central. Esse modelo tampouco explica os eventos de ejeção de matéria quaseperiódicos observados logo na base de jatos relativísticos associados a microquasares, NAGs e possivelmente também a surtos de raios gama (GRBs, do inglês gamma-ray bursts).

Essas ejeções intermitentes produzem uma emissão rádio sincrotrônica a partir de erupções brilhantes e intensas (flares, em inglês) não muito diferentes das que ocorrem na coroa solar. Nos microquasares, por exemplo, são normalmente detectados durante

\footnotetext{
${ }^{2}$ Basicamente, o processo de aceleração ocorre em uma região onde o disco e sua coroa magnetizada encontram-se em corrotação, com um perfil aproximadamente Kepleriano. Como a força de Lorentz tem apenas componentes perpendiculares ao campo, o gás é livre para mover-se ao longo das linhas sob a influência de outras forças. Na base da linha de campo, a força gravitacional é balanceada pela força centrífuga. Já ao longo da linha, a força centrífuga cresce com a distância ao eixo, de maneira que quando a sua componente paralela ao campo tornar-se maior que a gravitacional, o gás preso à linha é acelerado para fora do sistema (Spruit, 1996).
} 
uma fase de grande atividade nessas fontes. Um objeto frequentemente estudado e observado desde comprimentos de onda do rádio até os raios-X é o microquasar GRS 1915+105 (e.g., Dhawan et al., 2000). A uma distância de 12,5 kpc e com um buraco negro central de 10 massas solares, esse foi o primeiro objeto galáctico a exibir evidências de um jato com movimento aparentemente superluminal ${ }^{3}$ (Mirabel e Rodríguez, 1998, 1994). Embora esses sistemas sejam muito complexos, interessantes correlações entre as emissões em rádio e a atividade em raios-X são verificadas (Remillard e McClintock, 2006; Dhawan et al., 2000, veja as próximas seções para uma descrição mais detalhada).

Um modelo para explicar tanto a origem dos plasmóides superluminais, quanto os flares em rádio e a correlação com as observações em raios-X associadas a essas fontes, foi desenvolvido por de Gouveia Dal Pino e Lazarian (2005). Esse modelo descreve um cenário em que eventos de ejeção de matéria quase-periódicos podem ocorrer através de eventos de reconexão magnética violenta acompanhados por uma aceleração do gás a velocidades relativísticas pelo mecanismo de Fermi de primeira ordem (veja o capítulo 2 para uma descrição mais detalhada). As linhas de campo magnético, possivelmente criadas por um processo de dínamo turbulento (Livio et al., 2003; King et al., 2004; Uzdensky e Goodman, 2008), levantam-se do disco de acreção e, ao preencher a coroa, reconectam-se com as linhas da magnetosfera da fonte central ${ }^{4}$. Em episódios de acreção que se aproximam da taxa crítica de Eddington, a reconexão torna-se violenta e libera grandes quantidades de energia magnética em curtos períodos de tempo. Parte dessa energia aquece o gás, tanto da coroa quanto do disco, e parte acelera as partículas a velocidades relativísticas por processo de Fermi de primeira ordem, produzindo um espectro sincrotrônico de lei de potência com índice espectral comparável ao observado em microquasares e NAGs (de Gouveia Dal Pino e Lazarian, 2005). Estudos realizados posteriormente por Piovezan

\footnotetext{
${ }^{3}$ Movimentos superluminais consistem em velocidades aparentemente maiores que a velocidade da luz, porém, constituem um fenômeno puramente geométrico em relação à linha de visada do observador, facilmente explicável dentro da teoria de relatividade especial. Neste caso, as componentes dos jatos são lançados a velocidades relativísticas, ou seja, próximas de $c$ (veja Mirabel e Rodríguez, 1998).

${ }^{4}$ Como veremos no capítulo 2 , a reconexão entre as linhas de campo magnético só será rápida e eficiente se a resistividade magnética local for anômala, ou se o meio for turbulento. Na presença da turbulência, por exemplo, Lazarian e Vishniac (1999) demonstraram que a reconexão magnética pode tornar-se extremamente eficiente e independente da resistividade local em qualquer meio astrofísico (veja também Kowal et al., 2009).
} 
(2009), e complementados nesta dissertação, revelaram que a taxa de energia magnética liberada nesses eventos é mais do que suficiente para explicar a luminosidade em rádio tanto dos microquasares quanto dos NAGs menos luminosos (veja também de Gouveia Dal Pino et al., 2010a,b).

Nesta dissertação, o modelo analítico de reconexão, originalmente generalizado para os NAGs por Piovezan (2009), foi revisado e complementado. Paralelamente, investigamos a formação de eventos de reconexão magnética através de simulações magnetohidrodinâmicas axissimétricas (2.5D-MHD), da interação entre o campo magnético poloidal ancorado em um disco de acreção viscoso (satisfazendo ao modelo padrão de Shakura e Sunyaev, 1973) e a magnetosfera dipolar de uma fonte central em rotação.

Nas seções subsequentes, apresentaremos uma breve descrição sobre as principais características observacionais que indicam a presença de um evento de reconexão magnética violenta em microquasares, NAGs e OEJs; que por sua vez, dão sustentabilidade ao modelo de reconexão aqui descrito. No capítulo 2, será realizada uma descrição mais completa do modelo de de Gouveia Dal Pino e Lazarian (2005), assim como será apresentada a análise complementar, realizada neste trabalho, da energia magnética liberada em eventos de reconexão violenta, dos microquasares aos NAGs. No capítulo 3, serão apresentados os modelos e os resultados das simulações numéricas, bem como, uma discussão sobre o desenvolvimento de eventos de reconexão magnética (também denominados de lençóis de corrente) e as suas semelhanças com o modelo aqui citado. Por fim, no capítulo 4, a conclusão e as perspectivas futuras desse trabalho serão apresentadas.

\subsection{Sistemas estelares binários com buracos negros (ou microquasares)}

A primeira forte evidência da presença de um buraco negro foi obtida através das observações no óptico e em raios-X da fonte Cygnus X-1 (Bolton, 1972; Webster e Murdin, 1972), um sistema binário caracterizado pela presença de uma estrela não-degenerada cuja matéria é capturada por um disco de acreção em torno de um buraco negro (veja figura $1.1)$.

Atualmente, vinte sistemas similares a Cygnus X-1 já foram identificados com objetos primários massivos demais para serem estrelas de nêutrons ou estrelas degeneradas de qualquer tipo (para uma descrição mais detalha dessas vinte fontes veja Remillard e 


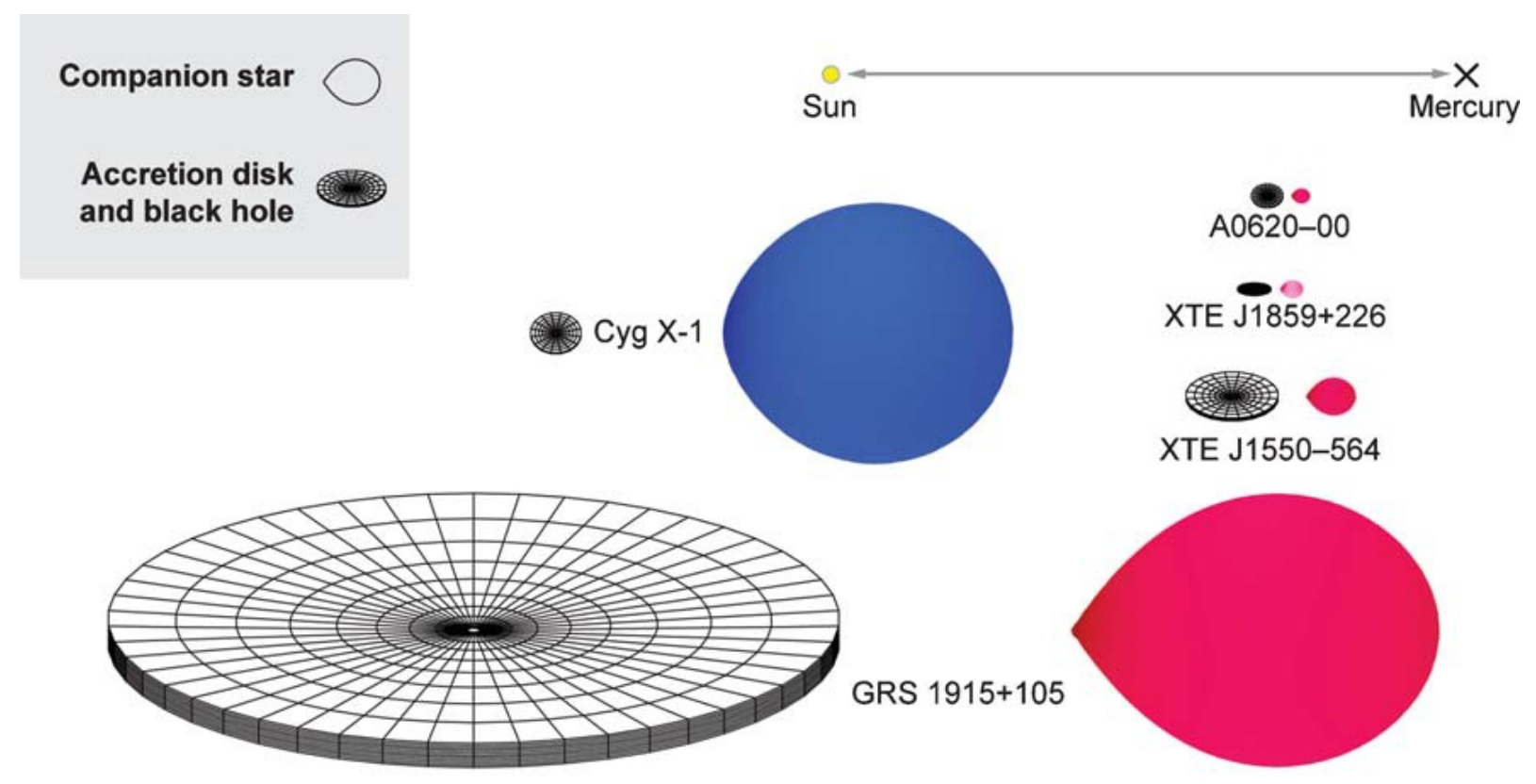

Figura 1.1: Esquema em escala de cinco microquasares em nossa Galáxia. A distância entre o Sol e Mercúrio (0,4 UA) é mostrada na parte superior desse painel. A cor da estrela secundária é um indicador da sua temperatura superficial. Adaptado de Remillard e McClintock (2006).

McClintock, 2006). Em outras palavras, são objetos com dimensões típicas de aproximadamente $10 \mathrm{~km}$ e que apresentam massas superiores a $3 M_{\odot}$, caracterizando, portanto, buracos negros de massa estelar. Apesar das diferenças de escala física com os quasares (também classificados como NAGs; veja adiante), essas fontes apresentam características morfológicas em comum, o que levou a serem também chamadas de microquasares, denominação que será utilizada nessa dissertação. Essas similaridades morfológicas serão discutidas adiante na seção 1.2 .

Após a descoberta de Cygnus X-1, o segundo microquasar identificado foi LMC X-3 (Cowley et al., 1983). Ambos apresentam uma intensa e persistente emissão em raios-X, e os objetos secundários são estrelas massivas do tipo O/B (Remillard e McClintock, 2006). Já o terceiro microquasar identificado, A 0620-00, é notavelmente diferente (McClintock e Remillard, 1986). A sua descoberta ocorreu em 1975, quando apresentou uma intensa emissão em raios-X, decaindo ao longo de um ano, até atingir um estado de baixa emissão que se prolonga até hoje (McClintock et al., 1995). Essas características são interpretadas como diferentes estados de emissão que os microquasares podem sofrer: desde uma fase de intensa e persistente emissão em raios-X, até uma fase transiente, onde apresentam 
emissões intensas seguidas por períodos de baixa atividade (sendo essa última, comumente denominada de estado quiescente).

\subsubsection{Espectro em raios- $X$}

O espectro em raios-X dos microquasares frequentemente exibe uma forma composta por uma componente térmica e outra não-térmica, no qual uma das componentes pode dominar. A componente térmica originária da região interna do disco de acreção é modelada por uma aproximação de corpo negro e exibe temperaturas próximas a $1 \mathrm{keV}$. Já a componente não-térmica é usualmente modelada por uma lei de potência caracterizada por um índice $\Gamma$, onde a distribuição de elétrons é dada por $N(E) d E \propto E^{-\Gamma}$. Essa lei de potência, por sua vez, estende-se a regiões mais energéticas quando comparadas com a componente térmica e pode sofrer uma quebra ou um corte exponencial nas altas energias.

O espectro em raios-X dos microquasares também pode apresentar uma linha de emissão Fe K $\alpha$ que é frequentemente alargada relativisticamente. Em algumas dessas fontes, particularmente naquelas cuja inclinação permite observar o disco frontalmente, o modelo espectral requer a inclusão de uma componente de reflexão (Done e Nayakshin, 2001). Nesse caso, a lei de potência em raios-X é refletida pelo disco de acreção e produz uma saliência no espectro entre 10 e $30 \mathrm{keV}$ (espectral bump, em inglês).

Examinando a emissão em raios-X na banda 2-20 keV, os microquasares em geral apresentam dois estados principais de emissão, um quiescente e outro explosivo (outburst, em inglês). O primeiro é caracterizado por baixas luminosidades em raios-X e um espectro não-térmico "duro". Esse estado possui longa durabilidade, o que permite obter parâmetros físicos importantes como o espectro da estrela secundária, que se torna proeminente.

Por outro lado, durante o estado de outburst a fonte apresenta atividade e emissão intensas, e pode ser subclassificada em três estados ativos principais e muitos outros intermediários. Remillard e McClintock (2006) classificaram os três estados ativos a partir do espectro em raios-X obtido da base de dados do satélite RXTE, eliminando o critério de luminosidade que era utilizada em classificações anteriores (veja Tananbaum et al., 1972).

O primeiro estado foi classificado como térmico (TS, do inglês thermal state), onde o fluxo é dominado pela radiação quente da região interna do disco de acreção. Frequentemente, há uma segunda componente não-térmica cuja contribuição é limitada a intensi- 


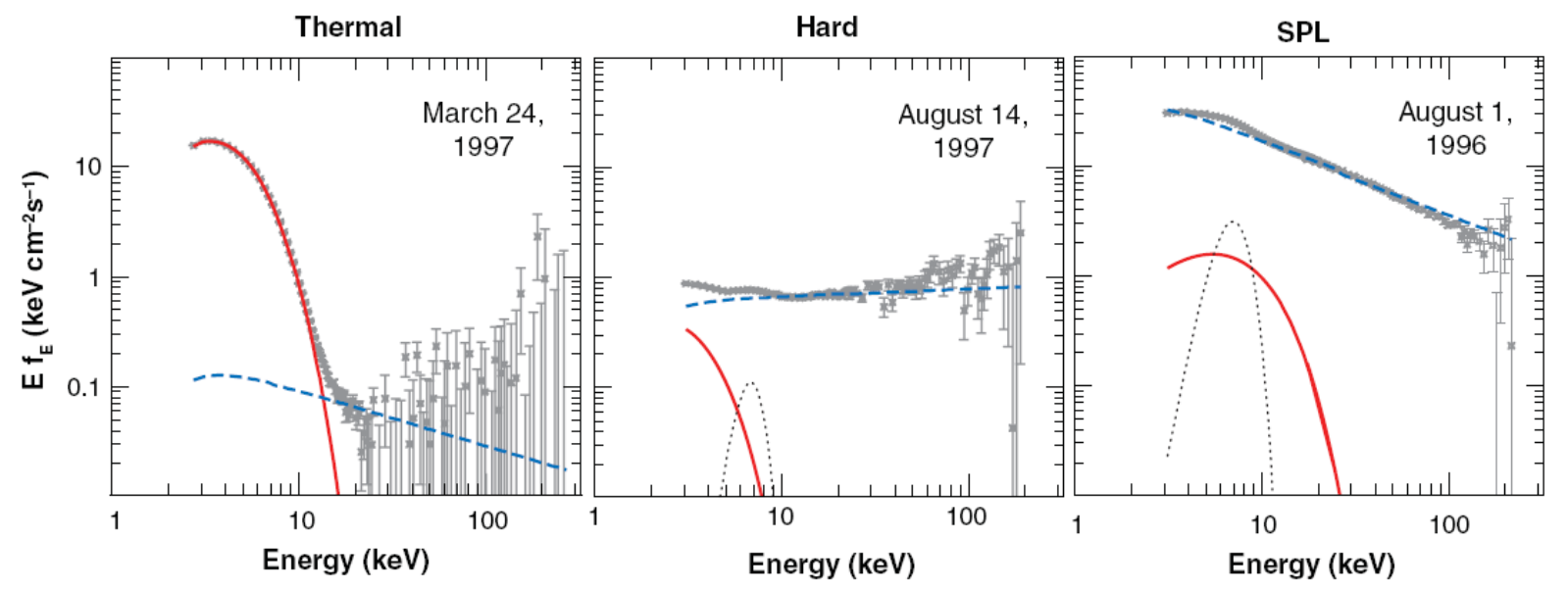

Figura 1.2: Exemplo dos três estados ativos do microquasar GRO J1655-40. Da esquerda para direita são ilustrados, respectivamente, os estados TS, HS e SPLS. A linha vermelha corresponde ao espectro de energia modelado com uma componente térmica e a linha tracejada azul a uma lei de potência. Já a linha pontilhada corresponde à linha de emissão Fe K $\alpha$ alargada relativisticamente. Figura adaptada de Remillard e McClintock (2006).

dades menores que $25 \%$ do fluxo na banda 2-20 keV. Esse estado é ilustrado no primeiro espectro à esquerda da figura 1.2, obtido das observações do microquasar GRO J1655-40. O espectro da figura mostra que a componente térmica (linha vermelha) é mais intensa que a componente em lei de potência (linha tracejada azul) para energias menores que 10 $\mathrm{keV}$.

Já o segundo estado foi classificado como "duro" (HS, do inglês hard state), caracterizado por uma lei de potência não-térmica (com $\Gamma \sim 1,7)$ que contribui com mais de $80 \%$ do fluxo na banda 2-20 keV. Esse estado é ilustrado no espectro do meio da figura 1.2. Além disso, durante o HS, o disco de acreção parece ser pouco brilhante e frio comparado ao TS e há evidências da presença de um jato nuclear em rádio quase estacionário, com uma clara correlação com a emissão em raios-X "dura".

Por fim, o terceiro estado foi classificado de acordo com o espectro dominante em lei de potência com índice espectral $\Gamma \sim 2,5$ (SPLS, do inglês steep power law state). Em algumas fontes, essa lei de potência foi detectada sem quebras até energias da ordem de 1 MeV (Remillard e McClintock, 2006). Além disso, uma componente térmica considerável está presente. Um exemplo desse estado está ilustrado no espectro mais à direita da figura 1.2. 
A transição entre esses três estados é frequentemente interpretada como devida a mudanças no fluxo de acreção. Por exemplo, durante o TS, a emissão térmica em raios-X "mole" é atribuída às regiões mais internas dos discos de acreção que se estendem até a última órbita estável do buraco negro. Ela é produzida pelo aquecimento do gás à medida que o mesmo perde energia gravitacional ao ser acretado na direção do buraco negro, alcançando temperaturas da ordem de $10^{7} \mathrm{~K}$. Por outro lado, durante o HS, a fraca emissão térmica sugere que o disco é truncado em raios superiores ao da última órbita estável. Por sua vez, a forte emissão em raios-X "dura" é usualmente atribuída ao espalhamento Compton inverso dos fótons de raios-X "moles", produzidos nas regiões mais externas do disco, pelos elétrons relativísticos produzidos nas regiões mais internas do sistema (Remillard e McClintock, 2006; Malzac, 2007).

\subsubsection{Emissão simultânea em rádio e raios- $X$}

Além do objeto GRO J1655-40, outro microquasar amplamente investigado é o GRS 1915+105. Dhawan et al. (2000) efetuaram medidas dessa fonte obtendo espectros simultâneos em rádio e em raios-X, em várias épocas, identificando dois estados principais de atividade, o plateau e o flare (veja figura 1.3). Durante o estado de plateau, a emissão em raios-X "mole" é fraca, enquanto que a emissão em raios-X "dura" é intensa. O espectro em rádio correspondente é produzido por um pequeno jato nuclear, na escala de parsecs, com um índice espectral próximo de zero.

Por outro lado, durante a fase de flare, a ejeção em rádio torna-se opticamente fina e é expulsa a velocidades relativísticas, estendendo-se por centenas de unidades astronômicas e apresentando um espectro de emissão em rádio com índice espectral entre 0,5 e 0,8. Durante essa fase, a emissão em raios-X "mole" é também intensa e exibe uma alta variabilidade, enquanto que a emissão em raios-X "dura" enfraquece por um período de poucos dias, e depois se recupera.

Em termos dos estados espectrais em raios-X (proposto por Remillard e McClintock, 2006), vários trabalhos verificaram que os flares em rádio ocorrem durante o SPLS (e.g., Fender et al., 2004). Além disso, esses mesmos trabalhos argumentam que a emissão em raios-X, tanto no plateau quanto no flare, são diferentes manifestações desse mesmo estado (e.g., Reig et al., 2003). As observações em rádio e raios-X de microquasares como XTE 


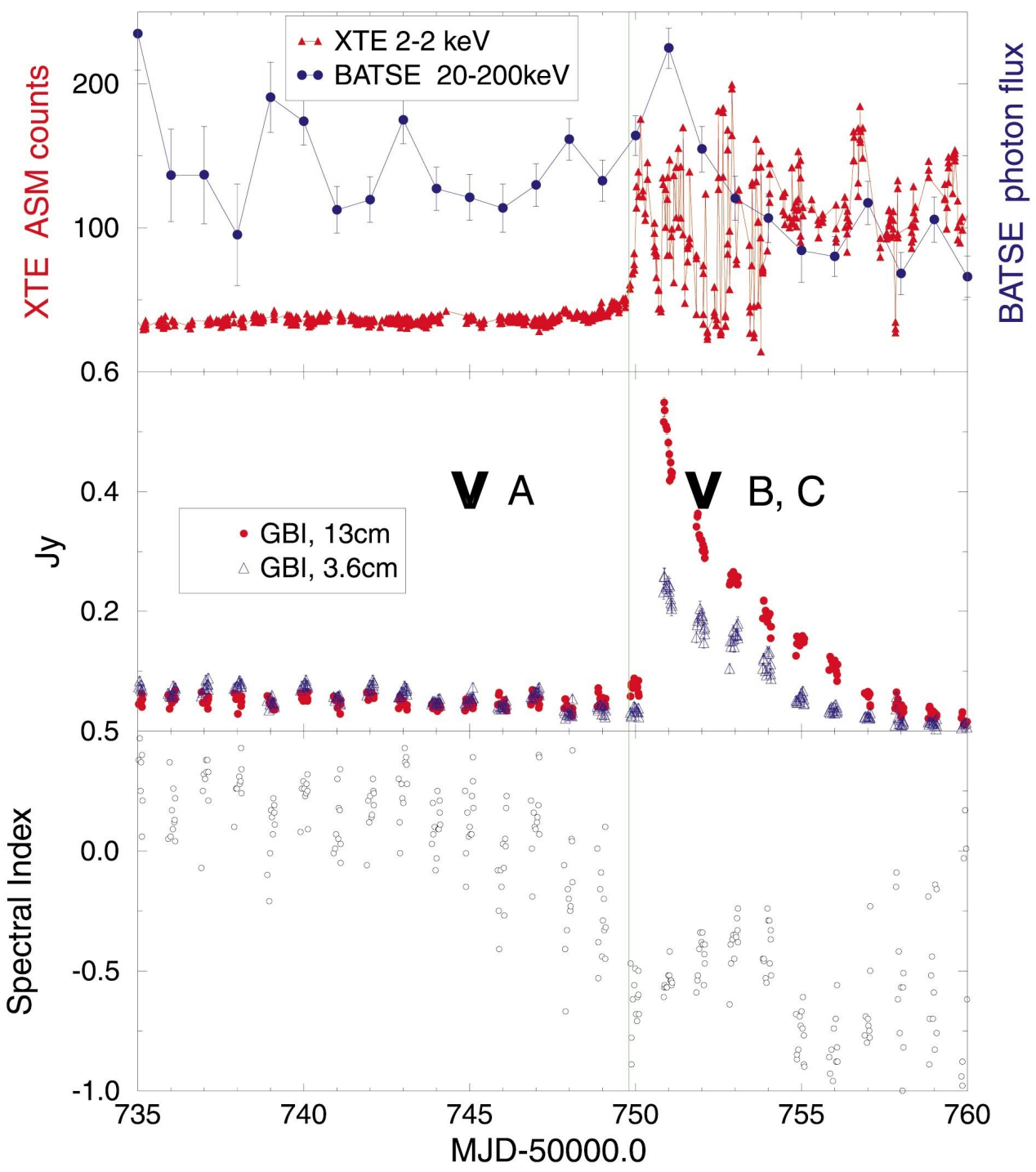

Figura 1.3: Observações em rádio e raios-X do microquasar GRS1915+105 obtidas entre 14 de Outubro e 8 de Novembro de 1997. No diagrama superior é apresentada a emissão em raios-X "mole" na banda 2-12 keV (triângulos vermelhos) e "dura" na banda 20-100 keV (círculos azuis). Já no painel do meio é apresentada a emissão rádio (em Jansky) em 13 e 3,6 cm (círculos vermelhos e triângulos azuis, respectivamente). No painel inferior é apresentado o índice espectral da emissão não-térmica em rádio. Todos os diagramas estão em função do tempo. Os estados plateau e flare estão representados, respectivamente, à direita e à esquerda da linha vertical preta. Figura adaptada de Dhawan et al. (2000). 
J1859+226 e XTE J1550-564, sugerem que as ejeções relativísticas ocorrem quando a fonte encontra-se numa fase muito ativa do SPLS (e.g., Hannikainen et al., 2001; Brocksopp et al., 2002). De acordo com Fender et al. (2004), a origem da emissão opticamente fina poderia ser devido a choques que são formados por um jato quando o sistema passa de uma fase "dura" para uma fase "mole" do SPLS.

Já o modelo de de Gouveia Dal Pino e Lazarian (2005) propôs um mecanismo que pode ser responsável pela aceleração inicial do jato a velocidades relativísticas no caso do microquasar GRS 1915+105. Esse mecanismo está relacionado com eventos de reconexão magnética violenta entre as linhas de campo magnético da região interna do disco de acreção e aquelas que estão ancoradas no horizonte do buraco negro. Esse modelo será descrito no capítulo 2, onde será também explicado como ele pode ser responsável pela transição entre as fases "dura" e "mole" da emissão em raios-X do SPLS.

\subsection{Núcleos Ativos de Galáxias}

Algumas classes de galáxias e objetos extragalácticos apresentam características peculiares, tais como, a presença de altas luminosidades, entre $10^{43} \mathrm{~L}_{\odot}$ e $10^{48} \mathrm{~L}_{\odot}$; uma variabilidade temporal no fluxo de energia que pode durar semanas ou meses; uma intensa emissão não-térmica em comprimentos de onda no rádio, infravermelho, ultravioleta e raios-X; e, frequentemente, estruturas em forma de jatos que emergem a velocidades relativísticas da região nuclear, produzindo uma emissão em rádio não muito distinta daquelas apresentadas na seção anterior para o caso dos microquasares. Tais objetos são classificados como núcleos ativos de galáxias. Além desses objetos, ainda há aqueles com propriedades semelhantes aos NAGs, porém muito mais luminosos e distantes, os quais são chamados de quasares (do inglês, quasi-stellar object). Atualmente, acredita-se que os mesmos sejam casos extremos de NAGs, apesar de exibirem uma morfologia compacta com um aspecto quase-estelar.

Acredita-se que a região central do NAG é formada basicamente por um buraco negro supermassivo e um disco de acreção ao seu redor, onde provavelmente são produzidas as altas luminosidades desses objetos. O jato, por sua vez, é formado na região central onde a matéria do meio interestelar e das estrelas destruídas pela alta gravidade são acretadas até o buraco negro supermassivo através do disco de acreção. Devido à viscosidade, o material 
no disco é aquecido a altas temperaturas e, eventualmente, a matéria mais energética é ejetada na direção normal ao disco, produzindo um vento coronal na região mais central do sistema. As linhas de campo magnético que se erguem do disco aceleram, ao mesmo tempo em que colimam, a parte mais interna desse fluxo pelo processo magneto-centrífugo (conforme mencionado no início deste capítulo), produzindo um jato cujas partículas aceleradas a velocidades relativísticas produzem uma emissão síncrotron observada em rádio. Em torno desse sistema, próximo ao núcleo, existem duas regiões: uma mais interna, formada por nuvens densas e de baixa ionização que produzem linhas de emissão largas, a qual chamaremos de RLL (região de linhas largas); e uma mais externa, formada por nuvens de baixa densidade que produzem linhas estreitas permitidas e proibidas, a qual chamaremos de RLE (região de linhas estreitas). Por fim, ao redor de todo o NAG existe ainda um extenso toro molecular de gás opaco à luz.

A partir das propriedades observacionais dessas fontes, em diferentes comprimentos de onda, é possível classificar os NAGs e quasares em diferentes objetos, tais como, galáxias Seyfert do tipo I e II, rádio galáxias, LINERs e objetos BL Lac's (para uma descrição mais detalhada desses objetos veja Peterson, 1997). Em contrapartida, acredita-se que todas essas classes sejam na realidade diferentes manifestações de um mesmo objeto visto por um observador em diferentes ângulos. Trata-se do modelo unificado para NAGs e quasares.

De acordo com a descrição padrão, os NAGs podem ser classificados entre aqueles cuja emissão em rádio é intensa e de natureza não-térmica (radio loud, em inglês), como as rádio galáxias; ou entre aqueles cuja emissão em rádio é fraca ou não detectável (radio quiet, em inglês), como as galáxias Seyfert e LINERs.

Além disso, podemos explicar, em linhas gerais, as diferenças entre algumas classes de NAGs a partir do modelo unificado. Por exemplo, as galáxias Seyfert do tipo I e II são conhecidas por apresentarem um toro de gás empoeirado e emissões intermediárias entre linhas largas e estreitas. As de tipo II são observadas quando a linha de visada do observador, na direção da região central do sistema, intercepta diretamente o toro molecular (em ângulos maiores que 45 graus com relação ao eixo de simetria do sistema). Assim, a emissão proveniente da RLL será fortemente absorvida pelo toro e apenas as linhas estreitas da RLE serão diretamente visíveis. Por outro lado, se a linha de visada não intercepta o toro molecular, a região nuclear do NAG pode ser observada diretamente, 
expondo a RLL, caracterizando, assim, galáxias Seyfert do tipo I.

Entre os NAGs, existem ainda algumas classes de galáxias com uma atividade moderada na região nuclear, porém, ainda superior à galáxias normais. Entre esses tipos de galáxias, estão os LINERs (do inglês, low inonization nuclear emission regions). Essas galáxias apresentam características espectroscópicas similares às galáxias Seyfert de tipo II, exceto pelo fato de que os LINERs apresentam linhas de baixa ionização relativamente fortes.

\subsubsection{Propriedades em rádio e jatos relativísticos}

A morfologia em rádio de quasares e rádio galáxias é frequentemente descrita em termos de duas componentes, uma extensa (i.e, resolvida espacialmente) e a outra compacta (i.e., não-resolvida em resoluções da ordem de 1"). Essas duas componentes possuem diferentes características espectrais, embora o mecanismo síncrotron pareça atuar em ambos os casos. Por exemplo, enquanto o espectro em rádio correspondente à componente extensa é mais inclinado, com valores típicos de $\Gamma \simeq 2,4$ para as altas frequências, e $\Gamma \simeq-4$ para as baixas frequências; as fontes compactas apresentam espectros mais planos, com $\Gamma \leq 2$. Isso se, como no caso dos microquasares, uma lei de potência for admitida para a modelagem da emissão não-térmica (para uma discussão mais detalhada veja Peterson, 1997).

A morfologia da componente extensa é geralmente dupla, ou seja, apresenta dois lóbulos de emissão, com diferentes graus de simetria, que são identificados como jatos que emergem em duas direções diametralmente opostas tanto em quasares quanto em NAGs. Em contrapartida, é possível identificar fontes nas quais somente um dos lóbulos pode ser observado. Além disso, a componente extensa pode apresentar dimensões da ordem de megaparsecs, em contraste com a componente compacta que possui dimensões da ordem de 0,01 pc (cuja localização geralmente coincide com a posição dos quasares e o centro de NAGs). A maior diferença entre essas duas componentes, é que a "extensa" é opticamente fina para a sua própria emissão em rádio, o que não é verdade para o caso das fontes compactas, que são opticamente espessas.

A componente extensa pode ser subclassificada em fontes de classe I e classe II (conhecidas como as rádio fontes Faranoff-Riley I e II, ou FR I e FR II, respectivamente), segundo um critério de luminosidade adotado por Fanaroff e Riley (1974). Essencialmente, esse critério separa as rádio fontes cujas extremidades são brilhantes (classe II) daquelas cujas 
extremidades se mostram mais fracas (classe I). Em princípio, o limite adotado para a divisão entre uma classe e outra não possui um significado físico, mas revelou-se de grande utilidade. Por exemplo, Bridle e Perley (1984) encontraram que luminosidades da ordem de $L_{\nu}(1,4 G H Z) \simeq 10^{32} \operatorname{ergs~s}^{-1} \mathrm{~Hz}^{-1}$ podem ser um limite adequado para separar esses dois tipos de fontes. Exemplos de rádio fontes FR I e FR II são mostrados na figura 1.4.

A origem dos lóbulos brilhantes observados nas rádio galáxias está relacionada com o choque gerado entre um jato e o meio intergaláctico em torno. Esses jatos, por sua vez, são produzidos na região central correspondente à componente compacta. Eles apresentam frequentemente uma estrutura de nós internos brilhantes entre a fonte central e o ponto onde a componente extensa é produzida, indicando a presença de uma variabilidade no processo de ejeção do material desde a fonte. Muitas vezes os jatos são observados em apenas um lado das rádio fontes, e nos casos em que os jatos são vistos em ambos os lados (i.e., "um contra-jato"), frequentemente um dos lados é muito mais fraco do que o outro. A diferença de brilho é atribuída, principalmente, ao relativistic beaming ${ }^{5}$, que preferencialmente aumenta o brilho superficial do jato que está se aproximando do observador.

\subsubsection{Similaridades com microquasares e o plano fundamental}

Uma rápida análise das escalas físicas entre quasares e microquasares pode, a principio, gerar um interpretação equivocada a respeito da ligação entre esses dois objetos (veja tabela 1.1). Entretanto, apesar das diferentes escalas físicas, tanto microquasares quanto quasares formam uma classe de objetos morfologicamente similares (veja figura 1.5), assim como havíamos mencionado anteriormente. Acredita-se, inclusive, que a analogia é mais que morfológica, de maneira que os processos físicos que ocorrem em um podem estar ocorrendo, também, no outro.

\footnotetext{
${ }^{5}$ Dado um referencial $K^{\prime}$ que se desloca a uma velocidade próxima de $c$ em relação ao referencial $K$ do observador, se uma fonte emite fótons de forma isotrópica em $K^{\prime}$, o observador no referencial $K$ verá uma emissão concentrada na direção da linha de visada devido a efeitos relativísticos (Rybicki e Lightman, 1986)
} 

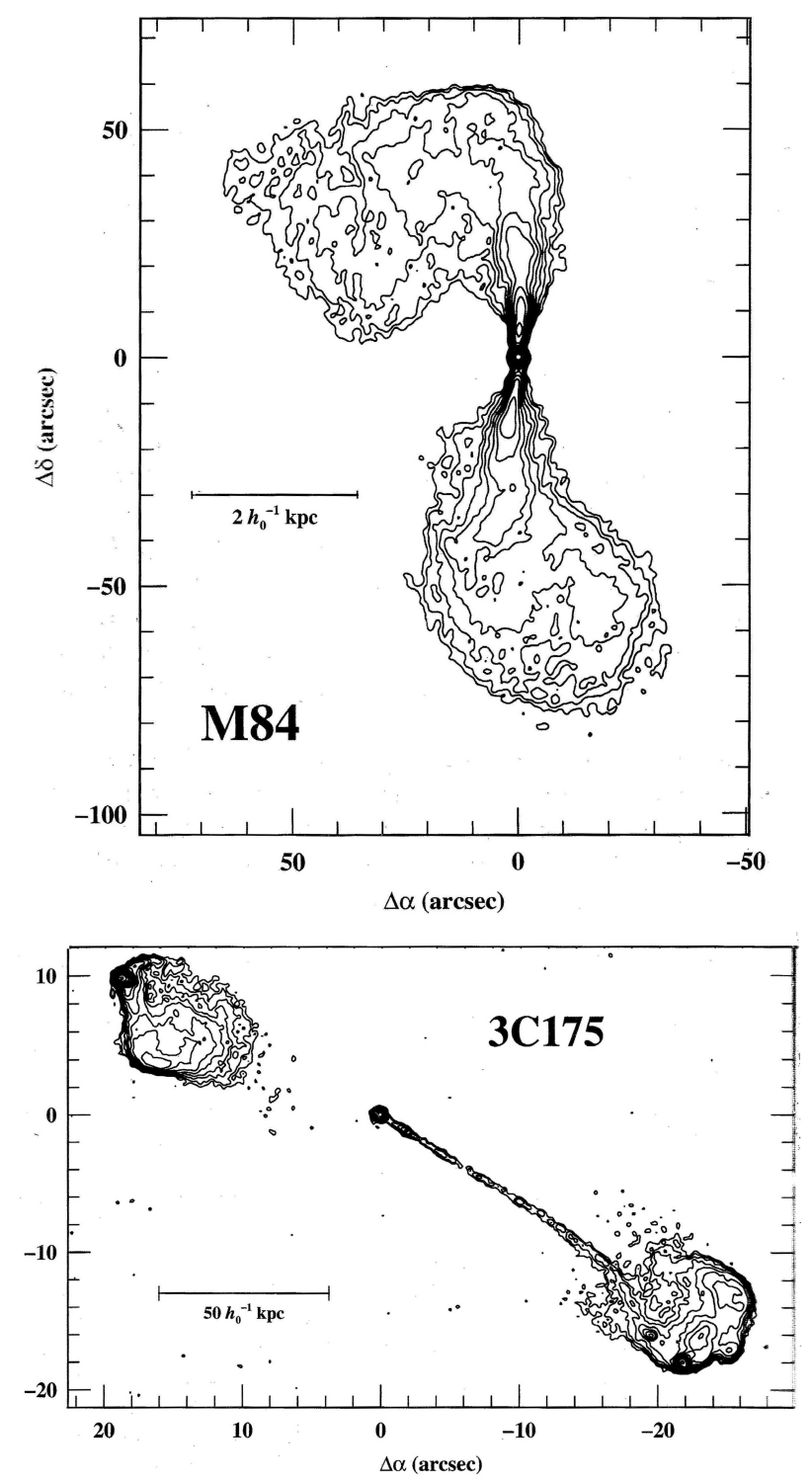

Figura 1.4: Exemplos de rádio galáxias do tipo FR I (à acima) e FR II (à baixo). A primeira corresponde ao mapa em rádio da galáxia M84, do aglomerado de Virgo; e a segunda corresponde ao quasar 3C 175. Nessa última, a posição do quasar coincide com a localização da fonte compacta brilhante. O jato, por sua vez, estende-se da fonte compacta ao lóbulo de um dos lados. Objetos FR II possuem lóbulos muito brilhantes, provavelmente, produzidos pela ejeção do plasma relativístico nos choques formados pelo impacto supersônico entre o jato e o meio intergaláctico. Figuras adaptadas de Peterson (1997) 

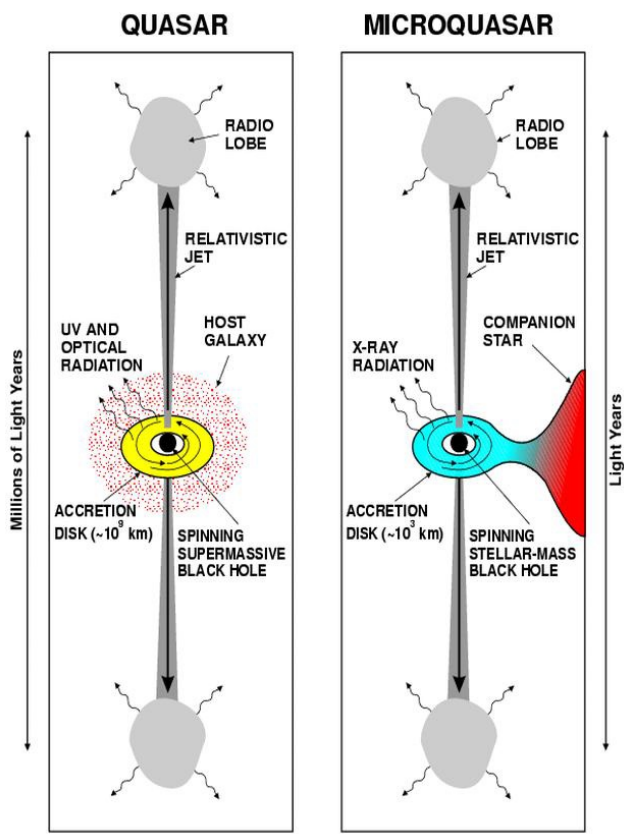

Figura 1.5: Similaridades morfológicas e diferenças de escala entre NAGs/quasares (à esquerda) e microquasares (à direita). Figura retirada de Mirabel e Rodríguez (1998).

Tabela 1.1 - Tabela comparativa entre NAGs/Quasares e microquasares. Nessa tabela $L$ é a dimensão típica do jato ou do disco, $T$ a temperatura típica do disco e $M$ a massa do buraco negro central

\begin{tabular}{lcccc}
\hline \hline Objeto Astrofísico & $L_{\text {jato }}$ & $L_{\text {disco }}$ & $T_{\text {disco }}$ & $M_{B N}$ \\
\hline NAGs/Quasares & $\sim 10^{6} \mathrm{pc}$ & $\sim 10^{9} \mathrm{~km}$ & $\sim 10^{5} \mathrm{~K}$ & $10^{6-9} M_{\odot}$ \\
Microquasares & $1 \mathrm{pc}$ & $\sim 10^{3} \mathrm{~km}$ & $\sim 10^{7} \mathrm{~K}$ & $1-10 M_{\odot}$ \\
& & & & \\
\hline
\end{tabular}

Trabalhos recentes desenvolvidos por Merloni et al. (2003) e Falcke et al. (2004) (veja também Nagar et al., 2005) demonstraram a existência de um "plano fundamental" que correlaciona a massa do buraco negro central com a luminosidade em raios-X e a emissão em rádio, que se aplica tanto a microquasares quanto a quasares e NAGs. Tal correlação está associada tanto ao processo de ejeção de matéria quanto ao disco de acreção, e pode ser matematicamente entendida como um plano tridimensional (representado de perfil na figura 1.6). Esse resultado sugere que a física da acreção por buracos negros e a produção dos jatos é independente da escala. Como as características temporais do fluxo de matéria em torno de um buraco negro são proporcionais à sua massa, variações espectrais com 


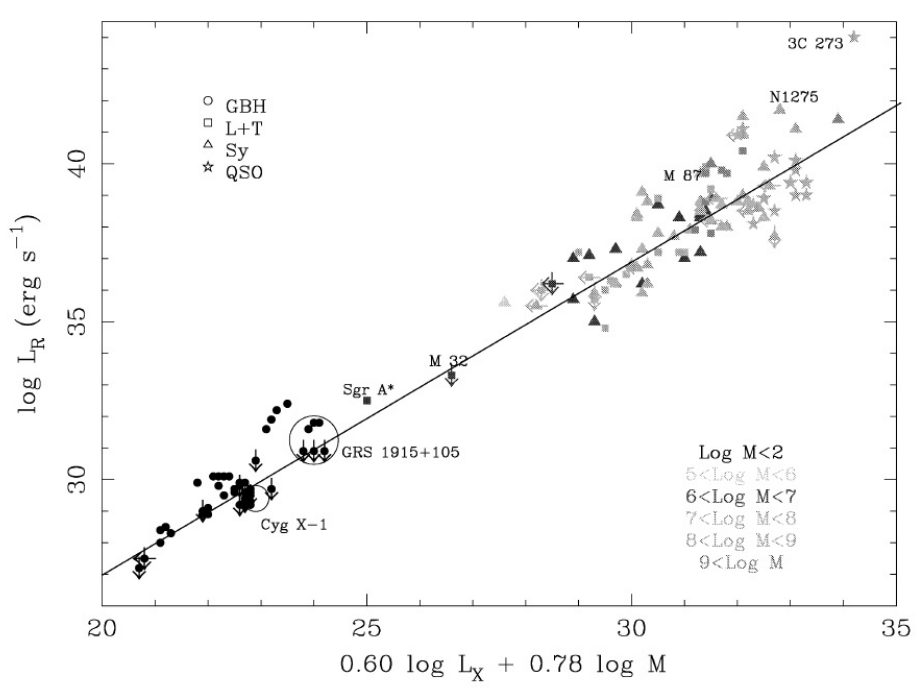

Figura 1.6: Plano fundamental dos microqusares e NAGs. Neste gráfico, $M$ é a massa do buraco negro central, $L_{R}$ é a luminosidade da emissão rádio, e $L_{X}$ a luminosidades em raios-X do sistema. Figura extraída de Merloni et al. (2003).

intervalos de minutos nos microquasares podem corresponder a fenômenos análogos nos quasares, com durações de milhares de anos. Portanto, as variações com minutos de duração em microquasares poderiam revelar fenômenos que não somos capazes de estudar na escala de quasares e NAGs.

Essas similaridades são muito importantes, já que nos possibilitam entender aspectos da física dos NAGs através do estudo dos microquasares, que além do mais, são mais fáceis de observar em diferentes comprimentos de onda por sua proximidade. Um exemplo disso, são as ejeções de matéria quase-periódicas observadas em microquasares durante uma fase de grande atividade dessas fontes. Essas ejeções, por sua vez, apresentam características morfológicas similares às dos jatos em rádio produzidos na região nuclear dos NAGs, de maneira que uma generalização quase direta pode ser realizada. Além disso, veremos no capítulo 2 que o modelo de reconexão magnética violenta de de Gouveia Dal Pino e Lazarian (2005) fornece uma interpretação física simples para a correlação empírica determinada pelo plano fundamental acima, entre a massa e a luminosidade rádio das fontes, dos microquasares aos NAGs. 


\subsection{Objetos Estelares Jovens}

As estrelas são formadas a partir de nuvens interestelares através de um processo de instabilidade gravitacional que leva à contração da nuvem (a chamada instabilidade de Jeans, veja Maciel, 1999; Kippenhahn e Weigert, 1994). À medida que a nuvem colapsa, fragmentos dessa nuvem tornam-se instáveis e colapsam mais rapidamente que a nuvem original. A fragmentação termina quando a massa dos fragmentos é da ordem da massa das estrelas. Neste ponto, forma-se uma estrutura com uma região central mais densa em equilíbrio hidrostático, o qual denominamos de protoestrela. Neste estágio, a temperatura central não é alta o suficiente para iniciar a ignição das reações nucleares do hidrogênio, de maneira que esses objetos emitem sua energia preferencialmente no infravermelho, já que as suas temperaturas superficiais são tipicamente da ordem de $10^{3} \mathrm{~K}$. Em contrapartida, na fase pré-sequência principal, se a massa da protoestrela for maior que $0,08 M_{\odot}$, este objeto pode alcançar temperaturas centrais suficientemente altas para a ignição do hidrogênio, tornando-se um estrela propriamente dita de sequência principal. Os objetos estelares jovens (OEJs) correspondem a sistemas astrofísicos em todas as fases que compreendem a formação da protoestrela e a formação da estrela de sequência principal, durante os estágios em que sua energia é emitida essencialmente pelo processo de colapso gravitacional.

Podemos dividir os OEJs em classes morfológicas (de 0 a III), classificadas de acordo com as suas distribuições de espectro de energia (SED, do inglês spectral energy distribution, veja Feigelson e Montmerle, 1999) cujo índice espectral, na banda do infravermelho (2, 2-25 $\mu \mathrm{m}$ ), é definido como $\alpha_{I V}=\frac{d \log \left(\lambda F_{\lambda}\right)}{d \lambda}($ Schulz, 2005), onde $\lambda$ é o comprimento de onda; e $F_{\lambda}$ a densidade de fluxo observável.

Essa classificação foi proposta originalmente por Lada (1987), levando-se em consideração que a emissão no infravermelho fornece uma medida qualitativa da quantidade de material que circunda os núcleos densos que irão originar as estrelas. Assim, objetos protoestelares completamente embebidos em seus "envelopes" de gás e poeira corresponderiam às fases menos evoluídas, e as protoestrelas cujos envelopes foram quase completamente acretados, aos estágio mais evoluídos.

Os objetos de classe 0 são constituídos por jovens protoestrelas recém formadas pelo colapso gravitacional das nuvens, e possuem idades da ordem de $10^{4}$ anos. Estes objetos são quase completamente embebidos por um massivo e frio "envelope", que ainda está 
em processo de colapso em direção às regiões mais centrais. Além disso, estes objetos apresentam um fluxo de matéria bem colimado e um disco de acreção que são rapidamente formados dentro de seus envelopes.

Os objetos de classe I apresentam um índice espectral $\alpha_{I V}>0$, e possuem idades de aproximadamente $10^{5}$ anos. Nestes objetos, parte da matéria do "envelope" já se tornou um disco de acreção com algumas centenas de unidades astronômicas de extensão. Além disso, um fluxo de matéria também está presente, porém, menos colimado que os fluxos presente nos objetos de classe 0 .

Os objetos de classe II, com idades entre $10^{6}$ e $10^{7}$ anos, são constituídos pelas chamadas estrelas T Tauri clássicas, e apresentam um índice espectral $-2<\alpha_{I V}<0$. Nesta fase, o "envelope" que circundava a região central já foi quase completamente consumido, tornando-a opticamente visível. Entretanto, o disco de acreção ainda permanece ativo, com a presença de ventos e jatos intensos produzidos nas regiões mais centrais do sistema.

Por fim, os objetos de classe III apresentam um índice espectral $\alpha_{I V}<-2$, e estrelas $T$ Tauri fracas que provavelmente não acretam mais matéria. Elas apresentam somente resquícios dos discos de acreção, que são completamente desacoplados da fonte central.

\subsubsection{Taxas de acreção}

Acredita-se que o processo de acreção de matéria através de um envelope ou disco de acreção domine, durante grande parte do tempo, a evolução dos OEJs. Em contrapartida, detalhes quantitativos das taxas de acreção ainda são altamente incertos e, provavelmente, variam muito com o tempo.

Estudos numéricos do colapso esférico sugerem que, inicialmente, o processo da acreção passa por um surto que dura cerca de $10^{4}$ anos (correspondente a objetos de classe 0, veja Schulz, 2005). Metade do envelope que circunda a protoestrela é acretado em $10^{5}$ anos (objetos de classe I) e, praticamente todo ele, dentro de $10^{6}$ anos (objetos de classe II e III). Esses mesmos estudos indicam que as taxas de acreção são, inicialmente, da ordem de $10^{-4} M_{\odot} /$ ano, que rapidamente diminuem com o tempo (e.g, Nakamura, 2000; Schulz, 2005). Observações revelam que nos estágios mais evoluídos, as taxas de acreção são menores que $10^{-7} M_{\odot} /$ ano. Já grandes surveys de estrelas T Tauri (e.g., Beckwith et al., 1990) têm demonstrado que as taxas de acreção, em geral, são menores que $10^{-6} M_{\odot} /$ ano, 


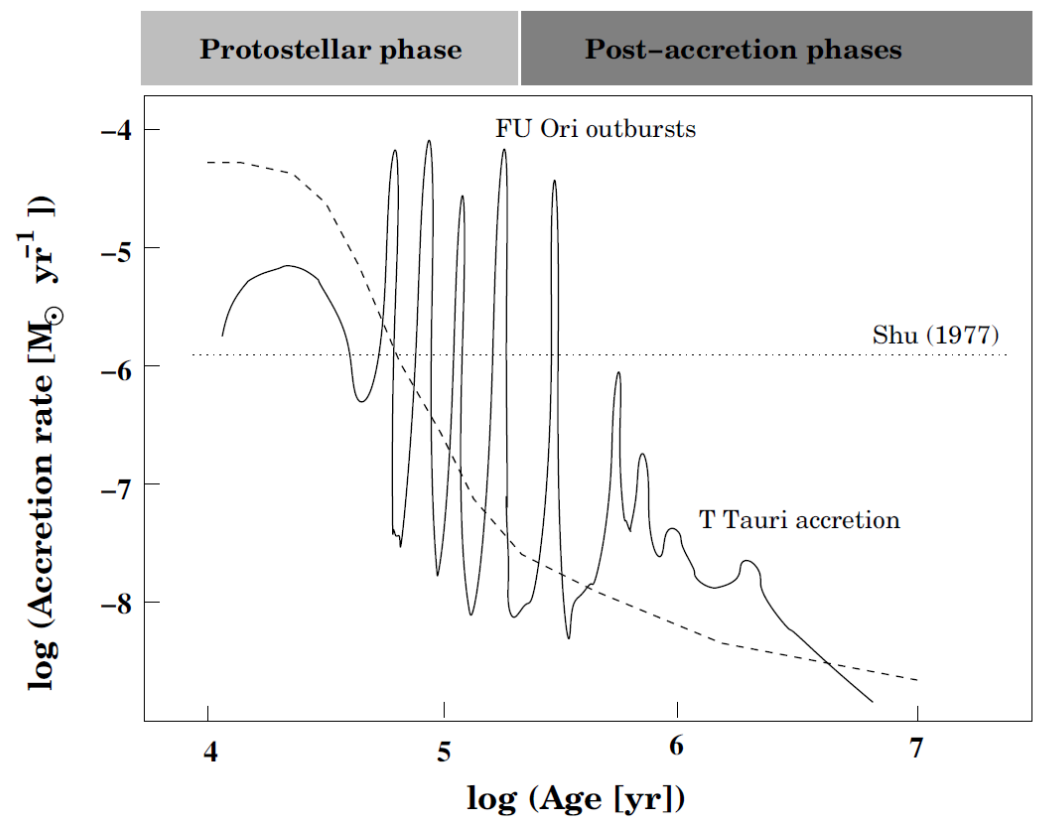

Figura 1.7: O diagrama esquemático acima mostra a evolução temporal da taxa de acreção para OEJs de baixa massa. A linha pontilhada corresponde à taxa de acreção segundo um dos primeiros cenários de formação estelar (Shu, 1977). A linha tracejada representa aproximadamente os resultados das simulações numéricas mais realísticas de formação de estrelas. A linha contínua mostra algumas características adicionais observadas, como os outbursts do tipo FU Ori e as estrelas T Tauri clássicas. Figura extraída de Schulz (2005).

apesar de que em alguns casos as taxas possam ser tão altas quanto $10^{-5} M_{\odot} /$ ano, durante curtos intervalos de tempo (Schulz, 2005). Estes valores, por sua vez, são muito baixos se comparados à taxa de acreção crítica de Eddington $\left(\sim 10^{-2} M_{\odot} /\right.$ ano $)$ para estrelas $T$ Tauri típicas, de forma que o processo de acreção desses objetos é altamente subcrítico. A figura 1.7 ilustra esquematicamente a dependência da taxa de acreção com o tempo.

\subsubsection{Atividade magnética}

Os objetos estelares jovens exibem, frequentemente, uma forte e variável emissão em raios-X (e.g, Feigelson e Montmerle, 1999) que, por sua vez, sugere a presença de uma intensa atividade magnética. De fato, campos magnéticos da ordem de kG têm sido estimados a partir do efeito Zeeman nas linhas espectrais da fotosfera das estrelas T Tauri e, também, a partir da sua emissão maser ciclotrônica (e.g, Bouvier et al., 2007).

Segundo Bouvier et al. (2007), o campo magnético médio da maior parte das estrelas T Tauri é da ordem de $2,5 \mathrm{kG}$, com alguns campos chegando a $6 \mathrm{kG}$ nas regiões mais ativas. 


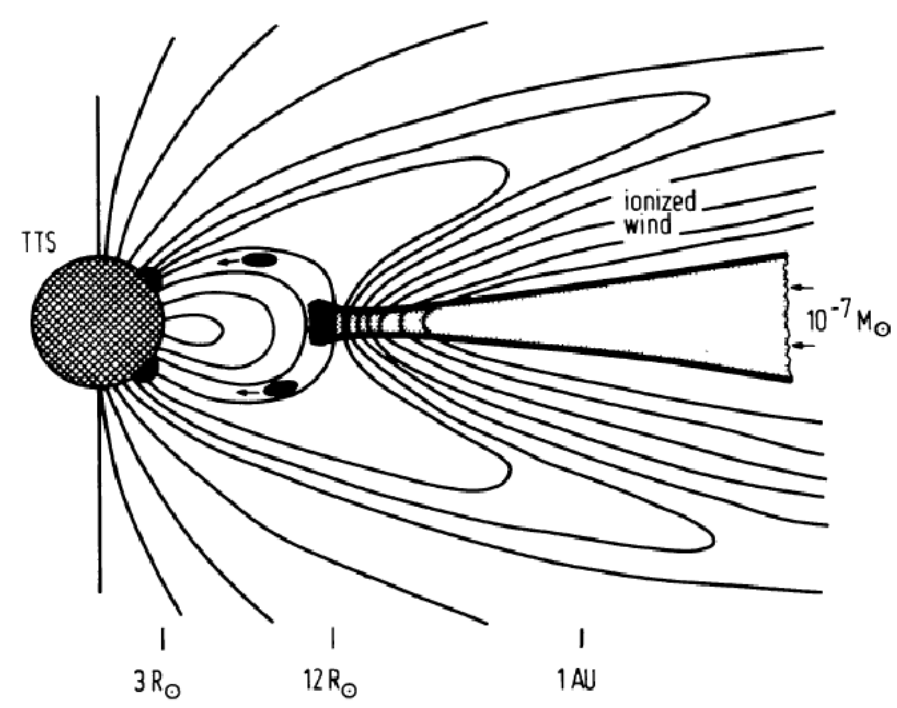

Figura 1.8: Figura esquemática da estrutura de acreção magnetosférica em estrelas T Tauri. Figura extraída de Camenzind (1990).

Já a topologia do campo é frequentemente assumida como uma configuração de dipolo magnético. De fato, se considerarmos um campo magnético multipolar, as componentes de ordem superior rapidamente decaem com a distância, o que implica que a componente dominante, a alguns raios estelares, é a dipolar. Na superfície destes objetos, a configuração magnética provavelmente é mais complicada. Assim, em primeira aproximação, espera-se que o campo assuma uma estrutura de dipolo. Estes fortes campos magnéticos quase dipolares são capazes de alterar, de forma significativa, o processo de acreção de matéria na região mais interna do disco.

Assumindo que a magnetosfera das estrelas T Tauri é predominantemente dipolar em grande escala, Camenzind (1990) e Königl (1991) mostraram que a região interna do disco de acreção deve ser truncada pela pressão magnética a distâncias de alguns raios estelares. O material do disco é então conduzido ao longo das linhas do campo magnético até a superfície da estrela, originando os chamados funis de acreção (veja a figura 1.8 e uma descrição mais detalhada no capítulo 3).

Assim como o processo de acreção na região mais interna de OEJs, os flares em raios$\mathrm{X}$ também estão associados à atividade magnética dessas fontes. Acredita-se que estes flares são resultantes de eventos de reconexão magnética que ocorrem na coroa da fonte central (Feigelson e Montmerle, 1999). Uma vez liberada a energia armazenada no campo magnético, a condução térmica pode agir ao longo da linha de campo no sentido de aque- 
cer a região de transição entre a coroa e a fotosfera, resultando no fenômeno conhecido como evaporação cromosférica. Este fenômeno também ocorre no Sol e é responsável por aumentar a densidade de partículas ao longo das linhas magnéticas, aumentando com isso, a luminosidade em raios-X emitida pelo sistema.

Embora a emissão em raios-X dos OEJs seja geralmente explicada em função dos pequenos arcos magnéticos na coroa protoestelar, um resultado bastante interessante foi apresentado por Favata et al. (2005), a partir das observações do COUP (Chandra Orion Ultra-deep Project). Essas observações revelaram que as emissões em raios-X podem estar relacionadas a eventos de reconexão em arcos magnéticos que conectam a fonte central com a região mais interna do disco de acreção.

Com base nestas observações, Piovezan (2009) analisou as condições sob as quais os eventos de reconexão magnética violenta poderiam ocorrer em OEJs, utilizando o modelo de de Gouveia Dal Pino e Lazarian (2005) (veja também de Gouveia Dal Pino et al., 2010a,b). Esta análise será brevemente descrita no capítulo 2. Além disso, no capítulo 3, analisaremos a formação de eventos de reconexão magnética nas regiões mais internas de OEJs, a partir de simulações magnetohidrodinâmicas axissimétricas (2.5D-MHD), da interação entre o campo magnético poloidal ancorado em um disco de acreção viscoso e a magnetosfera dipolar de uma fonte central em rotação. A partir dos testes aqui realizados, discutiremos os resultados obtidos com base em algumas das características observacionais de OEJs descritas acima, tais como as taxas de acreção do sistema. 


\section{Capítulo 2}

\section{Estudo analítico de eventos de reconexão magnética}

Neste capítulo apresentaremos o modelo originalmente desenvolvido por de Gouveia Dal Pino e Lazarian (2005) para explicar os flares e as ejeções superluminais observadas em microquasares. Serão discutidas comparações entre a potência magnética liberada em eventos de reconexão violenta, calculada sob a luz desse modelo, e as observações da luminosidade em rádio emitida por microquasares. Por fim, apresentaremos uma generalização desse modelo, aplicando-o também a núcleos ativos de galáxias e a objetos estelares jovens. Parte dessa análise foi iniciada na dissertação de mestrado de Piovezan (2009) e complementada no presente trabalho. Os resultados descritos neste capítulo foram também publicados em de Gouveia Dal Pino et al. (2010a,b).

\subsection{Cenário de reconexão de de Gouveia Dal Pino e Lazarian}

Conforme ressaltado na introdução, o cenário desenvolvido por de Gouveia Dal Pino e Lazarian (2005) invoca a interação entre um disco de acreção magnetizado e a magnetosfera ancorada à última órbita estável de um buraco negro. O processo de acreção induz o encontro dos fluxos magnéticos do disco e do horizonte do buraco negro, que sob certas circunstâncias, as quais serão descritas a seguir, provoca um evento de reconexão magnética violenta.

\subsubsection{Formação da magnetosfera de um buraco negro}

Acredita-se que a magnetosfera ancorada ao horizonte do buraco negro seja formada através de um processo de acreção do fluxo magnético de seu disco de acreção (Wang et al., 2002). MacDonald et al. (1986) demonstraram que independentemente da forma 
caótica com que o campo é depositado nessa região, eventos de reconexão entre pequenos arcos magnéticos, em curtos períodos de tempo, irão produzir um campo ordenado. Essa estrutura magnética alcança uma configuração livre de forças $(\text { force-free })^{1}$ através de um processo de acoplamento magnético entre o horizonte do buraco negro e o disco, cuja amplitude é determinada pelo fluxo magnético total depositado durante toda a história evolutiva do sistema. Esses depósitos podem causar flutuações estocásticas no campo ancorado no horizonte do buraco negro, que cresce até que se torne intenso o suficiente para truncar o disco a uma distância $R_{X}$ do centro do sistema (cuja avalição quantitativa será apresentada adiante), diminuindo a acreção. Nessa região, o campo máximo resultante é então definido pelo equilíbrio entre a pressão dinâmica do gás e a pressão magnética (Wang et al., 2003; MacDonald et al., 1986).

\subsubsection{Origem do campo magnético poloidal do disco}

A origem do campo magnético poloidal em larga escala associado ao disco é ainda controversa. Entretanto, acredita-se que a ação de um dínamo turbulento (Livio et al., 2003; King et al., 2004; Uzdensky e Goodman, 2008) induzido pela rotação diferencial e a instabilidade magneto-rotacional (Balbus e Hawley, 1998) sejam ingredientes essenciais para a sua produção.

Embora a geração de campos poloidais em larga escala ainda não tenha sido definitivamente revelada por simulações numéricas globais (e.g., Kudoh et al., 2002), a ação de um dínamo turbulento seguido por um processo de acreção do fluxo magnético congelado no plasma pode resultar no aumento gradual do campo magnético nas regiões internas do disco de acreção, próximo à fonte central (e.g., Merloni, 2003; Livio et al., 2003; Tagger et al., 2004).

Mesmo sem a ação de um dínamo, um campo poloidal pode ser formado na região mais interna do disco simplesmente pela acreção do fluxo magnético existente nas regiões mais externas. Esse processo foi recentemente demonstrado através de simulações numéricas tridimensionais realizadas por Beckwith et al. (2009). Eles encontraram que o fluxo

\footnotetext{
${ }^{1}$ Uma configuração force-free é definida quando $\mathbf{J} \times \mathbf{B}=0$, onde $\mathbf{J}$ é a densidade de corrente e $\mathbf{B}$ o campo magnético. Essa configuração ocorre em regiões onde a densidade de energia magnética é dominante, como a coroa próxima à superfície solar, ou a região coronal logo acima de um disco de acreção
} 
magnético é dominado por um mecanismo que atua sobretudo na região coronal acima do disco. Neste, a tensão magnética induzida pela rotação diferencial pode produzir arcos magnéticos que se esticam radialmente na direção das regiões internas do disco e então reconectam. Eventualmente formam um campo magnético dipolar na região interna, cuja intensidade é regulada pela combinação das pressões envolvidas (i.e., as pressões magnética, térmica do gás, e da radiação). Embora os estudos numéricos ainda sejam preliminares e a condição de saturação do mecanismo não seja completamente compreendida, esse resultado é uma demonstração de que é possível estabelecer um campo de larga escala na região interna do disco e na vizinhança em torno do horizonte do buraco negro.

\subsubsection{Formação de um evento de reconexão magnética}

Conforme observado na introdução, de acordo com o cenário magneto-centrífugo proposto por Blandford e Payne (1982), o fluxo magnético poloidal somado à rotação diferencial do disco pode dar origem a um vento que remove momento angular do sistema e aumenta a taxa de acreção. Consequentemente, isso eleva a pressão dinâmica do gás que, em seguida, deve empurrar as linhas de campo magnético para a região interna do disco, de encontro às linhas que estão ancoradas no horizonte do buraco negro. Eventualmente, se essas linhas possuírem polaridades opostas, ocorrerá um evento de reconexão magnética entre elas. Além disso, com o acúmulo do campo magnético poloidal na região interna do disco, a razão entre a pressão total do gás e a pressão magnética (fator $\beta$ ) deverá diminuir.

Segundo o modelo de de Gouveia Dal Pino e Lazarian (2005), esse evento se tornará violento somente quando a taxa de acreção do disco alcançar valores próximos ao limite de Eddington (veja definição no anexo A) permitindo, assim, que o campo magnético seja acretado e acumulado rapidamente na região interna do disco de tal forma que o fator $\beta$ irá diminuir para valores menores ou da ordem de 1. Em outras palavras, taxas de acreção tão elevadas, em uma região de $\beta$ baixo, levarão as linhas magnéticas de polarizações opostas a avançarem, um de encontro ao outro, de forma suficientemente rápida para permitir que, sob determinadas condições (veja adiante), um evento de reconexão violenta ocorra, liberando uma quantidade substancial de energia antes acumulada.

Considerando a descrição acima, o esquema qualitativo do sistema, instantes antes de um evento de reconexão violenta, deve ser igual ao esquematizado na figura 2.1. Na região 


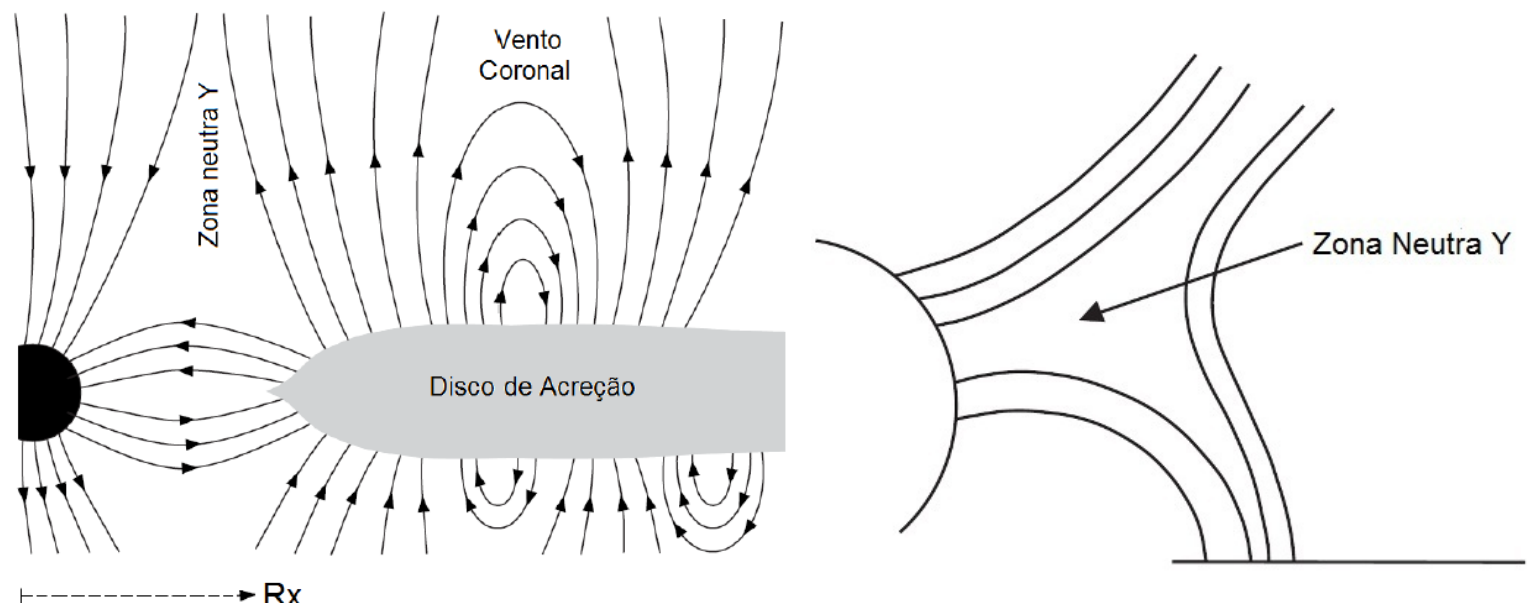

Figura 2.1: À esquerda é apresentado o esquema da configuração do campo magnético aproximadamente dipolar da fonte central e do campo poloidal que se ergue do disco de acreção, permeando a coroa logo acima deste. $\mathrm{O}$ raio $R_{X}$ corresponde à região onde o disco é truncado. À direita é destacada a região da zona neutra Y onde ocorrem os eventos de reconexão. Figuras adaptadas de de Gouveia Dal Pino e Lazarian (2005).

mais interna do disco, mais precisamente, nas proximidades do raio de truncamento $R_{X}$, há uma região propícia para a ocorrência desses eventos. Essa região localiza-se entre as linhas "abertas" que estão ancoradas no horizonte do buraco negro e as linhas de campo poloidal em larga escala do disco (tanto aquelas que estão "abertas" quanto aquelas que conectam o disco ao horizonte do buraco negro). Essa região é denominada de zona neutra "Y" (veja figura 2.1). O evento de reconexão nessa zona, por sua vez, pode ser entendido da seguinte forma: à medida que dois fluxos magnéticos de polarizações opostas avançam, um de encontro ao outro, é formado um lençol de corrente elétrica que deve fluir da zona "Y", na direção perpendicular aos fluxos convergentes (i.e., normal ao plano da figura 2.1). Na presença de uma resistividade elétrica finita, a dissipação dessas correntes permite o encontro dos fluxos e leva à reconexão magnética.

Diversos autores desenvolveram mecanismos para explicar como esse processo pode ocorrer e com que eficiência. Um dos primeiros modelos de reconexão foi desenvolvido por Parker em 1957 e ficou conhecido como o modelo de Sweet-Parker. Nesse modelo, dois fluxos de polarizações opostas reconectam-se sobre uma superfície, numa configuração semelhante à esquematizada na figura 2.2. O principal problema é que, para escalas astrofísicas, a eficiência desse mecanismo será pouco eficaz, ou ainda, a reconexão é dita "lenta". A razão disso, é que a taxa de reconexão dos fluxos magnéticos é dada por 

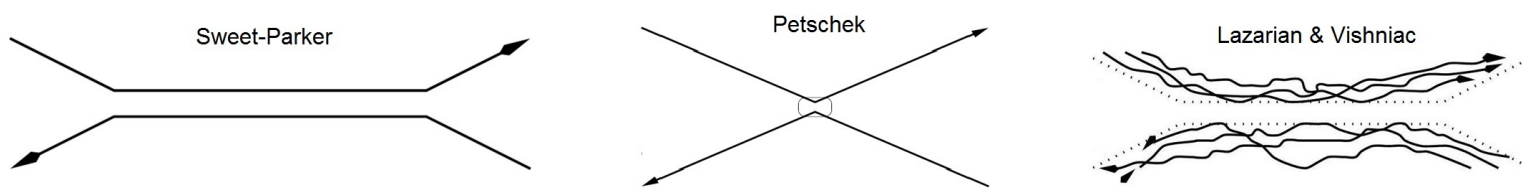

Figura 2.2: À esquerda, esquema da zona de reconexão segundo o modelo de Sweet-Parker; no centro, segundo o modelo de Petscheck; à direita, segundo o modelo de Lazarian e Vishniac (1999). Adaptado de Lazarian (2005).

$v_{\text {rec }} \cong S^{-1 / 2} v_{A}$, onde $S=L v_{A} / \eta$, sendo $v_{A}$ a velocidade de Alfvén; $L$ o comprimento da região onde se dá a reconexão; e $\eta$ a resistividade magnética ôhmica. Graças aos enormes valores típicos de $L$ em meios astrofísicos, $S$ é igualmente enorme para valores típicos de $\eta$ (por exemplo, no meio interestelar, $S \sim 10^{16}$ ).

Por outro lado, existe o modelo de Petschek, onde a reconexão não ocorre em um plano, mas em uma pequena parte do fluxo magnético (veja figura 2.2), de maneira que a tensão magnética produzida pela curvatura da linha de campo passa a ser importante e teremos a chamada reconexão "rápida". Nesse caso, o fluxo magnético forma uma zona em "X" que permite um escape fácil, tanto do fluido quanto do fluxo magnético. A taxa máxima de reconexão magnética $\left(v_{r e c} / v_{A}\right)$ que esse mecanismo alcança é dada por $\pi /(4 e \ln (S))$. Para valores de $S$ da ordem de $10^{8}$ e $10^{17}$, a taxa de reconexão encontra-se entre os valores de 0,005 e 0,01, que é um resultado ainda abaixo do esperado para uma reconexão altamente eficiente. Por exemplo, espera-se que no Sol as taxas de reconexão sejam da ordem de $v_{r e c} \cong 0,3 v_{A}$ (valor inferido a partir das observações, veja Aschwanden et al., 2001).

Uma das soluções a esse problema seria admitir a presença de uma resistividade magnética anômala na região de reconexão, já que o mecanismo de Sweet-Parker depende essencialmente da difusividade ôhmica do meio. Em contrapartida, Lazarian e Vishniac (1999) propuseram um modelo para reconexão rápida que independe da resistividade e invoca uma instabilidade mediada pela turbulência. Segundo esses autores, a taxa de reconexão aumenta devido à perturbações do campo magnético causadas pela turbulência. Essa, por consequência, leva à formação de diversos eventos de reconexão que ocorrem de forma simultânea (veja figura 2.2). Fluxos magnéticos não-paralelos irão reconectar-se muito lentamente se a velocidade de turbulência for muito menor do que $v_{A}$. Por outro lado, 
as ejeções de matéria produzidas pela reconexão aumentam o nível de turbulência e, portanto, a taxa de reconexão. Esse modelo de reconexão magnética "rápida", em presença de turbulência, foi recentemente testado com sucesso através de simulações numéricas magnetohidrodinâmicas tridimensionais (3D-MHD) de altíssima resolução (veja Kowal et al., 2011). Como resultado da reconexão, deve haver uma rápida e eficiente liberação de energia magnética, e o desenvolvimento de ejeções violentas que irão escapar da zona de reconexão, tal como se observam nos flares solares, por exemplo.

de Gouveia Dal Pino e Lazarian (2005) verificaram que para uma liberação eficiente de energia, é necessário recorrer a modelos de reconexão rápida, assim como proposto por Lazarian e Vishniac (1999). Os cálculos mais detalhados serão apresentados nas próximas seções, onde será invocado esse mecanismo de reconexão.

Essa discussão, por sua vez, revela que é possível ocorrer eventos de reconexão de forma violenta e eficiente, sendo essa última corroborada com diversas observações, como a dos flares solares, que demonstram que a velocidade de reconexão das linhas de campo pode alcançar valores da ordem de alguns décimos da velocidade de Alfvén (veja Takasaki et al., 2004).

Por fim, para facilitar a análise quantitativa desse cenário, de Gouveia Dal Pino e Lazarian (2005) admitiram que tanto o buraco negro quanto a região mais interna do disco de acreção estão em corrotação. Uma hipótese similar fora adotada anteriormente em modelos de discos de acreção ao redor de pulsares pelos mesmos autores (veja de Gouveia Dal Pino e Lazarian, 2000, 2001). Essa suposição evita que se leve em conta a transferência de energia e momento angular entre ambas as partes através das linhas de campo magnético que os conectam, o que poderia ocorrer caso ambos girassem a diferentes velocidades angulares (Blandford e Znajek, 1977), aumentando a complexidade e o número de parâmetros do modelo. Entretanto, é importante destacar que essa não é uma condição necessária para o seu desenvolvimento.

\subsection{Eventos de reconexão em microquasares}

Como discutido no capítulo anterior, Dhawan et al. (2000) efetuaram observações do microquasar GRS 1915+105, obtendo espectros simultâneos em rádio e em raios-X. A partir dessas observações foram identificados dois estados principais de emissão, o plateau 
e o flare. Reig et al. (2003), por sua vez, argumentaram que a emissão em raios-X tanto no plateau quanto no flare, são diferentes manifestações de um mesmo estado espectral em raios-X, o SPLS. Além disso, de acordo com Fender et al. (2004), a origem da emissão opticamente fina poderia ser produzida por choques provocados por um jato quando o sistema passa por uma transição entre uma fase "dura" para uma "mole" do SPLS. O modelo de de Gouveia Dal Pino e Lazarian (2005) tenta explicar justamente essa transição através de eventos de reconexão magnética violenta.

Para tanto, consideraremos que durante o estado de plateau, que antecede o flare em rádio, o campo magnético poloidal de larga escala é progressivamente formado no disco pelo processo de dínamo. Imediatamente antes do flare, a configuração inicial idealizada do sistema é aquela esquematizada na figura 2.1. Tanto a taxa de acreção do disco quanto a pressão magnética na região mais interna do sistema tornam-se muito elevados, permitindo um evento de reconexão violenta. A potência magnética que pode ser extraída desses eventos é obtida através da avaliação das condições físicas tanto do disco quanto da coroa, e que serão descritas a seguir.

\subsubsection{Parâmetros do disco de acreção}

Para avaliar as condições do sistema instantes antes da ocorrência de um evento de reconexão magnética violenta, consideremos os parâmetros físicos de um disco de acreção que gira em torno da fonte central de um microquasar. de Gouveia Dal Pino e Lazarian (2005) adotaram o modelo padrão de Shakura e Sunyaev (1973) que descreve um disco geometricamente fino, opticamente espesso, estacionário e com um perfil de velocidade Kepleriano cuja viscosidade é dada pela parametrização $\alpha$ (veja Frank et al., 1992, e o anexo A para uma breve descrição matemática).

Esses parâmetros foram determinados assumindo-se que o disco é truncado, aproximadamente, no raio da última órbita estável de um buraco negro, que corresponde a três vezes o raio de Schwartzschild $\left(R_{S}\right)$, de maneira que:

$$
R_{X} \simeq 3 R_{S}=3\left(\frac{2 G M}{c^{2}}\right)
$$

onde $G$ é a constante gravitacional e $c$ a velocidade da luz no vácuo. Admitindo que as massas típicas de buracos negros nas regiões centrais de microquasares são de aproximadamente $14 M_{\odot}\left(\right.$ veja Remillard e McClintock, 2006), obtém-se que $R_{X} \sim 10^{7} \mathrm{~cm}$. 
A partir do modelo de Shakura e Sunyaev (1973), os parâmetros de temperatura $\left(T_{d}\right)$, densidade numérica $\left(n_{d}\right)$, altura $\left(H_{d}\right)$ e densidade de energia emitida pelo disco $\left(U_{d}\right)$ foram estimados considerando que, através das observações em raios-X de microquasares, as temperaturas das regiões internas dos discos de acreção são da ordem de $10^{7} \mathrm{~K}$ (veja seção 1.1.1). Consequentemente, o hidrogênio, que é provavelmente o principal constituinte do material do disco, é completamente ionizado, sugerindo que a principal fonte de opacidade é o espalhamento Thomson. Em seguida, a partir do cálculo das pressões envolvidas, verifica-se que pressão térmica do gás é muito menor do que a pressão de radiação e, portanto, pode ser desprezada. Assim, obtém-se que (Frank et al., 1992; de Gouveia Dal Pino e Lazarian, 2005, de Gouveia Dal Pino et al., 2010a,b):

$$
\begin{aligned}
& T_{d} \cong 1,64 \times 10^{7} \alpha_{0,5}^{-1 / 4} M_{14}^{1 / 8} R_{X, 7}^{-3 / 8} \mathrm{~K} \\
& n_{d} \cong 3,65 \times 10^{18} \alpha_{0,5}^{-1} M_{14}^{-1 / 2} \dot{M}_{19}^{-2} R_{X, 7}^{3 / 2} q_{0,82}^{-8} \mathrm{~cm}^{-3}, \\
& H_{d} / R_{X} \cong 0,57 \dot{M}_{19} R_{X, 7}^{-1} q_{0,82}^{4} e \\
& U_{d} \cong 4,91 \times 10^{14} \alpha_{0,5}^{-1} M_{14}^{1 / 2} R_{X, 7}^{-3 / 2} \mathrm{erg} / \mathrm{cm}^{3}
\end{aligned}
$$

onde as variáveis $\alpha_{0,5}=\alpha /(0,5), R_{X, 7}=R_{X} /\left(10^{7} \mathrm{~cm}\right), M_{14}=M /\left(14 M_{\odot}\right), \dot{M}_{19}=$ $\dot{M} /\left(10^{19} \mathrm{~g} / \mathrm{s}\right)$ e $q_{0,82}=q /(0,82)$ são, respectivamente, as normalizações do parâmetro de viscosidade $\alpha$, do raio de truncamento $R_{X}$ do disco, da massa $M$ da fonte central, da taxa de acreção $\dot{M}$ e do fator $q=\left[1-\left(\frac{R_{S}}{R_{X}}\right)^{1 / 2}\right]^{1 / 4}$, todas em função de valores característicos estimados para os microquasares.

Já a taxa de acreção imediatamente antes de um evento de reconexão magnética violenta é determinada a partir do equilíbrio entre as pressões dinâmica do disco e magnética do horizonte de eventos do buraco negro $\left(\rho_{d} v_{r}^{2} \simeq B^{2} / 8 \pi\right)$. Nesse caso, assumindo uma geometria esférica, a velocidade de acreção radial $\left(v_{r}\right)$ pode ser aproximada pela velocidade de queda livre. Considerando-se também que a intensidade do campo ancorado no horizonte do buraco negro é equiparável ao campo magnético do disco $\left(B \simeq B_{d}\right)$, tem-se que:

$$
\frac{3 \dot{M}}{4 \pi R_{X}^{2}}\left(\frac{2 G M}{R_{X}}\right)^{1 / 2} \simeq \frac{B_{d}^{2}}{8 \pi} .
$$

A equação acima demonstra que a taxa de acreção desejada depende da intensidade do campo magnético do disco em $R_{X}$. Essa intensidade, por sua vez, é obtida a partir do 
fator $\beta$. Assim:

$$
\beta=\frac{P_{d}}{B^{2} / 8 \pi} \simeq \frac{P_{r a d}}{B_{d}^{2} / 8 \pi}
$$

onde, como citado anteriormente, a pressão térmica do gás foi desprezada em relação à pressão de radiação $\left(P_{\text {térmica }}<<P_{\text {rad }}\right)$.

Como a pressão de radiação é dada por:

$$
P_{\text {rad }}=\frac{4 \sigma T_{d}^{4}}{3 c}
$$

onde $\sigma$ é a constante de Stefan-Boltzmann; substituindo-a na equação (2.7), com o auxílio da equação (2.2), obtém-se que a intensidade do campo magnético do disco em $R_{X}$ é:

$$
B_{d} \cong 7.54 \times 10^{7} \beta_{0,8}^{-1 / 2} \alpha_{0,5}^{-1 / 2} M_{14}^{1 / 4} R_{X, 7}^{-3 / 4} \quad G,
$$

onde $\beta_{0,8}=\beta /(0,8)$, lembrando que durante o evento de reconexão violenta o fator $\beta$ torna-se menor ou da ordem de 1.

Por fim, substituindo essa intensidade na equação (2.6), obtém-se que a taxa de acreção imediatamente antes de um evento de reconexão violenta, na região do raio $R_{X}$ de truncamento do disco, é dada por:

$$
\dot{M} \sim 1 \times 10^{19} \beta_{0,8}^{-1} \alpha_{0,5}^{-1} R_{X, 7} \quad g / s .
$$

Em particular, de Gouveia Dal Pino e Lazarian (2005) normalizaram a taxa de acreção das equações (2.3) e (2.4) em função da taxa crítica de Eddington, cujo valor, a uma distância de $10^{7} \mathrm{~cm}$ de uma fonte de $14 M_{\odot}$, é da ordem de $10^{19} \mathrm{~g} / \mathrm{s}$. Como esperado, esse valor é equiparável ao obtido na equação (2.10), indicando que nos instantes que antecedem a um evento de reconexão violenta, o sistema estará submetido à altas taxas de acreção. Essas porém, ocorrerão em períodos curtos de tempo, assim como será demonstrado adiante.

\subsubsection{Parâmetros da coroa magnetizada}

Os parâmetros para a coroa quente, rarefeita e altamente magnetizada, que se encontra ao redor do sistema disco-fonte central, foram estimados a partir de um modelo simples proposto por Liu et al. (2002), originalmente desenvolvido para sistemas possivelmente 
contendo buracos negros, como os microquasares. Primeiramente, esses autores admitiram que o calor na coroa é gerado por reconexão magnética, tal como na coroa solar, e é irradiado através do espalhamento Compton, de maneira que:

$$
\frac{B^{2}}{4 \pi} v_{A} \approx \frac{4 k_{B} T_{c}}{m_{e} c^{2}} n_{c} \sigma_{T} c U_{\text {rad }} l
$$

onde $B$ é a intensidade do campo magnético na coroa, $T_{c}$ e $n_{c}$ são, respectivamente, a temperatura e a densidade numérica na coroa, $U_{\text {rad }}$ é a densidade de energia dos fótons que serão espalhados pelo processo Compton, $l$ é o comprimento de um arco magnético que se ergue na coroa, $k_{B}$ é a constante de Boltzmann, $m_{e}$ é a massa do elétron e $\sigma_{T}$ é a seção de choque por espalhamento Thomson. A velocidade de Alfvén correspondente é dada por:

$$
v_{A}=\frac{B^{2}}{\sqrt{4 \pi n_{c} m_{p}}}
$$

onde $m_{p}$ é a massa do próton e $n_{c} m_{p}$ a densidade na região coronal. Note que para campos magnéticos da ordem do que foi calculado na equação (2.9), a velocidade de Alfvén será da ordem da velocidade da luz ${ }^{2}$.

Em seguida, Liu et al. (2002) admitiram que a distribuição de densidade do gás logo acima do disco é constituída pela evaporação cromosférica que ocorre na base dos arcos magnéticos ancorados no disco, assim como ocorre na coroa solar. Além disso, admite-se que o plasma evaporado é difundido por toda a extensão do arco magnético de comprimento l. É fácil demonstrar nesse caso que:

$$
\frac{k_{0} T_{c}^{7 / 2}}{l} \approx \frac{\gamma}{\gamma-1} n_{c} k_{B} T_{c}\left(\frac{k_{B} T_{c}}{m_{p}}\right),
$$

onde $k_{0}=10^{-6} \mathrm{erg} \mathrm{cm}^{-1} \mathrm{~s}^{-1} K^{-7 / 2}$; e $\gamma$ é a razão entre os calores específicos do gás coronal, que para o caso de um gás monoatômico ideal é igual a 5/3.

Finalmente, a temperatura e a densidade numérica da coroa são obtidas a partir da solução de um sistema composto pelas equações (2.11) e (2.13), onde se admite que $U_{\text {rad }} \approx$ $U_{d}$ e $B \approx B_{d}$. Portanto:

$$
T_{c} \cong 4,10 \times 10^{9} \alpha_{0,5}^{-1 / 8} \beta_{0,8}^{-3 / 8} M_{14}^{1 / 16} R_{X, 7}^{-3 / 16} l_{100}^{1 / 8} \quad K e
$$

\footnotetext{
${ }^{2}$ No limite relativístico, $v_{A}=\gamma_{A} v_{A 0}$, onde $\gamma_{A}=\left[1+\left(\frac{v_{A 0}}{c}\right)^{2}\right]$ e $v_{A 0}$ é dado pela equação (2.12).
} 


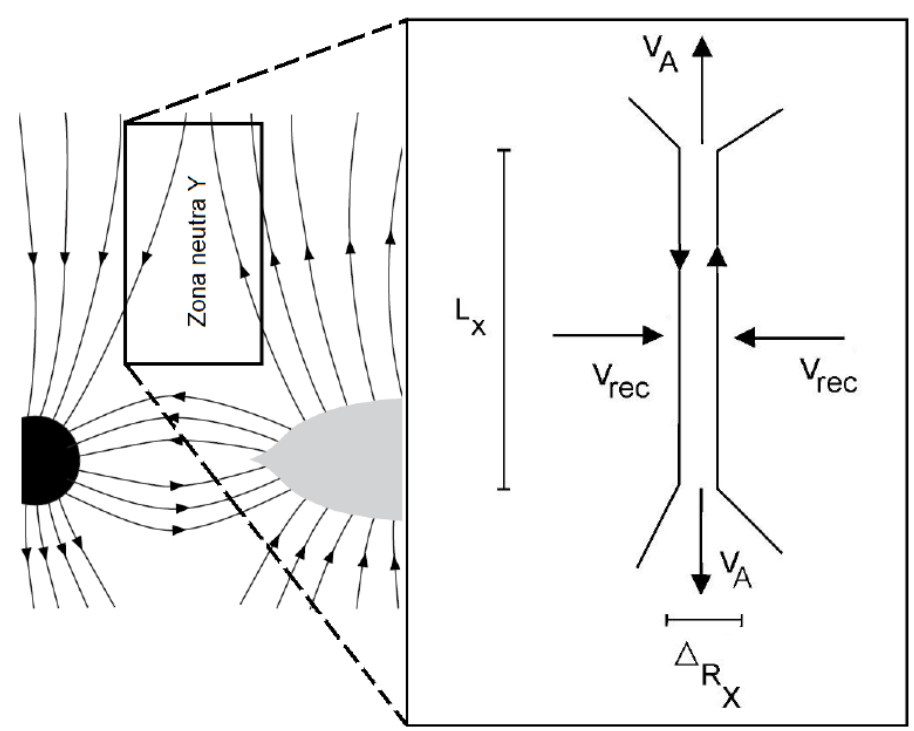

Figura 2.3: Esquema da zona de reconexão. Figura extraída de Piovezan (2009).

$$
n_{c} \cong 5,36 \times 10^{15} \alpha_{0,5}^{-1 / 4} \beta_{0,8}^{-3 / 4} M_{14}^{1 / 8} R_{X, 7}^{-3 / 8} l_{100}^{-3 / 4} \mathrm{~cm}^{-3},
$$

onde $l_{100}=l /\left(100 R_{X}\right)$ é a normalização do comprimento do arco magnético na zona de reconexão.

\subsubsection{Taxa de energia magnética liberada na reconexão magnética}

A figura 2.3 ilustra uma zona de reconexão de espessura $\Delta R_{X}$ e altura $L_{X}$, onde dois fluxos magnéticos de polarizações opostas avançam, um de encontro ao outro, a uma velocidade de reconexão $v_{r e c}$. A taxa de energia (ou potência) magnética que pode ser extraída da zona de reconexão, segundo esse cenário, é dada por:

$$
\dot{W}_{B} \approx \frac{B^{2}}{8 \pi} \frac{\Delta V}{\Delta t}
$$

onde $B$ é a intensidade do campo magnético que sofrerá a reconexão, $\Delta V=4 \pi R_{X} \Delta R_{X} L_{X}$ é o volume da zona de reconexão e $\Delta t=\Delta R_{X} / v_{\text {rec }}$ é o tempo de reconexão.

De acordo com a figura 2.3, a conservação do fluxo implica que $L_{X} / \Delta R_{X} \approx v_{A} / v_{\text {rec }}$; e escrevendo a velocidade de reconexão como uma fração da velocidade Alfvén na coroa, $v_{r e c}=\xi v_{A}$, onde $\xi$ é a taxa (ou eficiência) de reconexão das linhas de campo magnético, verifica-se que:

$$
\dot{W}_{B} \approx \frac{B^{2}}{8 \pi} \xi v_{A}\left(4 \pi R_{X} \Delta R_{X}\right)
$$


Para que a liberação de energia magnética seja altamente eficiente, de Gouveia Dal Pino e Lazarian (2005) invocaram um mecanismo de reconexão rápida, de forma que $\xi \lesssim 1$ (assim como discutido na seção 2.1.3). Taxas de reconexão tão elevadas são corroboradas por diversas evidências observacionais como as dos flares solares, que indicam que as velocidades de reconexão podem ser tão altas quanto alguns décimos da velocidade Alfvén $\left(v_{r e c} \sim v_{A}\right.$, veja Takasaki et al., 2004).

Para estimar o valor da espessura $\Delta R_{X}$, em um modelo de reconexão rápida, podemos computar uma resistividade anômala ${ }^{3}$ muito acima do valor ôhmico, como proposto por Lazarian e Vishniac (1999). Segundo esses autores, essa resistividade será formada na zona de reconexão quando o gradiente do campo magnético $\left(\Delta B / \Delta R_{X}\right)$ atingir uma intensidade tal que a velocidade de deriva dos elétrons $\left(v_{e}\right)$ se torna da ordem da velocidade térmica dos íons $\left(v_{t}\right)$. Sendo $J$ a densidade de corrente, a condição para o surgimento da resistividade anômala é:

$$
J>J_{\text {crit }}=n_{e} e v_{e} \cong n i Z e v_{t} .
$$

onde $n_{e}$ e $n_{i}$ são, respectivamente, a densidade numérica de elétrons e íons; $e$ a carga do elétron e $Z$ o número atômico dos íons.

Agora, como na largura $\Delta R_{X}$ o campo magnético varia de $\Delta B$, então pela lei de Ampère, tem-se que:

$$
4 \pi J \approx \frac{c \Delta B}{\Delta R_{X}} .
$$

Assim, para $J \sim J_{\text {crit }}$, a largura da zona de reconexão pode ser estimada pela relação:

$$
\Delta R_{X} \approx \frac{c \Delta B}{4 \pi n_{i} Z e v_{t}}
$$

onde $\Delta B \approx 2 B \approx 2 B_{d}$ corresponde ao campo magnético na zona de reconexão e é dada pela equação (2.9), conforme foi discutido na seção 2.2.1. Assumindo-se que $n_{i}=n_{c} \mathrm{e}$ $v_{t}=v_{t, c}$ são, respectivamente, a densidade numérica e a velocidade térmica dos íons de carga $Z e$ na coroa, a velocidade térmica correspondente será dada por (de Gouveia Dal Pino e Lazarian, 2005):

$$
v_{t, c}=\left(\frac{5 k_{B} T_{c}}{3 m_{p}}\right) \cong 7,52 \times 10^{8} \alpha_{0,5}^{-1 / 16} \beta_{0,8}^{-3 / 16} M_{14}^{1 / 32} R_{X, 7}^{-3 / 32} l_{100}^{1 / 16} \mathrm{~cm} \mathrm{~s}^{-1} .
$$

\footnotetext{
${ }^{3}$ Essa resistividade anômala terá um papel equivalente à ação da turbulência na zona de reconexão de modo a torná-la rápida.
} 
onde a temperatura coronal $T_{c}$ foi substituída pela equação (2.14).

Por fim, substituindo as equações (2.9), (2.15) e (2.21) em (2.20), tem-se que:

$$
\left(\frac{\Delta R_{X}}{R_{X}}\right) \cong 1,86 \times 10^{-5} Z^{-1} \alpha_{0,5}^{-3 / 16} \beta_{0,8}^{7 / 16} M_{14}^{3 / 32} R_{X, 7}^{-41 / 32} l_{100}^{11 / 16}
$$

A potência magnética liberada durante o evento de reconexão pode ser agora estimada a partir das equações $(2.9),(2.17)$, e (2.22), de maneira que:

$$
\dot{W}_{B} \cong 1,6 \times 10^{35} \alpha_{0,5}^{-19 / 16} \beta_{0,8}^{-9 / 16} M_{14}^{19 / 32} R_{X, 7}^{-25 / 32} l_{100}^{11 / 16} \mathrm{erg} / \mathrm{s},
$$

onde, conforme calculado na seção 2.2.1, $v_{A} \sim c$.

Já o tempo de reconexão correspondente será dado por:

$$
t_{r e c} \cong \frac{R_{X}}{\xi v_{A}} \cong 10^{-4} \xi^{-1} R_{X, 7} \quad s
$$

Essas relações demonstram que em um processo eficiente de reconexão a liberação de energia magnética ocorrerá em curtos períodos de tempo, assim como exigido para a produção dos flares em rádio observados nas regiões centrais dos microquasares. Após a reconexão, a destruição do fluxo magnético vertical no disco interno aumentará o fator $\beta$, e a coroa retornará a uma condição de baixa magnetização, com a maior parte da energia dissipada localmente no disco.

\subsubsection{Aceleração de partículas e emissão em rádio}

De acordo com o modelo de de Gouveia Dal Pino e Lazarian (2005) aqui descrito, sempre que o fator $\beta$ reduzir-se para valores menores ou da ordem de 1 e a taxa de acreção for equiparável ao valor crítico de Eddington, as linhas de polarização oposta, próximo ao raio $R_{X}$ em que o disco foi truncado, serão pressionadas uma contra as outras de maneira suficientemente rápida para permitir um evento de reconexão violenta. Assim, a energia até então armazenada no campo magnético será liberada e parte dela poderá acelerar as partículas carregadas na região coronal do disco a velocidade relativísticas, formando na base dos jatos súbitas ejeções superluminais, como as observadas nos microquasares por meio da radiação rádio sincrotrônica.

de Gouveia Dal Pino e Lazarian (2005) propuseram um mecanismo para acelerar partículas a velocidades relativísticas "dentro" da zona de reconexão por um processo 
semelhante ao mecanismo de Fermi de primeira ordem, originalmente invocado para explicar a produção de raios cósmicos em choques magnetizados (e.g., Longair, 1992; Bell, 1978a,b). Como ilustrado no esquema da figura 2.3, os fluxos magnéticos à esquerda e à direita da zona de reconexão deslocam-se, um em relação ao outro, com uma velocidade $v_{\text {rec }}$. Consequentemente, as partículas carregadas do fluxo esquerdo "veem" as partículas do fluxo direito aproximarem-se com velocidade $2 v_{r e c}$, de maneira que (de Gouveia Dal Pino e Lazarian, 2005):

$$
\frac{\Delta E}{E}=\frac{2 v_{r e c}}{c} \cos \theta
$$

onde $\Delta E / E$ é o ganho energético de cada partícula pelo processo de aceleração e $\theta$ é o ângulo de inclinação entre a velocidade das partículas e o campo magnético.

O ganho energético médio por cruzamento na zona de reconexão é obtida a partir de uma distribuição de probabilidade das partículas $p(\theta)=2 \sin \theta \cos \theta d \theta$ (e.g., Longair, 1992), portanto:

$$
\left\langle\frac{\Delta E}{E}\right\rangle=\frac{v_{r e c}}{c} \int_{0}^{\pi / 2} 2 \cos ^{2} \theta \sin \theta d \theta=\frac{4}{3} \frac{v_{r e c}}{c} .
$$

Para uma viagem completa de ida e volta entre os fluxos magnéticos esquerdo e direito, o ganho energético médio será duas vezes maior. Consequentemente, a razão entre as energias final e inicial das partículas $\left(E / E_{0}\right)$, após uma viagem completa, é dada por:

$$
\delta=\frac{E}{E_{0}}=1+\frac{8}{3} \frac{v_{r e c}}{c} .
$$

Agora, supondo que a probabilidade de escape de uma partícula da zona de aceleração é semelhante ao calculado para uma frente de choque $\left(4 v_{r e c} / c\right)$, a probabilidade de a mesma permanecer na zona de reconexão será (Bell, 1978a,b):

$$
P=1-\frac{4 v_{r e c}}{c},
$$

o que implica em uma distribuição energética de elétrons (veja, e.g., Longair, 1992):

$$
N(E) d E \sim E^{-1+\frac{\ln P}{\ln \delta}} d E
$$

Substituindo as equações (2.27) e (2.28) na equação acima, obtém-se para o mecanismo de aceleração de Fermi de primeira ordem na zona de reconexão (de Gouveia Dal Pino e Lazarian, 2005):

$$
N(E) d E \propto E^{-5 / 2} .
$$


Por fim, a radiação síncrotron associada aos elétrons com uma distribuição $N(E) d E \propto$ $E^{-\Gamma}$ apresenta um espectro típico em rádio dado por $S_{\nu} \propto \nu^{-\alpha_{r}}$, onde $\alpha_{r}=(\Gamma-1) / 2$. Assim, para $\Gamma=5 / 2$ tem-se que $S_{\nu} \propto \nu^{-0,75}$. Esse valor é consistente com a faixa de índices espectrais em rádio observadas durante os flares do microquasar GRS $1915+105$ $\left(-0,2<\alpha_{R}<-1,0\right.$; veja, Dhawan et al., 2000; Hannikainen et al., 2001). Nota-se que o espectro produzido pela aceleração de Fermi de primeira ordem, dentro da zona de reconexão, é mais inclinado do que o produzido em choques (no qual $N(E) \propto E^{-2}$ e $S_{\nu} \propto \nu^{-0,5}$ veja, Longair, 1992), demonstrando que esse processo será em princípio menos eficiente para acelerar as partículas mais energéticas. No entanto, estudos recentes de Kowal et al. (2011), que vem testando numericamente o modelo de aceleração de Fermi de primeira ordem na zona de reconexão magnética, demonstram que o processo é altamente eficiente. De qualquer modo, ambos os processos poderiam estar atuando na região de reconexão, pois as partículas também poderiam ser aceleradas em choques produzidos por plasmons ejetados da zona de reconexão.

\subsubsection{Análise do espaço de parâmetros para microquasares}

Uma estimativa do espectro de elétrons relativísticos que são acelerados na região coronal, durante um episódio de reconexão magnética, indica que a maior parte desses elétrons deve ser reabsorvida nesse momento (Piovezan, 2009), pois a região próxima ao disco de acreção é opticamente espessa. Contudo, à medida que a ejeção expande, a mesma dilui-se, tornando-se opticamente transparente para a sua própria radiação, primeiro no infravermelho e, em seguida, em rádio. O cálculo da evolução desse espectro (e.g., Reynoso e Romero, 2009; del Valle et al., 2011) não foi levado em consideração no desenvolvimento quantitativo do presente modelo, uma vez que requer a construção de um perfil mais detalhado para a coroa. No entanto, algumas previsões podem ser realizadas comparando-se a potência liberada durante um evento de reconexão magnética violenta com as luminosidades em rádio emitidas pelos microquasares.

Piovezan (2009) (veja também de Gouveia Dal Pino et al., 2010a,b) calculou a taxa de energia magnética liberada em um evento de reconexão magnética violenta a partir da variação do espaço de parâmetros da equação (2.23) e comparou os valores obtidos com as luminosidades da radiação rádio sincrotrônica emitida pelos jatos da região nuclear dos 
microquasares GRS 1915 + 105, XTE J1859 + 226 e XTE J1550 - 564 (e.g. Merloni et al., 2003).

A análise realizada por Piovezan (2009) indica que a potência magnética liberada em eventos de reconexão magnética violenta é mais do que suficiente para explicar as luminosidades rádio sincrotrônica emitidas durante a fase de flare dos microquasares analisados. Por outro lado, o fato de a potência magnética liberada superar em até quatro ordens de magnitude as luminosidades em rádio dessas fontes (veja Piovezan, 2009; de Gouveia Dal Pino et al., 2010a,b), implica que somente uma pequena fração dessa energia será necessária para acelerar as partículas a velocidades relativísticas. A maior parte da energia liberada será direcionada, provavelmente, para o aquecimento tanto da região coronal quanto do gás do disco, através da condução térmica ao longo das linhas de campo magnético. Esse aquecimento adicional pode perturbar a acreção do disco e resultar na variabilidade na emissão de raios-X "mole" como observado, por exemplo, durante os flares da fonte GRS $1915+105$ (Dhawan et al., 2000, veja figura 1.3).

\subsubsection{Emissão em raios-X e a transição entre as fases do SPLS}

Conforme observado em Piovezan (2009) e de Gouveia Dal Pino et al. (2010a,b), a emissão intensificada em raios-X, que frequentemente acompanha os flares em microquasares, pode ser explicada dentro do modelo de de Gouveia Dal Pino e Lazarian (2005) como consequência do aumento da taxa de acreção imediatamente antes do evento de reconexão magnética violenta.

A emissão em raios-X "mole" do disco pode ser estimada a partir da potência liberada no processo de acreção. Para uma taxa de acreção da ordem do limite crítico de Eddington, esta potência é dada por (Frank et al., 1992, veja também o anexo A):

$$
\dot{W}_{a c} \cong \frac{G M_{B N} \dot{M}}{R_{X}} \cong 1.87 \times 10^{39} M_{14} \dot{M}_{19} R_{X, 7}^{-1} \mathrm{erg} / \mathrm{s}
$$

que é compatível com a emissão em raios-X "mole" observada por Remillard e McClintock (2006).

Por outro lado, a componente em raios-X "dura" pode ser explicada a partir do espalhamento Compton inverso entre os fótons de raios-X "moles", e os elétrons tanto da coroa quanto do jato nuclear (Zdziarski, 2000). Se esse for o caso, espera-se que após o 
flare em rádio, a luminosidade em raios-X "dura" decaia devido à diminuição do número de elétrons relativísticos, os quais em sua maior parte, são ejetados para longe do sistema. De fato, esse decaimento é observado a partir da emissão rádio de microquasares, assim como constatado por Dhawan et al. (2000).

De acordo com o cenário aqui apresentado, um campo magnético poloidal é progressivamente construído por um dínamo turbulento durante a fase "dura" do SPLS. O campo poloidal, por sua vez, produz um vento que remove momento angular do disco e aumenta a taxa de acreção. Imediatamente antes da transição para a fase "mole" do SPLS, teremos uma configuração semelhante a apresentada na figura 2.1. Quando os eventos de reconexão magnética violenta ocorrem, grandes quantidades de energia são liberadas, produzindo os flares em rádio e raios-X. Particularmente, a fonte GRS $1915+105$ estaria transitando justamente entre as fases "dura" e "mole" do SPLS, assim como demonstrado na figura 1.3.

\subsection{Generalização do modelo para NAGs}

Conforme vimos no capítulo 1, apesar das diferenças de escala física, tanto os núcleos ativos de galáxias quanto os microquasares possuem características morfológicas comuns (veja Mirabel e Rodríguez, 1998, e a seção 1.2 para uma descrição mais detalhada). De fato, estudos recentes indicam que essas similaridades são mais do que morfológicas (Merloni et al., 2003) e, se esse for o caso, uma generalização do cenário proposto por de Gouveia Dal Pino e Lazarian (2005) para as fontes extragalácticas é quase direta. Em particular, jatos relativísticos de NAGs também são produzidos a partir de eventos de ejeção de matéria quase-periódicos. Essas ejeções, por sua vez, produzem um espectro síncrotron em lei de potência com índices espectrais semelhantes aos apresentados pelos microquasares, reforçando a ideia de que existe uma forte conexão entre essas duas classes de fontes.

A seguir, será descrita brevemente a análise realizada para a avaliação da taxa de energia magnética liberada pelos NAGs. Uma descrição mais detalhada das equações pode ser encontrada em Piovezan (2009). 
2.3.1 Taxa de energia magnética e análise do espaço de parâmetros para os NAGs

Observações das regiões centrais de NAGs indicam a presença de uma forte emissão no ultravioleta, que é interpretada como a emissão térmica proveniente de um disco de acreção em torno de um buraco negro supermassivo. Portanto, segundo a aproximação de um corpo negro, estima-se que as temperaturas típicas desses discos sejam da ordem de $10^{5} \mathrm{~K}$. A essas temperaturas, ainda é possível admitir as mesmas suposições adotadas na seção 2.2.1, portanto:

$$
\begin{aligned}
& T_{d} \cong 2,79 \times 10^{5} \alpha_{0,5}^{-1 / 4} M_{8}^{1 / 8} R_{X, 14}^{-3 / 8} \mathrm{~K}, \\
& n_{d} \cong 2,63 \times 10^{11} \alpha_{0,5}^{-1} M_{8}^{-1 / 2} \dot{M}_{26}^{-2} R_{X, 14}^{3 / 2} q_{0,81}^{-8} \mathrm{~cm}^{-3}, \\
& H_{d} / R_{X} \cong 0,72 \dot{M}_{26} R_{X, 14}^{-1} q_{0,81}^{4}, \\
& U_{d} \cong 4,15 \times 10^{7} \alpha_{0,5}^{-1} M_{8}^{1 / 2} R_{X, 14}^{-3 / 2} \mathrm{erg} / \mathrm{cm}^{3} \mathrm{e} \\
& B_{d} \cong 2,19 \times 10^{4} \beta_{0,8}^{-1 / 2} \alpha_{0,5}^{-1 / 2} M_{8}^{1 / 4} R_{X, 14}^{-3 / 4} \mathrm{G},
\end{aligned}
$$

onde $R_{X, 14}=R_{X} /\left(10^{14} \mathrm{~cm}\right), M_{8}=M /\left(10^{8} M_{\odot}\right), \dot{M}_{26}=\dot{M} /\left(10^{26} \mathrm{~g} / \mathrm{s}\right)$ e $q_{0,81}=q /(0,81)$ são, respectivamente, as novas normalizações definidas em função de valores característicos estimados para os NAGs. Por exemplo, estima-se que a massa de buracos negros localizados nas regiões centrais dos NAGs sejam da ordem de $10^{8} M_{\odot}$ que, segundo a equação (2.1), implica em raios internos para os discos da ordem de $10^{14} \mathrm{~cm}$. Por fim, a partir desses valores, a taxa de acreção crítica de Eddington é estimada em torno de $10^{26} \mathrm{~g} / \mathrm{s}$.

Assim como citado na seção 2.2.2, o modelo para a coroa desenvolvida por Liu et al. (2002) é válido tanto para os microquasares quanto para os NAGs. Portanto, a temperatura e a densidade numérica da coroa também são obtidas a partir da solução de um sistema composto pelas equações (2.11) e (2.13), de forma que:

$$
\begin{aligned}
& T_{c} \cong 4,02 \times 10^{9} \alpha_{0,5}^{-15 / 32} \beta_{0,8}^{-3 / 8} M_{8}^{25 / 64} \dot{M}_{26}^{-1} R_{X, 14}^{75 / 64} l_{100}^{1 / 8} K e \\
& n_{c} \cong 5,14 \times 10^{8} \alpha_{0,5}^{-15 / 16} \beta_{0,8}^{-3 / 4} M_{8}^{-25 / 32} \dot{M}_{26}^{-2} R_{X, 14}^{75 / 32} l_{100}^{-3 / 4} \mathrm{~cm}^{-3}
\end{aligned}
$$

Por fim, a partir da mesma análise realizada na seção 2.2.3, a largura característica da zona de reconexão será:

$$
\left(\frac{\Delta R_{X}}{R_{X}}\right) \cong 5,7 \times 10^{-9} Z^{-1} \alpha_{0,5}^{0,67} \beta_{0,8}^{0,94} M_{8}^{1,23} \dot{M}_{26}^{2,5} R_{X, 14}^{-4,68} l_{100}^{0,69},
$$


e, portanto, a potência magnética e o tempo de reconexão serão, respectivamente, dados por:

$$
\begin{aligned}
& \dot{W}_{B} \cong 4,11 \times 10^{38} \alpha_{0,5}^{-19 / 16} \beta_{0,8}^{-9 / 16} M_{8}^{19 / 32} R_{X, 7}^{-25 / 32} l_{100}^{11 / 16} \mathrm{erg} / \mathrm{s} \quad \text { e } \\
& t_{r e c} \cong \frac{R_{X}}{\xi v_{A}} \cong 3,3 \times 10^{3} \xi^{-1} R_{X, 14} \mathrm{~s} .
\end{aligned}
$$

\subsubsection{Resultado da generalização do modelo de reconexão magnética violenta: dos} microquasares aos NAGs

A Figura 2.4 mostra um resumo da generalização do cenário de reconexão magnética para as fontes relativísticas, incluindo tanto microquasares quanto NAGs, onde a potência magnética liberada na reconexão foi calculada a partir da variação do espaço de parâmetros da equações (2.23) e (2.40).

No caso dos microquasares foram utilizados os mesmos valores obtidos por Piovezan (2009). Já para o caso dos NAGs, a massa foi variada dentro de um intervalo entre $10^{6} M_{\odot}$ e $10^{10} M_{\odot}$. Em seguida, para uma dada massa $M$, o raio interno do disco $R_{X}$ foi calculado como o indicado na equação (2.1) e o comprimento do arco magnético $l$ foi variado em três intervalos distintos $\left(0<l<3 R_{X}, 3 R_{X}<l<10 R_{X}\right.$ e $\left.10 R_{X}<l<333 R_{X}\right)$, complementando o trabalho desenvolvido por Piovezan (2009). Por fim, o parâmetro de viscosidade $\alpha$ e o fator $\beta$ assumiram valores entre os seguintes intervalos: $0,05<\alpha<0,5$ e $0,1<\beta<1$.

As potências magnéticas calculadas foram, por sua vez, comparadas com os limites superiores para as luminosidades em rádio observadas de jatos nucleares que emergem das regiões centrais de galáxias Seyfert, de LINERs e de quasares. Essas comparações foram originalmente realizadas por Piovezan (2009) a partir da análise da emissão em rádio de oito fontes obtidas em Kellermann et al. (1998). As massas dos buracos negros centrais das respectivas fontes foram obtidas em Marchesini et al. (2004) e Merloni et al. (2003). Em complementação a esse trabalho, incluímos medidas de emissão em rádio de trinta e sete galáxias Seyfert e mais sessenta e uma LINERs, obtidas por Nagar et al. (2005). Desse novo conjunto de fontes, as massas dos respectivos buracos negros centrais $\left(M_{B}\right)$ foram estimadas a partir dos valores de velocidade de dispersão das estrelas dessas galáxias $\left(v_{\sigma}\right)$. Esses valores, por sua vez, foram obtidos a partir do catálogo HYPERLEDA e a relação 


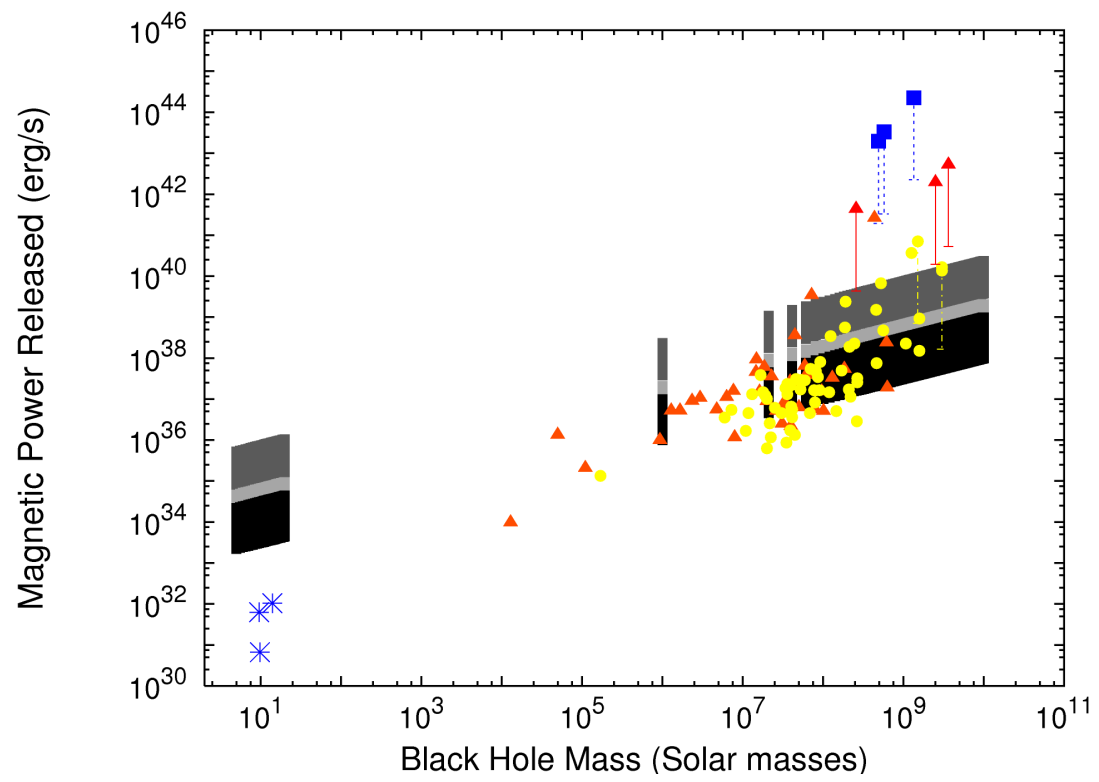

Figura 2.4: Potência magnética em função da massa do buraco negro central. As estrelas correspondem às luminosidades em rádio dos microquasares GRS 1915+105, XTE J1859+226 e XTE J1550-564. Os círculos, triângulos e quadrados correspondem, respectivamente, às luminosidades em rádio de jatos nucleares produzidos por LINERs, galáxias Seyfert e quasares (obtidos de Kellermann et al., 1998; Nagar et al., 2005). As barras de erro das oito fontes mais luminosas e massivas indicam uma redução por um fator 100 devido ao relativistic beaming (Rybicki e Lightman, 1986), que provavelmente afeta a emissão dos jatos relativísticos (Kellermann et al., 1998). A cor de cada uma das barras correspondem à variação do espaço de parâmetros para diferentes intervalos de comprimento dos arcos magnéticos $(l): 0 R_{X}<l<3 R_{X}$ em preto, $3 R_{X}<l<10 R_{X}$ em cinza claro, e $10 R_{X}<l<333 R_{X}$ em cinza escuro. Veja o texto para mais detalhes.

entre $M_{B}$ e $v_{\sigma}$ do trabalho de Tremaine et al. (2002). A relação das fontes, tanto de microquasares quanto de NAGs, e seus respectivos parâmetros estão contidos na tabela do anexo C.

A análise da figura 2.4 indica que a potência magnética liberada durante os eventos de reconexão violenta são capazes de explicar a emissão em rádio produzida por jatos nucleares tanto de microquasares quanto dos NAGs de menor luminosidade. Esses resultados são muito significativos, pois estabelecem uma clara correlação entre a potência magnética liberada desde buracos negros de massa estelar até buracos negros supermassivos de NAGs, compreendendo um intervalo de massas entre $5 M_{\odot}$ e $10^{10} M_{\odot}$.

A correlação estabelecida entre $\dot{W}_{B}$ e a massa dos buracos negros das fontes pode ser compreendida a partir da equação (2.23), onde o comprimento do arco magnético 
$l$ também está parametrizado em função $R_{X}$. Com isso, a equação (2.23) implica em uma dependência $\dot{W}_{B} \propto \alpha^{-19 / 16} \beta^{-9 / 16} M^{1 / 2}$. Em outras palavras, a potência liberada na reconexão magnética na coroa em torno dessas fontes depende apenas da massa do buraco negro $\left(\propto M^{0,5}\right)$, do parâmetro de viscosidade $\left(\propto \alpha^{-1,2}\right)$ e da razão entre as pressões de radiação e magnética do disco $\left(\propto \beta^{-0,56}\right)$. Em cada uma das faixas de cores do diagrama da figura 2.4, quanto maior o valor de $\beta$ e $\alpha$ menor será a potência magnética liberada para cada massa $M$. Contudo, como $\beta$ e $\alpha$ possuem uma variação bem menor no espaço paramétrico dos sistemas considerados, verifica-se uma dependência quase linear entre $\log \left(\dot{W}_{B}\right)$ e $\log \left(M_{B}\right)$, com uma inclinação da reta da ordem de 0,5 .

Essa correlação sugere que a emissão em rádio de alguns microquasares e NAGs de baixa luminosidade vem principalmente da atividade magnética na coroa (logo acima do disco de acreção) e é, portanto, aproximadamente independente da física da fonte central e do disco de acreção, tal como previsto pelo modelo de de Gouveia Dal Pino e Lazarian (2005).

É interessante notar também que esse resultado é consistente com uma correlação empírica encontrada entre a luminosidade em rádio e a emissão em raios-X "dura" para as fontes desde estrelas magneticamente ativas até microquasares e NAGs do tipo radio quiet (veja Laor e Behar, 2008; Soker e Vrtilek, 2009).

A correlação encontrada na figura 2.4 para microquasares e NAGs menos luminosos não se aplica a NAGs e quasares de maior luminosidade, conforme vemos no gráfico. Nesses casos, é possível que as regiões centrais dessas fontes sejam tão densas que "mascararam"a emissão devido à atividade magnética coronal, e a emissão rádio observada possivelmente origina-se mais acima no jato. Por exemplo, ela pode ser devido à aceleração dos elétrons em choques que se formam graças à expansão supersônica do fluido coronal do jato.

\subsection{Reconexão magnética em objetos estelares jovens}

Objetos estelares jovens (OEJs) diferenciam-se em muitos aspectos em relação aos microquasares e NAGs, a começar, pelos seus jatos que apresentam emissão térmica ao invés da não-térmica como nos jatos relativísticos. Além disso, apresentam linhas de emissão a partir das quais as suas propriedades físicas, tais como densidade e temperatura, podem ser inferidas. Por outro lado, tal como as fontes centrais de microquasares, os OEJs 
também podem exibir uma intensa atividade magnética que no caso resulta em uma forte e variável emissão em raios-X (e.g, Bouvier et al., 2007).

Os flares em raios-X observados nessas fontes são frequentemente atribuídos a atividade magnética na coroa estelar (Feigelson e Montmerle, 1999). No entanto, as observações de algumas fontes denominadas COUP (do inglês, Chandra Orion Ultra-deep Project) revelou que essas emissões podem estar relacionadas a eventos de reconexão magnética em arcos magnéticos que conectam a estrela central com a região interna do disco de acreção (Favata et al., 2005).

Estudos numéricos recentes da interação entre a magnetosfera do disco e o campo dipolar da estrela central revelaram que a rotação diferencial e o transporte de momento angular podem levar à quebra e reconexão das linhas de campo magnético, de modo similar ao esquematizado na figura 2.1 (e.g., Goodson e Winglee, 1999; Matt et al., 2002; Uzdensky et al., 2002; Romanova et al., 2004; von Rekowski e Brandenburg, 2004; Zanni e Ferreira, 2009; Alencar, 2007).

As evidências numéricas e observacionais aqui citadas reforçam a ideia de que os flares em raios-X poderiam estar associados a um processo de reconexão entre os campos magnéticos da estrela e da região interna do disco de acreção. Com base nesta, Piovezan (2009) analisou as condições sob as quais os eventos de reconexão magnética violenta poderiam ocorrer em OEJs, utilizando o modelo de de Gouveia Dal Pino e Lazarian (2005) (veja também de Gouveia Dal Pino et al., 2010a,b). Essa análise será brevemente descrita aqui, pois a mesma será útil para compreender melhor os modelos numéricos que serão apresentados no capítulo 3.

\subsubsection{Taxa de energia magnética e análise do espaço de parâmetros}

Para estimar a taxa de energia liberada através de um evento de reconexão magnética violenta na região de interação entre o disco e a estrela, Piovezan (2009) considerou que a configuração inicial do sistema é aquela esquematizada na figura 2.1. Por outro lado, os parâmetros do disco e da coroa dos OEJs foram obtidos a partir dos valores médios estimados diretamente das observações (Favata et al., 2005), diferentemente dos microquasares e NAGs, cujos parâmetros foram obtidos a partir dos modelos de discos de acreção de Shakura e Sunyaev (1973) e da coroa de Liu et al. (2002). 
O campo magnético estelar foi obtido a partir de uma configuração de campo quase dipolar, de maneira que a sua intensidade no raio mais interno do disco $\left(R_{X}\right)$ é dada por:

$$
B_{X}=\mu B_{*}\left(\frac{R_{*}}{R_{X}}\right)^{3},
$$

onde $B_{*}$ e $R_{*}$ são, respectivamente, a intensidade do campo e o raio na superfície da estrela, e $\mu$ é um parâmetro que representa pequenas deformações na configuração do campo de dipolo devido à pressão dinâmica do gás do disco, cujo valor é maior ou da ordem da unidade (e.g., Shu et al., 1994).

O raio $R_{X}$, por sua vez, foi determinado a partir do equilíbrio entre a pressão dinâmica do gás e pressão magnética da estrela na região equatorial onde o disco é truncado $\left(\rho_{d} v_{r}^{2} \simeq\right.$ $\left.B^{2} / 8 \pi\right)$. Assumindo uma geometria esférica e que a velocidade de acreção radial $\left(v_{r}\right)$ pode ser aproximada pela velocidade de queda livre, obtém-se que (e.g., Bouvier et al., 2007):

$$
\frac{R_{X}}{R_{*}}=\frac{\left(\mu B_{*}\right)^{4 / 7} R_{*}^{5 / 7}}{\dot{M}^{2 / 7}\left(2 G M_{*}^{1 / 7}\right)},
$$

onde $M_{*}$ é a massa estelar.

A partir da equação (2.43) acima, é possível estimar a taxa máxima de acreção que esse sistema pode suportar, assumindo que o material do disco efetivamente alcança a superfície da estrela $\left(R_{X}=R_{*}\right)$, de maneira que:

$$
\dot{M}_{\text {max }}=1.12 \times 10^{22}\left(\mu B_{*}\right)_{5000}^{2} R_{2}^{5 / 2} M_{1}^{-1 / 2} \quad g / s,
$$

onde $\left(\mu B_{*}\right)_{5000}=\mu B_{*} /(5000 G), R_{2}=R_{*} /\left(2 R_{\odot}\right)$, e $M_{1}=M_{*} /\left(1 M_{\odot}\right)$ são, respectivamente, as normalizações dos parâmetros estelares de campo magnético efetivo, raio e massa, todas em função de valores típicos para os OEJs.

Adotando a mesma análise realizada na seção 2.2.3, a potência magnética liberada e o tempo de reconexão são dados por (Piovezan, 2009):

$$
\begin{aligned}
& \dot{W}_{B} \cong 4,3 \times 10^{21}\left(\mu B_{*}\right)_{5000}^{-16 / 7} M_{1}^{11 / 7} \dot{M}_{19}^{22 / 7} R_{2}^{-48 / 7} n_{11}^{-3 / 2} T_{8}^{-1 / 2} \mathrm{erg} / \mathrm{s} e \\
& t_{r e c} \cong 3,9 \times 10^{3} \xi^{-1} n_{c}^{-1 / 2} T_{c}^{-1 / 2} s,
\end{aligned}
$$

onde $\dot{M}_{19}=\dot{M} /\left(10^{19} \mathrm{~g} / \mathrm{s}\right), n_{11}=n_{c} /\left(10^{11} \mathrm{~cm}^{-3}\right)$ e $T_{8}=T_{c} /\left(10^{8} \mathrm{~K}\right)$, são respectivamente as normalizações para a taxa de acreção do disco, temperatura e densidade coronal. 
Por fim, a potência magnética associada à taxa de acreção máxima, calculada pela equação (2.44), é estimada em:

$$
\dot{W}_{B, \max } \cong 1.4 \times 10^{31}\left(\mu B_{*}\right)_{5000}^{-16 / 7} M_{1}^{11 / 7} \dot{M}_{\max }^{22 / 7} R_{2}^{-48 / 7} n_{11}^{-3 / 2} T_{8}^{-1 / 2} \mathrm{erg} / \mathrm{s} .
$$

de Gouveia Dal Pino et al. (2010) argumentaram que a energia liberada pelo evento de reconexão pode aquecer o gás na base dos jatos protoestelares (Ray et al., 2007). Estimativas preliminares indicam que grande parte da energia magnética liberada pode ser conduzida termicamente até distâncias da ordem de 10 AU (Pesenti et al., 2003) em uma escala de tempo $\tau_{\text {cond }} \sim 10^{8} n_{10} T_{8}^{-5 / 2} l_{10}^{2}$ s. Esse valor é comparável, por exemplo, com o tempo dinâmico do jato protoestelar de DGTau (e.g, Bacciotti et al., 2002; Cerqueira e de Gouveia Dal Pino, 2004).

\subsection{Discussões}

Neste capítulo, descrevemos a generalização do modelo originalmente proposto por de Gouveia Dal Pino e Lazarian (2005) para explicar a aceleração inicial de partículas relativísticas, bem como os flares em rádio associados a microquasares e NAGs. Nesse cenário, a ejeção inicial quase periódica de plasmons relativísticos poderia ocorrer através de eventos de reconexão violenta entre as linhas do campo magnético da região interna do disco de acreção e aquelas que estão ancoradas no horizonte do buraco negro. De acordo com esse modelo, o evento de reconexão violenta deve ocorrer sempre que a razão entre a pressão total do disco e a pressão magnética $(\beta)$ decresce para valores menores ou da ordem de 1 , e a taxa de acreção $(\dot{M})$ atinge valores da ordem do limite crítico de Eddington. A energia magnética liberada será usada, em parte, para aquecer o gás coronal e também o gás na superfície do disco, através da condução térmica ao longo das linhas de campo magnético. No caso dos microquasares, isso poderia aumentar a emissão em raiosX "mole", causando variações momentâneas na mesma, como observado na fonte GRS 1915+105. A parte restante da energia irá acelerar as partículas a velocidades relativísticas por processo de Fermi de primeira ordem, produzindo um espectro sincrotrônico de lei de potência com índices espectrais comparáveis aos observados. Esse processo de aceleração em zonas de reconexão magnética, proposto pela primeira vez por de Gouveia Dal Pino e Lazarian (2005), foi recentemente testado com sucesso por meio de simulações numéricas 
magnetohidrodinâmicas tridimensionais (3D-MHD; Kowal et al., 2011). Além disso, esse mecanismo vem sendo cada vez mais invocado para explicar a aceleração de raios cósmicos e raios cósmicos ultra energéticos (UHECRs, do inglês ultra high energy cosmic rays) em fontes astrofísicas: da magnetocauda da Terra e da coroa solar (Lazarian e Opher, 2009) aos surtos de raios gama (Kotera e Olinto, 2011).

A generalização do modelo para o caso dos NAGs, realizada nesse trabalho, indica que a atividade de reconexão magnética na região coronal, e na base de lançamento do jato, pode explicar a emissão rádio das ejeções relativísticas dos microquasares e NAGs de menor luminosidade. A potência liberada no evento de reconexão em função das massas dos buracos negros centrais entre $5 M_{\odot}$ e $10^{10} M_{\odot}$ obedece a uma correlação que se mantém por todo esse intervalo, abrangendo $10^{9}$ ordens de magnitude. De fato, o modelo prevê uma dependência dada por $\dot{W}_{B} \propto \alpha^{-19 / 16} \beta^{-9 / 16} M^{1 / 2}$. Embora as dependências com os parâmetros $\alpha$ e $\beta$ sejam ligeiramente mais fortes, o fato de variarem muito pouco para todas as classes de discos de acreção considerados, torna $\dot{W}_{B}$ essencialmente dependente de $M$, ou seja, $\dot{W}_{B} \propto M^{1 / 2}$. Isso explica a dependência quase linear observada no diagrama da figura 2.4. Esse bom ajuste do modelo às observações dos flares em rádio dessas fontes: dos microquasares aos NAGs de baixa luminosidade, é uma indicação de que o modelo de atividade magnética aqui descrito parece apropriado, apesar de sua simplicidade.

Já os NAGs e quasares mais luminosos não satisfazem à mesma correlação. Em outras palavras, nesses casos a emissão rádio dos jatos não pode ser explicada pelo modelo de reconexão magnética. Isso se deve, possivelmente, ao fato de que nessas fontes a densidade coronal seja tão alta que "mascara" a emissão devida à atividade magnética. A emissão rádio nesses casos deve então ser produzida mais acima no jato. Possivelmente deve-se à aceleração de elétrons relativísticos em choques que se formam à medida que o jato expande supersonicamente e se torna opticamente fino, conforme discutido na sessão 2.3.2.

Por fim, conforme verificado por Piovezan (2009), o mesmo modelo aplicado para o caso de OEJs, sugere que os flares em raios-X observados em um conjunto de fontes COUP (Favata et al., 2005) podem também ser produzidos por eventos de reconexão magnética violenta na região de interação entre as linhas poloidais do disco e a magnetosfera da estrela. Porém, esses eventos só ocorrerão com taxas de acreção da ordem de 100 a 1000 vezes maiores que os típicos inferidos das observações. Entretanto, taxas tão altas só serão 
sustentadas por períodos extremamente curtos.

O modelo simples de reconexão magnética aqui descrito parece explicar de modo bastante satisfatório os flares produzidos na coroa ao redor de discos de acreção associados a fontes compactas, desde OEJs até NAGs menos luminosos. Os resultados aqui descritos, baseados nesse modelo analítico simples, embora apresentem boa concordância qualitativa com as observações, carecem de comprovação a partir de uma modelagem mais realística, que leve em conta a multidimensionalidade e a dependência temporal dos processos físicos envolvidos no problema. Por essa razão, realizamos simulações magnetohidrodinâmicas axissimétricas (2.5D-MHD), baseadas na interação entre o campo magnético poloidal ancorado em um disco de acreção e a magnetosfera dipolar de uma fonte central em rotação, a fim de testar o modelo aqui apresentado.

No capítulo 3, apresentaremos resultados preliminares dessas simulações, onde mimetizamos algumas características do modelo de de Gouveia Dal Pino e Lazarian (2005), considerando condições que se assemelham ao dos OEJs. 
Capítulo 3

\section{Simulações magnetohidrodinâmicas axissimétricas de reconexão magnética em discos de acreção}

Neste capítulo, investigaremos a formação de lençóis de corrente (ou eventos de reconexão magnética) através de simulações magnetohidrodinâmicas axissimétricas (2.5DMHD), da interação entre o campo magnético poloidal acretado por um disco de acreção viscoso (modelo padrão de Shakura e Sunyaev, 1973) e a magnetosfera dipolar de uma fonte central em rotação. Para isso, utilizaremos um código numérico baseado no método de Godunov denominado PLUTO (veja Mignone et al., 2007, e uma breve descrição no anexo B). Esse código pode ser empregado tanto para resolver as equações da hidrodinâmica quanto da magnetohidrodinâmica, nos regimes clássico e relativístico, em um sistema de coordenadas cartesianas, cilíndricas ou esféricas. Por simplicidade, as simulações foram realizadas considerando-se condições que se assemelham às dos OEJs (e.g Zanni e Ferreira, 2009; Bessolaz et al., 2008; Romanova et al., 2002). Em contrapartida, esse cenário pode ser também relevante para o estudo de discos de acreção associados a outros tipos de fontes, tais como, variáveis cataclísmicas, estrelas de nêutrons e buracos negros, como vimos nos capítulos anteriores. Neste último caso, no entanto, a inexistência de uma superfície sólida na fonte central exigiria uma modificação das condições de contorno sobre a mesma. Porém, para a proposta do presente estudo, que é a investigação do processo de formação de zonas de reconexão nas regiões mais internas desses sistemas, essa limitação não chega a ser muito importante.

Os estudos dos diferentes aspectos de um cenário de interação entre discos de acreção e a magnetosfera das fontes centrais, baseados em modelos analíticos, podem ser encontrados, por exemplo, em Ghosh e Lamb (1979a,b) e Koldoba et al. (2002). Simulações análogas 
as que serão apresentadas neste capítulo, porém, com enfoques e objetivos distintos aos do presente trabalho, podem ser vistos em Beckwith et al. (2009), Gammie e Menou (1998), Goodson et al. (1999), Stone e Pringle (2001), entre outros. Por exemplo, Zanni e Ferreira (2009) desenvolveram um conjunto de simulações (cujas condições foram parcialmente reproduzidas nessa dissertação) para o estudo dos mecanismos que regulam a transferência de momento angular do sistema, considerando tanto os torques exercidos pela magnetosfera que conecta a estrela ao seu disco de acreção, quanto os torques exercidos pelo vento estelar ao longo das linhas de campo magnético "abertas" da fonte central. Já Romanova et al. (2002), supondo um cenário semelhante, não só analisaram o processo de transferência de momento angular do sistema para diversos valores de campo magnético e de rotação estelar, mas também estudaram a formação de funis de acreção (ou do inglês funnel flows, ou ainda simplesmente, FF ${ }^{1}$ em um regime quiescente do sistema. Romanova et al. (2011), por sua vez, estudaram a influência da instabilidade magneto-rotacional (Balbus e Hawley, 1998) no processo de acreção do disco, a partir de um sistema formado pela magnetosfera da fonte central e o campo poloidal do disco, supondo diversas configurações magnéticas.

Esses trabalhos foram usados como base para o desenvolvimento das simulações que serão apresentadas neste capítulo. A seguir, iremos apresentar a metodologia usada para a realização dessas simulações (veja apêndice B para maiores detalhes) e apresentaremos os resultados obtidos para diversos modelos. Na última seção deste capítulo discutiremos, por fim, a viabilidade de eventos de reconexão para esses modelos.

\subsection{Equações magnetohidrodinâmicas e o método computacional}

Empregaremos as equações da magnetohidrodinâmica para descrever o comportamento macroscópico de um fluido magnetizado. Estas podem ser derivadas da teoria cinética do plasma ou da combinação entre as equações da mecânica dos fluídos e das equações de Maxwell do eletromagnetismo (e.g., Goedbloed e Poedts, 2004).

As simulações aqui apresentadas foram realizadas a partir da solução numérica desse

\footnotetext{
${ }^{1}$ Os FFs são colunas de acreção que se formam na região de truncamento do disco devido à presença da magnetosfera dipolar da fonte central. O material em acreção barrado pela pressão magnética é, então, escoado até a estrela ao longo das linhas de campo magnético, alcançando a superfície estelar em regiões de latitude intermediária (veja Romanova et al., 2002, e a seção 3.6 adiante).
} 
sistema de equações na forma não ideal, onde foram incluídos os termos de viscosidade e resfriamento. Essas equações são dadas por:

$$
\begin{aligned}
& \frac{\partial \rho}{\partial t}+\nabla \cdot(\rho \boldsymbol{v})=0 \\
& \frac{\partial \rho \boldsymbol{v}}{\partial t}+\nabla \cdot\left[\rho \boldsymbol{v} \boldsymbol{v}+\left(p+\frac{\boldsymbol{B} \cdot \boldsymbol{B}}{8 \pi}\right) \boldsymbol{I}-\frac{\boldsymbol{B} \boldsymbol{B}}{4 \pi}-\boldsymbol{\tau}\right]=\rho \boldsymbol{g} \\
& \frac{\partial E}{\partial t}+\nabla \cdot\left[\left(E+p+\frac{\boldsymbol{B} \cdot \boldsymbol{B}}{8 \pi}\right) \boldsymbol{v}-\frac{(\boldsymbol{v} \cdot \boldsymbol{B}) \boldsymbol{B}}{4 \pi}-\boldsymbol{v} \cdot \boldsymbol{\tau}\right]=\rho \boldsymbol{g} \cdot \boldsymbol{v}-\Lambda_{\text {cool }} e \\
& \frac{\partial \boldsymbol{B}}{\partial t}+\nabla \times(\boldsymbol{B} \times \boldsymbol{v})=0
\end{aligned}
$$

que correspondem, respectivamente, à conservação de massa, momento, energia e indução magnética. Nessas equações, $\rho$ é a densidade; $p$ é a pressão térmica do gás; $\boldsymbol{v}$ é a velocidade; e $\boldsymbol{B}$ é o campo magnético. Além disso, $E$ corresponde à densidade de energia total do gás; $\boldsymbol{g}=-\boldsymbol{\nabla} \phi_{g}$ ao vetor aceleração da gravidade; $\phi_{g}=-G M / R$ ao potencial gravitacional da fonte central; e $\Lambda_{\text {cool }}$ ao termo de resfriamento. Por fim, o tensor de "estresse" viscoso é definido como:

$$
\boldsymbol{\tau}=\eta_{v}\left[(\boldsymbol{\nabla} \boldsymbol{v})+(\boldsymbol{\nabla} \boldsymbol{v})^{T}-2 / 3(\boldsymbol{\nabla} . \boldsymbol{v}) \boldsymbol{I}\right]
$$

onde $\eta_{v}$ é a chamada viscosidade dinâmica. Já o índice $T$ corresponde ao tensor transposto, tal que $\left(T_{i j}\right)^{T}=T_{j i}$; e $\boldsymbol{I}$ é o tensor identidade.

A solução numérica desse sistema de equações foi obtida com o auxílio do módulo MHD do PLUTO, para um sistema de coordenadas esféricas $(R, \theta, \phi)$ com simetria axissimétrica $\left(\partial_{\phi}=0\right)$ em torno do eixo de rotação do sistema disco de acreção-fonte central. Os fluxos entre as células da grade computacional (identificados como problemas de Riemann) foram computados através de um esquema do tipo HLL (solução aproximada de Harten, Lax, Van Leer), enquanto um esquema Runge-Kutta de segunda ordem foi usado para resolver a parte temporal das equações (para maiores detalhes veja Mignone et al., 2007; Toro, 2009, e o apêndice B). Particularmente, a escolha do esquema HLL deve-se ao fato de ser um dos esquemas mais difusivos disponíveis no código. Com isso, evitamos obter soluções na fronteira interna do sistema que poderiam gerar instabilidades indesejadas para a análise da reconexão, pois a viscosidade numérica naturalmente introduzida pelo esquema HLL ajuda a dissipá-las. 
Por fim, um método denominado de constrained transport (CT, veja Balsara e Spicer, 1999) foi usado para manter a divergência do campo magnético nulo $(\boldsymbol{\nabla} \cdot \boldsymbol{B}=0)$; enquanto que uma técnica de divisão de campo (field-splitting techinique; veja Powell et al., 1999) foi usada para tratarmos de forma adequada o intenso campo magnético de geometria dipolar próximo à fronteira interna do domínio computacional. Essa é uma técnica empregada em problemas onde um campo magnético intrínseco e livre de forças (force-free, veja capítulo 2) está presente, de forma que o campo total é separado em uma componente estática e uma componente de intensidade bem menor dependente do tempo. Uma breve descrição de ambos os métodos pode ser vista no apêndice B.

\subsection{Domínio Computacional}

Limitamos o domínio computacional a uma região angular que começa no eixo de rotação do sistema $(\theta=0)$ e termina no plano médio do disco $(\theta=\pi / 2)$, enquanto que a região radial foi delimitada por um raio interno em $R_{\text {min }}=R_{*}$, correspondente à superfície da fonte central, e uma região externa em $R_{\max }$. A grade computacional foi divida de forma uniforme em 100 células na direção angular, enquanto que na direção radial, a grade foi dividida em 256 células de forma não uniforme. Essa estratégia nos permite obter uma boa resolução nas regiões mais internas do sistema, as quais são de interesse para a análise da reconexão magnética. Para tanto, adicionamos no PLUTO uma função $\Delta R \sim R \Delta \theta$ (veja Zanni e Ferreira, 2009; Romanova et al., 2002) na direção radial, o que nos permite obter células aproximadamente quadradas no plano y-z (ver figura 3.1). A partir dos parâmetros admitidos acima, o domínio computacional é então limitado por uma região externa em $R_{\max } \simeq 50 R_{*}$.

\subsection{Condições iniciais no domínio e os termos de viscosidade e resfriamento}

As condições iniciais do sistema foram dividas em quatro partes: as correspondentes ao disco de acreção viscoso e ao seu campo magnético poloidal; à coroa e à magnetosfera da fonte central. O perfil inicial do disco foi obtido através de uma solução tridimensional analítica do modelo de parametrização $\alpha$ de Shakura e Sunyaev (1973), desenvolvida por 


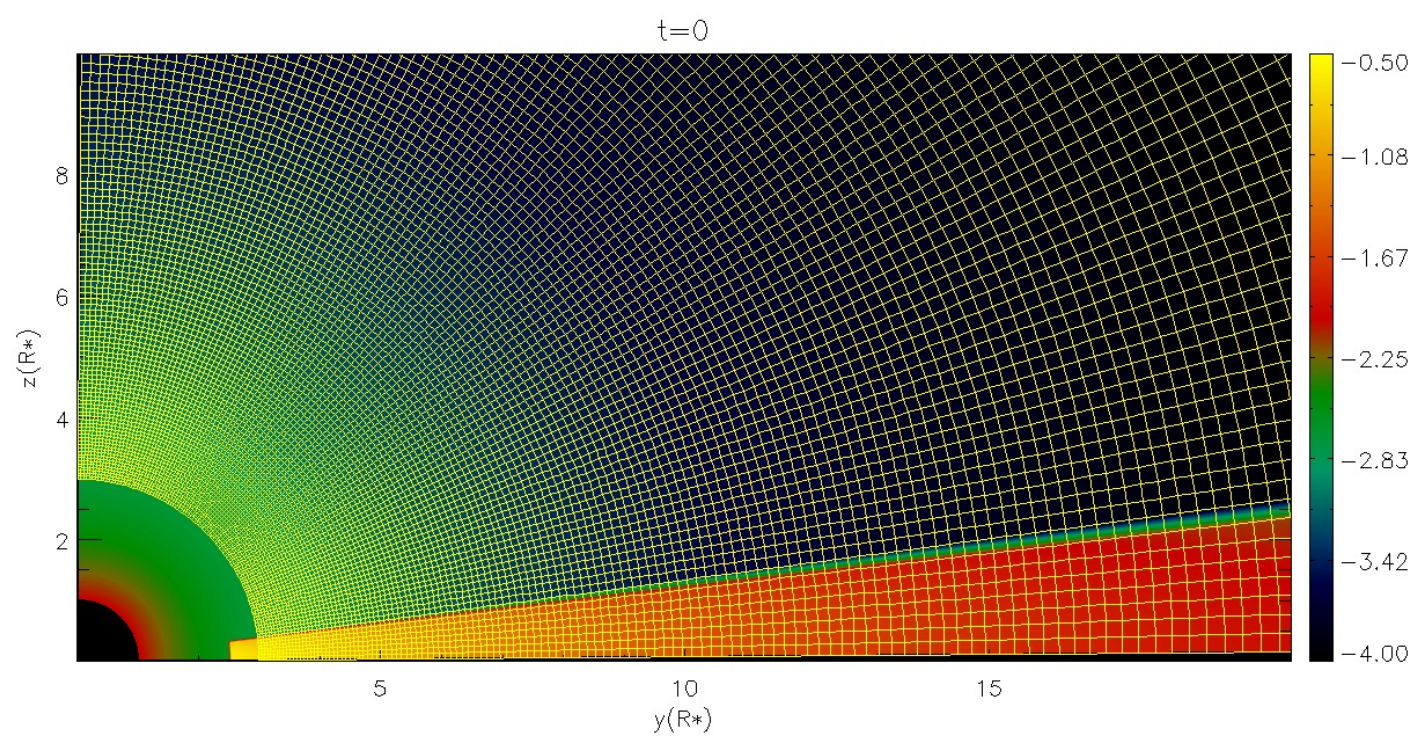

Figura 3.1: Perfil inicial do domínio (veja seção 3.3 adiante) com a grade computacional, em linhas amarelas, que demonstram a boa resolução obtida nas regiões mais internas do domínio.

Kluźniak e Kita (2000) (veja também, Regev e Gitelman, 2002; Umurhan et al., 2006). Essa solução vem da expansão do parâmetro $\epsilon=h / r$, definido como a razão entre a escala de altura e a coordenada radial do disco, nas equações MHD com termo viscoso (equações 3.1 e 3.2, sem os termos de campo magnético). A partir dessa solução, onde foi admitida uma equação de estado para um fluido politrópico $\left(P_{d} \propto \rho_{d}^{\gamma}, \gamma=5 / 3\right)$, a densidade e a pressão térmica são determinadas pelo equilíbrio vertical do disco:

$$
\begin{aligned}
& \rho_{d}=\rho_{d 0}\left\{\frac{2}{5 \epsilon^{2}}\left[\frac{R_{*}}{R}-\left(1-\frac{5 \epsilon^{2}}{2}\right) \frac{R_{*}}{r}\right]\right\}^{\frac{1}{\gamma-1}} e \\
& P_{d}=\epsilon^{2} \rho_{d 0} V_{K_{*}}^{2}\left(\frac{\rho_{d}}{\rho_{d 0}}\right)^{\gamma},
\end{aligned}
$$

onde $r=R \operatorname{sen} \theta$ é o raio em coordenadas cilíndricas e $R$ o raio em coordenadas esféricas. As constantes $\rho_{d 0}$ e $V_{K_{*}}$ correspondem, respectivamente, à densidade e à velocidade Kepleriana calculadas no meio plano do disco para $R=R_{*}$, sendo $R_{*}$ o raio da fonte central.

A velocidade de rotação, por sua vez, é definida a partir do equilíbrio radial do disco e das correções realizadas pela expansão do parâmetro $\epsilon$ definido acima. Devido a essas correções, o disco torna-se ligeiramente sub-Kepleriano, de forma que:

$$
v_{\phi d}=\left[\sqrt{1-\frac{5 \epsilon^{2}}{2}}+\frac{2}{3} \epsilon^{2} \alpha_{v}^{2} \Lambda\left(1-\frac{6}{5 \epsilon^{2} \tan ^{2} \theta}\right)\right] \sqrt{\frac{G M_{*}}{r}},
$$

onde $\Lambda=\frac{11}{5} /\left(1+\frac{64}{25} \alpha_{v}^{2}\right)$; e $\alpha_{v}$ é o parâmetro de viscosidade do modelo padrão. 
Já a componente radial da velocidade é dada por:

$$
v_{R d}=-\alpha_{v} \epsilon^{2}\left[10-\frac{32}{3} \Lambda \alpha_{v}^{2}-\Lambda\left(5-\frac{1}{\epsilon^{2} \tan ^{2} \theta}\right)\right] \sqrt{\frac{G M_{*}}{r}} .
$$

A coroa é modelada como uma atmosfera politrópica em equilíbrio hidrostático, portanto, a densidade e pressão são dadas por:

$$
\begin{aligned}
& \rho_{c}=\rho_{c 0}\left(\frac{R_{*}}{R}\right)^{\frac{1}{\gamma-1}} e \\
& P_{c}=\rho_{c 0} \frac{\gamma-1}{\gamma} \frac{G M_{*}}{R_{*}}\left(\frac{R_{*}}{R}\right)^{\frac{\gamma}{\gamma-1}},
\end{aligned}
$$

onde $\rho_{c 0}$ corresponde à densidade inicial da coroa calculada sobre a superfície da fonte central $\left(R=R_{*}\right)$.

Já para as componentes do campo magnético da fonte central, admitimos uma configuração de dipolo, de maneira que:

$$
B_{R}=\frac{2 B_{*} R_{*}^{3} \cos \theta}{R^{3}}, B_{\theta}=\frac{B_{*} R_{*}^{3} \operatorname{sen} \theta}{R^{3}} \text { e } B_{\phi}=0,
$$

onde $B_{*}$ é o campo magnético equatorial na superfície da fonte central.

Por fim, um campo magnético vertical somado à componente dipolar acima foi usado para construir o campo magnético poloidal do disco. As componentes desse campo vertical são dadas por:

$$
B_{R}=B_{d} \cos (\theta) \quad, \quad B_{\theta}=-B_{d} \operatorname{sen}(\theta) \text { e } B_{\phi}=0
$$

onde $B_{d}$ corresponde ao campo poloidal estimado para o disco de acreção.

Dados esses parâmetros, o raio de truncamento inicial do disco foi definido a partir da equipartição entre a pressão magnética da fonte central e a pressão térmica do disco $\left(B^{2} / 8 \pi=P_{d}\right)$, na região equatorial do sistema. Já a superfície do disco, foi definida a partir do equilíbrio entre as pressões iniciais do disco e da coroa $\left(P_{d}=P_{c}\right)$.

A viscosidade do disco é tratada através de uma função, desenvolvida por Zanni e Ferreira (2009) e baseada no modelo padrão de Shakura e Sunyaev (1973), a qual depende do tempo através da velocidade do som local $\left(\left.C_{s}^{2}(r)\right|_{\theta=\pi / 2}=P / \rho\right)$. Adicionamos esse termo no código PLUTO através da viscosidade cinemática $\left(\nu_{v}=\eta_{v} / \rho\right)$ :

$$
\nu_{v}=\frac{2}{3} \alpha_{v}\left[\left.C_{s}^{2}(r)\right|_{\theta=\pi / 2}+\frac{5}{2}\left(\frac{G M_{*}}{R}-\frac{G M_{*}}{r}\right)\right] \Omega_{K}^{-1},
$$


onde a expressão entre colchetes representa o perfil vertical de temperatura (lembrando que $r=R \operatorname{sen} \theta)$ para um disco politrópico em equilíbrio gravitacional.

Para evitar a expansão do disco de acreção devido ao aquecimento viscoso, adicionamos no código um termo artificial de resfriamento (usado por Zanni e Ferreira, 2009), de forma que:

$$
\Lambda_{\text {cool }}=\operatorname{Tr}\left(\boldsymbol{\tau} \boldsymbol{\tau}^{T}\right) / 2 \eta_{v}
$$

Esse termo, que não reflete o real mecanismo radiativo de resfriamento, passa a ser efetivo somente quando a entropia do disco torna-se $25 \%$ maior do que o seu valor inicial (Zanni e Ferreira, 2009) e, como consequência, torna o disco quase adiabático.

\subsection{Condições de contorno (ou de fronteira)}

As condições de contorno foram estabelecidas de diferentes formas para as quatro fronteiras. Para a fronteira limitada pelo plano médio do disco $(\theta=\pi / 2)$ uma condição de simetria ao longo da região equatorial do sistema (a qual chamaremos de eqüissimétrica) foi utilizada, onde os valores das variáveis dentro do domínio computacional, e imediatamente acima da fronteira, são copiadas para as células fantasmas ${ }^{2}$, com exceção da componente normal da velocidade $\left(v_{\theta}\right)$ e das componentes tangenciais do campo magnético $\left(B_{R, \phi}\right)$, que são copiadas com o sinal invertido, logo:

$$
q \rightarrow q \quad,\left\{\begin{array}{l}
v_{\theta}=-v_{\theta} \\
B_{\theta}=B_{\theta}
\end{array}, \begin{cases}v_{R}=v_{R} & , v_{\phi}=v_{\phi} \\
B_{R}=-B_{R} & , B_{\phi}=-B_{\phi}\end{cases}\right.
$$

onde $q$ corresponde às variáveis escalares.

Já na fronteira limitada pelo eixo de rotação do sistema $(\theta=0)$ foi fixada uma condição axissimétrica, similar à eqüissimétrica, onde os valores das variáveis dentro do domínio computacional também são copiados para as células fantasmas. Porém, nesse caso, são as componentes normal e toroidal, tanto da velocidade quanto do campo magnético $\left(v_{\theta, \phi} \mathrm{e}\right.$

\footnotetext{
${ }^{2}$ A células fantasmas formam uma região adicional da grade computacional que não faz parte da solução numérica das simulações. Elas são usadas justamente para definir as condições de contorno, que somadas às condições iniciais, fornecem a solução espacial e temporal do conjunto de equações MHD.
} 


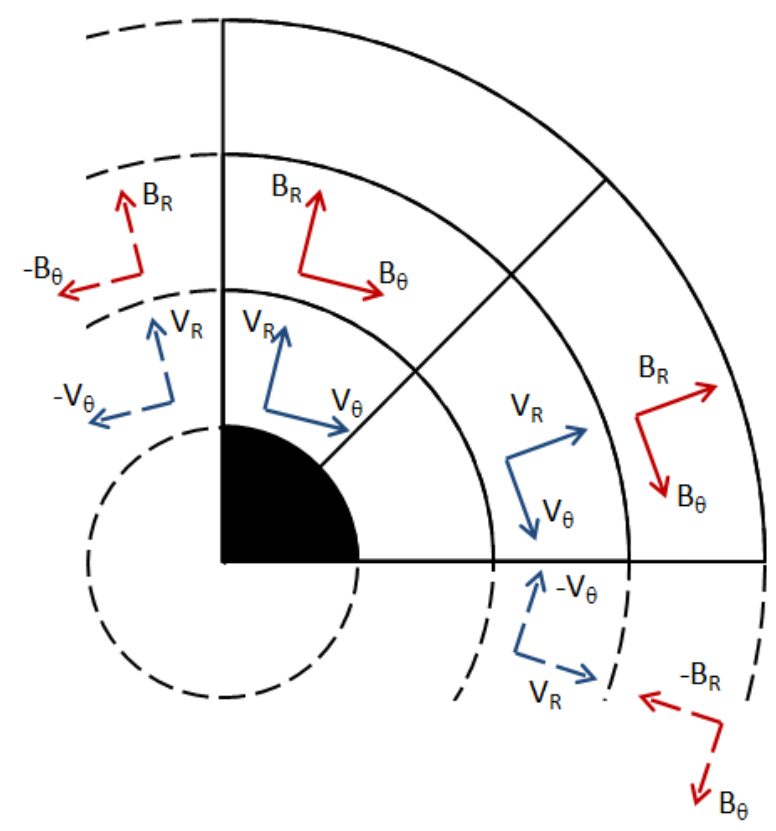

Figura 3.2: Desenho esquemático para as condições de fronteira eqüissímetrica e axissimétrica. As setas azuis e vermelhas correspondem, respectivamente, às componentes poloidais da velocidade e do campo magnético. As linhas contínuas representam os valores dentro do domínio computacional e as tracejadas correspondem aos valores nas células fantasmas.

$\left.B_{\theta, \phi}\right)$, que são invertidas (ver figura 3.2), ou seja:

$$
q \rightarrow q \quad,\left\{\begin{array}{l}
v_{R}=v_{R} \\
B_{R}=B_{R}
\end{array} \quad, \begin{cases}v_{\theta}=-v_{\theta} & , v_{\phi}=-v_{\phi} \\
B_{\theta}=-B_{\theta} & , \quad B_{\phi}=-B_{\phi}\end{cases}\right.
$$

Na região mais externa do domínio computacional usamos uma condição de descontinuidade tal que os gradientes de todas as variáveis hidrodinâmicas são nulos através da fronteira, ou seja:

$$
\frac{\partial \rho}{\partial R}=0, \frac{\partial P}{\partial R}=0, \frac{\partial \boldsymbol{v}}{\partial R}=0
$$

Para conservar a divergência nula, impomos que somente as componentes do campo magnético $B_{\theta}$ e $B_{\phi}$ tenham os seus gradientes nulos separadamente. Por sua vez, a componente $B_{R}$ é automaticamente obtida a partir de $\boldsymbol{\nabla} \cdot \boldsymbol{B}=0$.

Finalmente, para a fronteira interna (correspondente à fonte central), fixamos os valores de campo magnético inicial da mesma (componentes poloidais de dipolo $B_{R}$ e $B_{\theta}$ ), de maneira a manter a sua superfície sub-Alfvénica e, consequentemente, uma região onde a estrutura magnética será pouco afetada. Já a componente toroidal do campo foi mantida 
nula para evitar que o torque gerado pela rotação estelar influenciasse a estrutura da região interna do disco. A componente radial da velocidade $\left(v_{R}\right)$ foi obtida através de uma relação axissimétrica de conservação de massa (veja Zanni e Ferreira, 2009; Ustyugova et al., 1999), ou seja:

$$
\boldsymbol{v}_{p}=\frac{k}{4 \pi \rho} \boldsymbol{B}_{p}
$$

onde $\mathrm{k}$ é constante ao longo das linhas de campo. Uma condição adicional foi aplicada à fronteira interna, onde $\boldsymbol{v}_{p}=0$ caso o material entre no domínio computacional. As condições de contorno para as componentes $v_{\theta}$ e $v_{\phi}$ foram obtidas tratando a fronteira interna como uma superfície em rotação com velocidade angular $\Omega_{*}$, de forma que, no referencial em rotação com a fonte, o campo elétrico sobre a sua superfície seja nulo. Portanto:

$$
E_{\Omega=\Omega_{*}}=\boldsymbol{B} \times(\boldsymbol{v}-\boldsymbol{\Omega} \times \boldsymbol{R})=0 .
$$

Da equação (3.20) obtemos que:

$$
v_{\phi}=r \Omega_{*}+v_{R} \frac{B_{\phi}}{B_{R}}
$$

onde $v_{R} / B_{R}=v_{\theta} / B_{\theta}$, ou seja, a equação (3.20) impõe que a velocidade poloidal na fronteira seja paralela ao campo magnético poloidal.

Por fim, os valores de pressão e densidade foram obtidos admitindo-se que os seus gradientes são nulos através da fronteira interna. Definimos, também, um limiar de densidade e pressão para essa região, de maneira que os valores dessas variáveis não possam ser menores que cinco por cento dos seus perfis iniciais.

\subsection{Unidades de referência e dimensionalização das unidades}

Com a finalidade de aperfeiçoar os cálculos, evitando o surgimento de valores extremamente grandes ou pequenos $\left(\gtrsim 10^{12}\right.$ ou $\lesssim 10^{-9}$ em unidades físicas quaisquer; valores obtidos do manual do usuário do código PLUTO), realizamos as simulações a partir da normalização das variáveis em função de três unidades fundamentais: a de distância $\left(L_{0}\right)$, a de velocidade $\left(v_{0}\right)$ e a de densidade $\left(\rho_{0}\right)$. Assim, temos:

$$
L=\frac{L_{c g s}}{L_{0}}, \quad v=\frac{v_{c g s}}{v_{0}} \text { e } \rho=\frac{\rho_{c g s}}{\rho_{0}},
$$


onde $L, v$ e $\rho$ são os valores das variáveis em unidades normalizadas (ou do código); e $L_{c g s}$, $v_{c g s}$ e $\rho_{c g s}$ são os valores das variáveis em unidades físicas no sistema cgs.

A partir do sistema de normalização acima, as demais variáveis, como o tempo, a pressão e o campo magnético são definidas, respectivamente, como:

$$
t=\frac{t_{c g s}}{L_{0} / v_{0}} \quad, \quad p=\frac{p_{c g s}}{\rho_{0} v_{0}^{2}} \quad \text { e } B=\frac{B_{\text {cgs }}}{\sqrt{4 \pi \rho_{0} v_{0}^{2}}},
$$

onde $t, p$ e $B$ são os valores das variáveis em unidades do código.

Outra importante grandeza física é a taxa de acreção do sistema, que por sua vez é normalizada como:

$$
\dot{M}=\frac{\dot{M}_{c g s}}{\rho_{0} L_{0}^{2} V_{0}} .
$$

Para as nossas simulações, a unidade de referência para a distância foi definida a partir do raio da fonte central $\left(L_{0}=R_{*}\right)$. Já a unidade de referência para a velocidade foi dada pela velocidade Kepleriana calculada em $R=R_{*}$, de forma que $v_{0}=V_{K *}=\sqrt{G M_{*} / R_{*}}$. Por fim, a unidade de referência para a densidade foi definida como a densidade inicial no plano médio do disco, calculada em $R=R_{*}$.

A princípio, essas simulações são equivalentes para sistemas que contém tanto objetos protoestelares, quanto estrelas de nêutrons e buracos negros. Entretanto, conforme observado anteriormente, essas duas últimas fontes necessitam de um modelo mais complexo, já que a primeira encontra-se próxima do limite relativístico e a segunda, além de estar no limite relativístico, por tratar-se de um buraco negro, não possui uma fronteira sólida bem definida, como no caso das protoestrelas. Assim, essas simulações são mais adequadas a OEJs, de forma que escalonamos as variáveis do sistema em função de seus valores típicos:

$$
R_{*}=2 R_{\odot} \quad, \quad M_{*}=0.5 M_{\odot} \text { e } \rho_{d 0}=6 \times 10^{-11} \mathrm{~g} . \mathrm{cm}^{-3}
$$

onde $R_{\odot}=6 \times 10^{10} \mathrm{~cm}$ e $M_{\odot}=2 \times 10^{33} \mathrm{~g}$. Portanto, teremos que (veja também Zanni e Ferreira, 2009):

$$
\begin{aligned}
& V_{K *}=2,18 \times 10^{7}\left(\frac{M_{*}}{0.5 M_{\odot}}\right)^{1 / 2}\left(\frac{R_{*}}{2 R_{\odot}}\right)^{-1 / 2} \mathrm{~cm} / \mathrm{s} \\
& B_{0}=\sqrt{4 \pi \rho_{0} v_{0}^{2}}=599\left(\frac{\rho_{d 0}}{6 \times 10^{-11}}\right)^{1 / 2}\left(\frac{M_{*}}{0.5 M_{\odot}}\right)^{1 / 2}\left(\frac{R_{*}}{2 R_{\odot}}\right)^{-1 / 2} G,
\end{aligned}
$$




$$
\begin{aligned}
& t_{0}=\frac{L_{0}}{v_{0}}=7,4 \times 10^{-2}\left(\frac{M_{*}}{0.5 M_{\odot}}\right)^{-1 / 2}\left(\frac{R_{*}}{2 R_{\odot}}\right)^{3 / 2} \text { dias } e \\
& \dot{M}_{0}=\rho_{0} R_{0}^{2} V_{0}=4 \times 10^{-7}\left(\frac{\rho_{d 0}}{6 \times 10^{-11}}\right)\left(\frac{M_{*}}{0.5 M_{\odot}}\right)^{1 / 2}\left(\frac{R_{*}}{2 R_{\odot}}\right)^{3 / 2} M_{\odot} / \text { ano. }
\end{aligned}
$$

\subsection{Análise e resultados das simulações}

As condições iniciais e de contorno, normalizadas segundo a seção anterior, dependem basicamente de sete parâmetros: $\epsilon, \Omega_{*}, \rho_{c 0}, \alpha_{v}, B_{*}, B_{d}$ e $\xi$. O último parâmetro determina a rotação inicial efetiva do disco de acreção e é calculado como $v_{\phi d}^{\prime}=\xi v_{\phi d}$, onde $v_{\phi d}$ é dado pela equação (3.8); e $\xi$ é um valor entre 0 e 1. Os cinco primeiros parâmetros foram mantidos fixos e são, como vimos, característicos de OEJs, tendo sido baseados no artigo de Zanni e Ferreira (2009). Estes são apresentados na tabela 3.1.

Tabela 3.1 - Parâmetros fixos das simulações.

\begin{tabular}{lc}
\hline \hline Parâmetros & Valores \\
\hline$\epsilon$ & 0,1 \\
$\Omega_{*}$ & 0,1 \\
$\rho_{c 0}$ & 0,01 \\
$\alpha_{v}$ & 1,0 \\
$\mathrm{~B}_{*}$ & 2,5 \\
& \\
\hline
\end{tabular}

Em particular, admitimos um campo magnético equatorial na superfície estelar da ordem de 1,5 kG, que corresponde a aproximadamente 2,5 unidades do código (veja equação 3.27). A velocidade angular da fonte central, por sua vez, foi definida como sendo um décimo da velocidade Kepleriana em $R=R_{*}$. Essa velocidade implica em um período $P_{*}=2 \pi t_{0} / \Omega_{*}$ da ordem de 4,65 dias (veja equação 3.28). A partir daqui, usaremos o período de rotação da fonte central como unidade de referência para o tempo $\left(P_{*} \equiv 1\right.$ rotação estelar). Por fim, podemos interpretar o parâmetro $\epsilon$ como a razão entre a velocidade do som isotérmica $\left(C_{s}\right)$ e a velocidade Kepleriana avaliada no meio plano do disco $\left(V_{K}\right)$, de forma que um valor da ordem de 0,1 implica numa rotação supersônica, o que está em acordo com a teoria dos discos de acreção (veja anexo A). 
As simulações foram divididas em dois grupos de acordo com o campo magnético poloidal do disco $\left(B_{d}\right)$. Para cada uma delas, admitimos dois casos em função do parâmetro

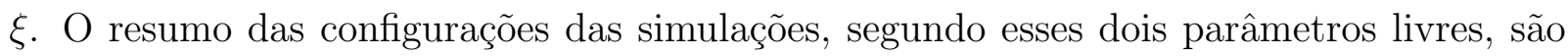
apresentados na tabela 3.2 .

Tabela 3.2 - Parâmetros livres e modelos da simulações.

\begin{tabular}{lcc}
\hline \hline Modelo & $B_{d}$ & $\xi$ \\
\hline I & 0 & 1,0 \\
II & 0 & 0,5 \\
III & 0,002 & 1,0 \\
IV & 0,002 & 0,5 \\
& & \\
\hline
\end{tabular}

Para as nossas simulações, admitimos que o campo magnético poloidal do disco possui um intensidade da ordem de $1 \mathrm{G}$, equivalente a 0,002 unidades do código. Esse campo possui orientação antiparalela ao campo dipolar inicial da fonte central na região equatorial do disco de acreção. Por fim, nos teste em que $B_{d}=0$, estamos realizando simulações somente com o campo puramente dipolar da fonte central (veja figura 3.3).

Nos modelos I e III, a velocidade de rotação inicial é dada pela equação 3.8, ou seja, $\operatorname{com} \xi=1$. Esses modelos correspondem à rotação de um disco inicialmente em estado estacionário cuja acreção se dá pela presença de um processo viscoso. Em particular, as condições iniciais para as simulações correspondentes ao modelo I foram realizadas por diversos autores, nos quais podemos destacar os trabalhos de Zanni e Ferreira (2009) e Romanova et al. (2002), assim como comentado no início deste capítulo. Os perfis de rotação desses modelos, representados na figura 3.4, são comparados ao perfil de um disco puramente Kepleriano sem acreção.

Já para os modelos II e IV, admitimos um perfil de rotação $50 \%$ menor que aquela aplicada aos demais modelos, ou seja, $\operatorname{com} \xi=0,5$ (veja figura 3.4). Com uma rotação menor que a Kepleriana, a barreira centrífuga não será intensa o suficiente e permitirá a ação mais eficaz da força gravitacional no processo de acreção. Essa força, por sua vez, acretará o material do disco a taxas de acreção maiores que as encontradas nos modelos I e III, 

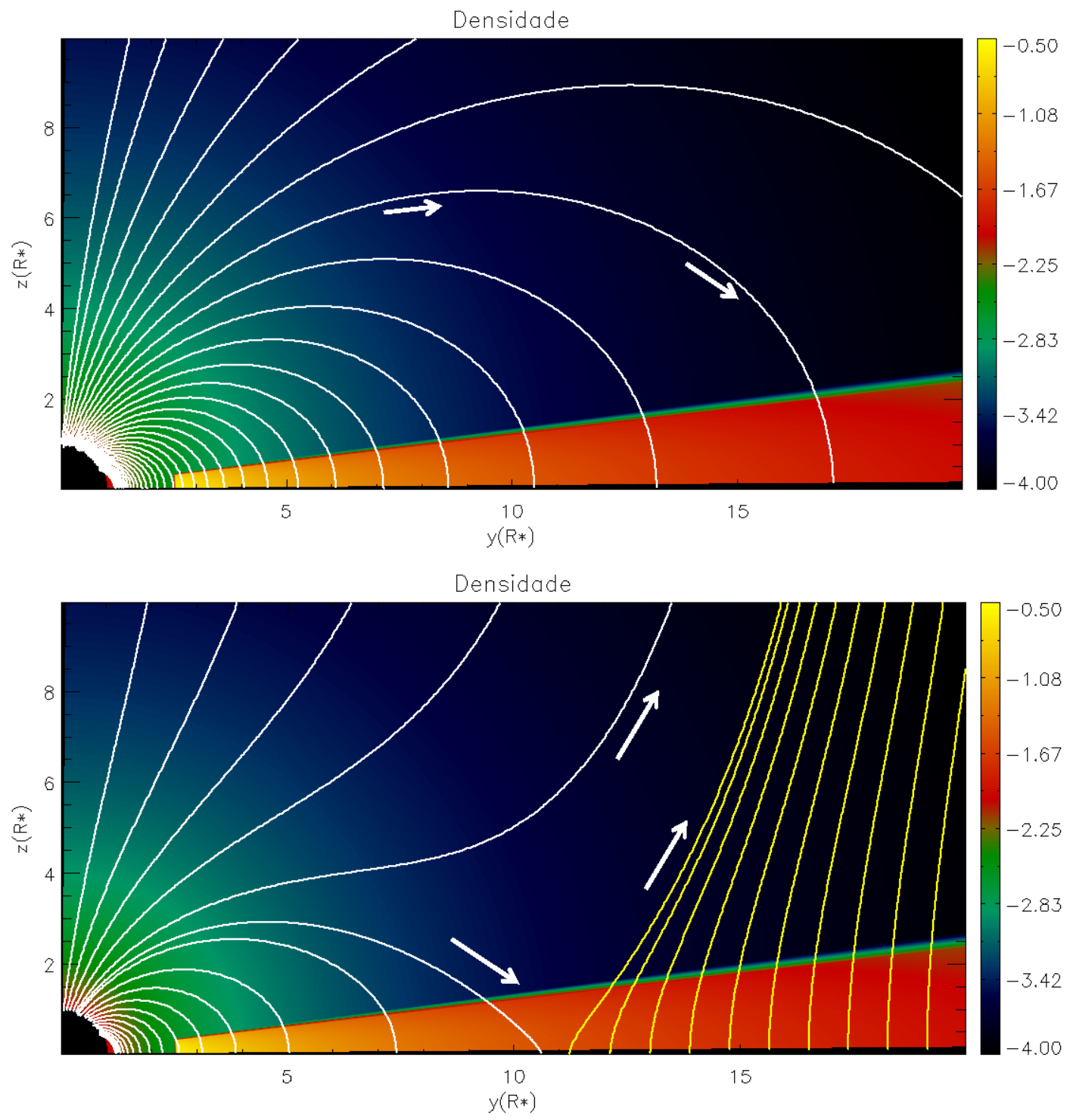

Figura 3.3: Perfil inicial do sistema disco-fonte central. O gráfico superior corresponde à configuração de campo magnético dos modelos I e II, onde é admitido um campo estelar puramente dipolar da ordem de $1,5 \mathrm{kG}\left(B_{*}=2,5\right.$ e $\left.B_{d}=0\right)$. Já o gráfico inferior corresponde à configuração magnética dos modelos III e IV, onde é admitida a presença tanto do campo dipolar da fonte central quanto do campo poloidal do disco de acreção $\left(B_{*}=2,5\right.$ e $\left.B_{d}=0,002\right)$, sendo esse último da ordem de $1 \mathrm{G}$. As linhas brancas correspondem ao campo conectado à fonte central, enquanto que as linhas amarelas representam o campo magnético poloidal do disco. As linhas foram interpoladas a partir do campo magnético de forma arbitrária, somente para demonstrar o seu comportamento em um determinado instante. As cores de fundo correspondem ao logaritmo da densidade em unidades do código; e as setas brancas correspondem à orientação dos campos. 


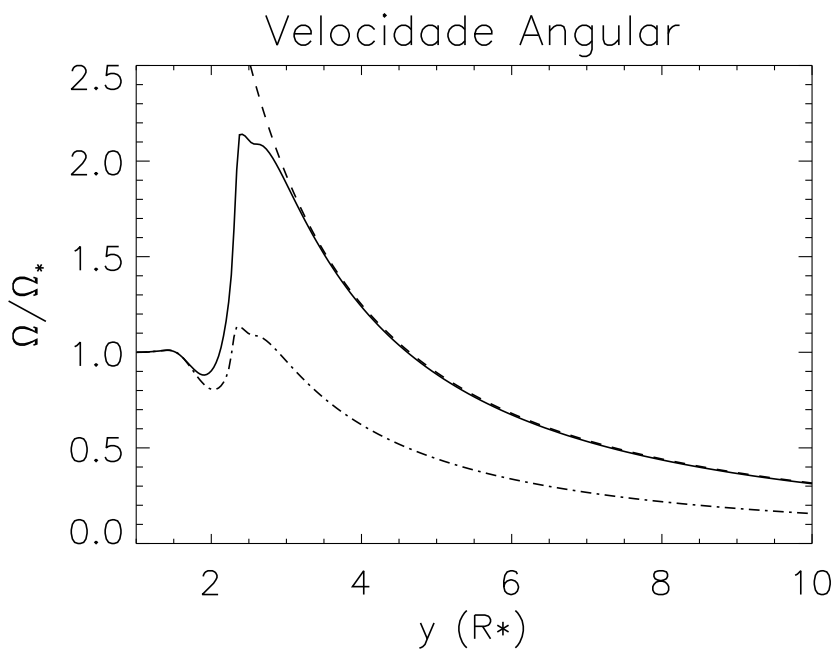

Figura 3.4: Perfis de rotação no plano equatorial do sistema, obtidos em $t=0,2 P_{*}$, e normalizados em função da velocidade angular da fonte central $\left(\Omega_{*}=0,1\right)$. A linha tracejada corresponde a um perfil de rotação puramente Kepleriano, enquanto que a linha contínua corresponde ao perfil adotado para os modelos I e III $(\xi=1)$. A linha tracejada e pontilhada corresponde aos modelos II e IV, onde admitimos um perfil $50 \%$ menor que aquele aplicado ao primeiro grupo $(\xi=0,5)$. Em ambas as simulações, o disco é truncado em torno de $2,5 R_{*}$

permitindo a formação rápida de uma configuração magnética propícia à reconexão. Vale ressaltar que esse não é o mecanismo físico (discutido no capítulo 2) que leva ao aumento da acreção do disco, mas é um método eficaz para estudar um sistema cuja acreção das linhas de campo magnético, tanto do disco quanto da coroa, ocorra de forma mais intensa e mais rápida, a fim de induzirmos mais rapidamente a formação de eventos de reconexão magnética. Na realidade, como vimos no capítulo 2, a elevação da acreção do disco pode ocorrer devido à formação de um vento magneto-centrífugo, que extrai momento angular do disco; ou através do aumento da viscosidade (via instabilidade magneto-rotacional, por exemplo) a qual pode acarretar o transporte eficiente de momento angular das partes mais internas para as partes mais externas do disco, conforme intensamente discutido na literatura (e.g. Balbus e Hawley, 1998).

\subsubsection{Simulações com campo magnético puramente dipolar (modelos I e II)}

A evolução do modelo I ( $\xi=1)$ é ilustrada na figura 3.5 e corresponde a aproximadamente 5, $6 P_{*}$ (veja seção anterior), equivalente a aproximadamente vinte dias em unidades físicas (veja equação 3.28). A evolução do modelo II $(\xi=0,5)$, por sua vez, é ilustrada na 
figura 3.6 e corresponde a aproximadamente $1,3 P_{*}$, ou seis dias em unidades físicas. A configuração inicial desses modelos $(e m t=0)$ com a presença do campo dipolar da fonte central, e sem o campo poloidal do disco, é esquematizada no gráfico superior da figura 3.3.

A partir de uma análise qualitativa dos gráficos das figuras 3.5 e 3.6, é possível verificar claramente uma mudança da configuração da região interna, tanto do disco quanto da magnetosfera, por causa da acreção, com a formação de um funil de acreção que conecta o gás do disco à fonte central. Em ambos os modelos, observa-se a formação de um processo de acreção das linhas magnéticas que vem das regiões externas para as regiões mais internas do disco de acreção. O modelo I (figura 3.5) apresenta, paralelamente ao processo de acreção do fluxo magnético, uma expansão das linhas de campo que ocorre, inicialmente, nas regiões coronais mais internas do sistema. Esse processo foi também observado por Zanni e Ferreira (2009) e Bessolaz et al. (2008), e descrito com maiores detalhes por Uzdensky et al. (2002). Segundo esses autores, a torção do campo magnético devido à rotação diferencial do sistema disco-fonte central leva à expansão da estrutura magnetosférica na coroa com o objetivo de aliviar a tensão do campo magnético toroidal. Em nossas simulações, a expansão inicial do campo magnético força as linhas mais externas a expandirem-se também, até alcançarem a fronteira externa. Examinado os dois gráficos inferiores da figura 3.5 (para o modelo I), observa-se que o esticamento das linhas dipolares combinado à compressão causada pela acreção leva à formação de um lençol de corrente que separa o fluxo magnetosférico em duas partes: um associado à fonte e outro ao disco. Esse efeito, em particular, foi obtido por Zanni e Ferreira (2009) e Bessolaz et al. (2008), porém, o encontro máximo das linhas no processo de reconexão ocorrerá, neste caso, fora do domínio computacional.

Em contrapartida, no modelo II, a expansão das linhas de campo magnético somadas a um rápido processo de acreção das mesmas (que ocorre em um período da ordem de 1 rotação estelar), permite-nos visualizar o evento de reconexão entre as linhas de campo magnético que conectam a fonte central à região mais interna do disco de acreção ainda dentro do domínio computacional, entre $0,9 P_{*}$ e $1,3 P_{*}$. O evento de reconexão, por sua vez, é acompanhado por uma forte ejeção de matéria que estica as linhas magnéticas "fechadas" de forma mais eficiente e rápida do que aquelas apresentadas no modelo I. O 

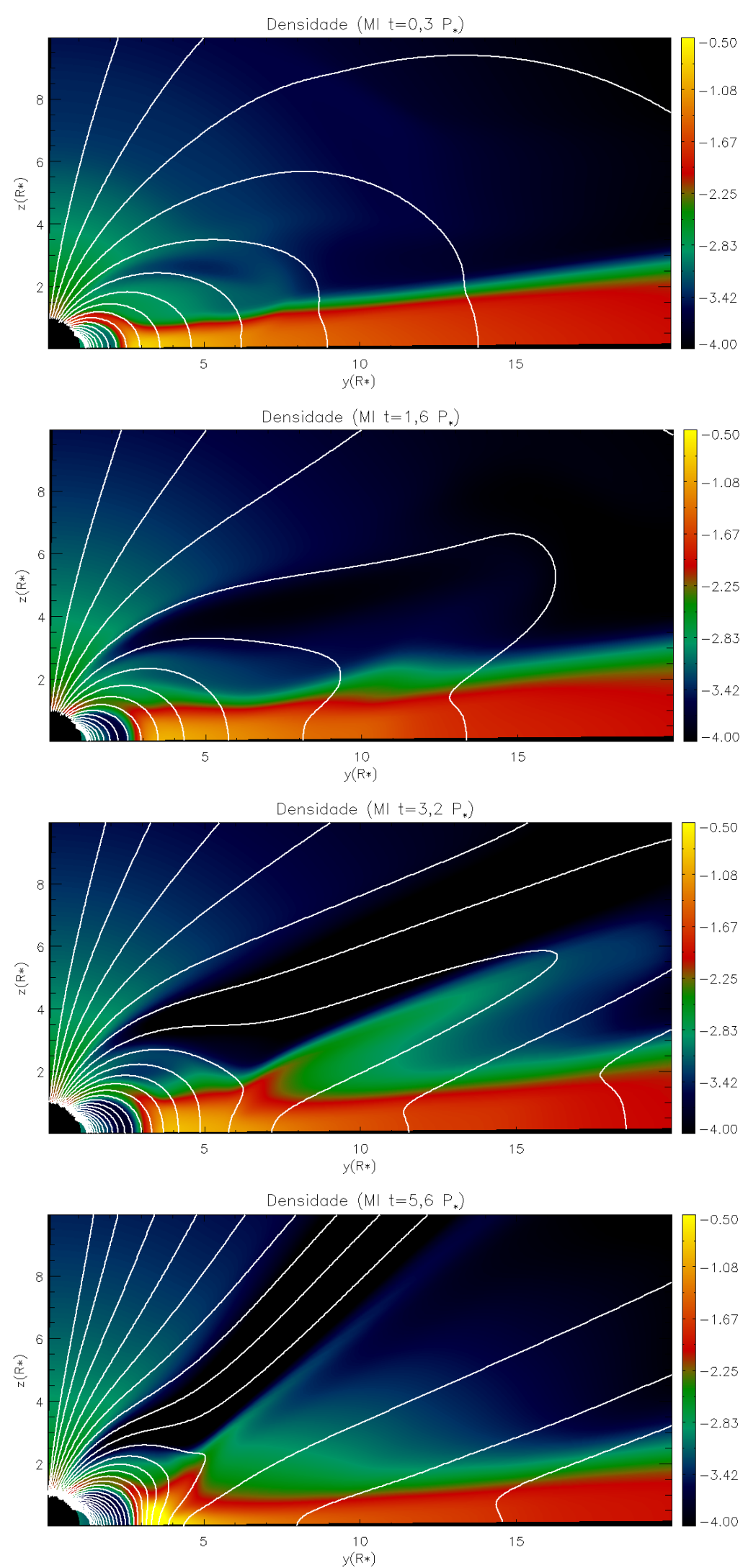

Figura 3.5: Perfil das simulações do modelo I $\left(B_{d}=0\right.$ e $\left.\xi=1\right)$ em $t=0,3 P_{*}, t=1,6 P_{*}, t=3,2 P_{*}$ e $t=5,6 P_{*}\left(P_{*}=2 \pi t_{0} / \Omega_{*}\right)$. As linhas brancas correspondem ao campo magnético da fonte central e foram interpoladas a partir do campo magnético de forma arbitrária. As cores de fundo correspondem ao logaritmo da densidade em unidades do código. 

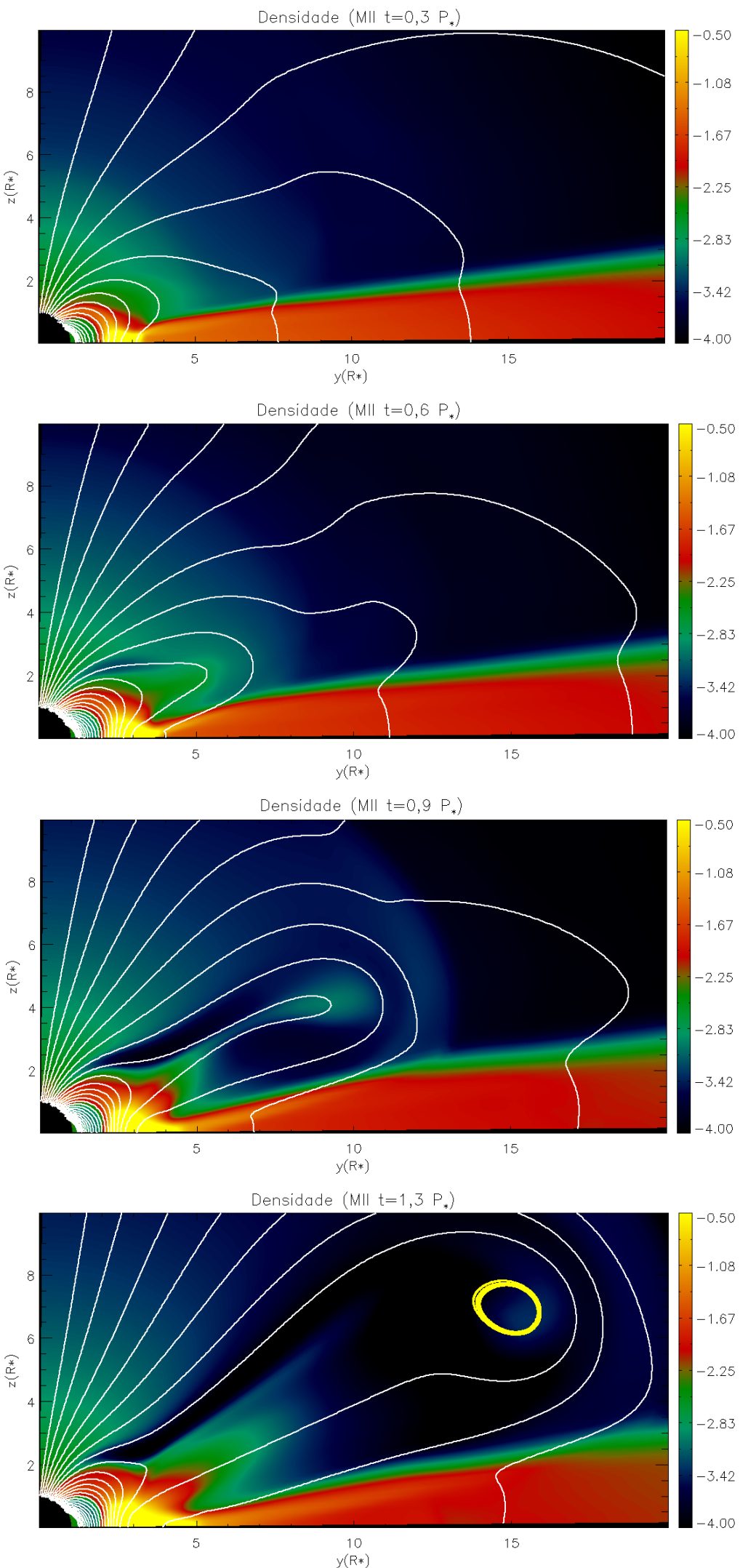

Figura 3.6: Perfil das simulações do modelo II $\left(B_{d}=0\right.$ e $\left.\xi=0,5\right)$ em $t=0,3 P_{*}, t=0,6 P_{*}, t=0,9$ $P_{*}$ e $t=1,3 P_{*}$. Aqui, as linhas amarelas correspondem ao campo magnético reconectado e que não está mais ligado a fonte central. 
processo ocorre de tal forma que ao longo do lençol de corrente (onde se dá a reconexão) formam-se ilhas magnéticas (típicas em reconexão bidimensional) dentro das quais o campo magnético é nulo. No último gráfico da figura 3.6, observamos uma dessas ilhas dentro dos contornos amarelos.

A figura 3.7 mostra, para o modelo II, o comportamento do campo de velocidades em $t=0,3 P_{*}$ e $t=1,3 P_{*}$, onde a ejeção de matéria do disco pode ser observada com mais clareza. Paralelamente, a mesma figura mostra a distribuição da intensidade do campo magnético do sistema em escala logarítmica, onde é possível discernir a região de reconexão no último gráfico, a partir de um forte gradiente de $\boldsymbol{B}$, que se anula no lençol de corrente. Além disso, no mesmo gráfico, é possível observar várias diminutas ilhas magnéticas ao longo do lençol e uma ilha maior na sua extremidade (sendo essa última também observada na figura 3.6).

Como descrito na seção anterior, a velocidade de rotação do modelo II foi reduzida para $50 \%$ da rotação inicial do modelo I. Essa diferença implica em um considerável aumento da taxa de acreção do sistema. A figura 3.8 mostra o comportamento da acreção sobre a superfície da fonte central (linha contínua) e do disco de acreção (linha tracejada) em função do tempo, para ambos os modelos. A taxa de acreção foi calculada a partir da equação (3.1), admitindo-se uma geometria esférica e simetria ao longo do eixo de rotação do sistema, de maneira que:

$$
\dot{M}=-4 \pi R^{2} \int_{S} \rho v_{R} \operatorname{sen} \theta d \theta
$$

A taxa de acreção sobre a superfície estelar foi obtida tomando-se $R=R_{*}$ e $0 \leq \theta \leq \pi / 2$; já a taxa de acreção do disco foi obtida tomando-se $R=4 R_{*}$ e $\theta^{\prime} \leq \theta \leq \pi / 2$, onde $\theta^{\prime}$ é o ângulo correspondente à superfície do disco de acreção no raio $R$ (lembrando que $\theta=\pi / 2$ corresponde à região equatorial do disco). A escolha de um raio $R=4 R_{*}$, por sua vez, foi arbitrária e corresponde a um valor menor que o raio de corrotação inicial do modelo I $\left(R_{\text {corr }} \cong 4,6 R_{*}\right)$ e maior que o raio de corrotação inicial do modelo II $\left(R_{\text {corr }} \cong 2,6 R_{*}\right)$.

No caso do modelo I, as taxas de acreção sobre a fonte central e do disco variam entre valores de 0,01 e 0,1 unidades do código, que convertidas em unidades físicas correspondem à aproximadamente $10^{-9}-10^{-8} M_{\odot} /$ ano (veja equação 3.29 ). Esses são valores típicos encontrados para estrelas T Tauri de classe II e correspondem a taxas bem menores do que as previstas por de Gouveia Dal Pino et al. (2010a,b), para a formação de eventos de 

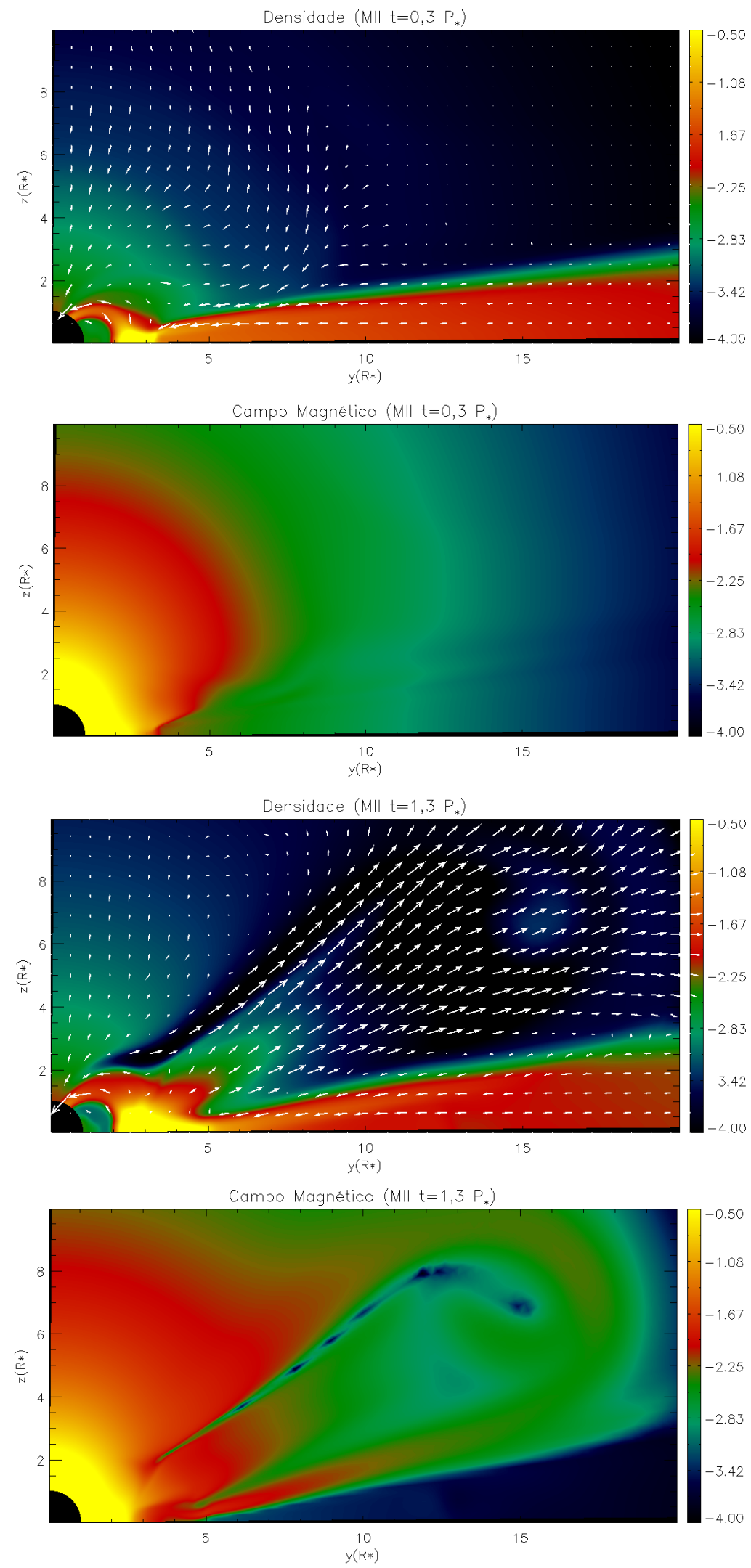

Figura 3.7: Perfil do modelo II em $t=0,3 P_{*}$ e $t=1,3 P_{*}$. Os gráficos representam o perfil de densidade sobreposta por vetores que correspondem à orientação do campo de velocidades; e a distribuição da intensidade do campo magnético do sistema (ambas em escala logarítmica). No último gráfico é possível discernir a região de reconexão. 

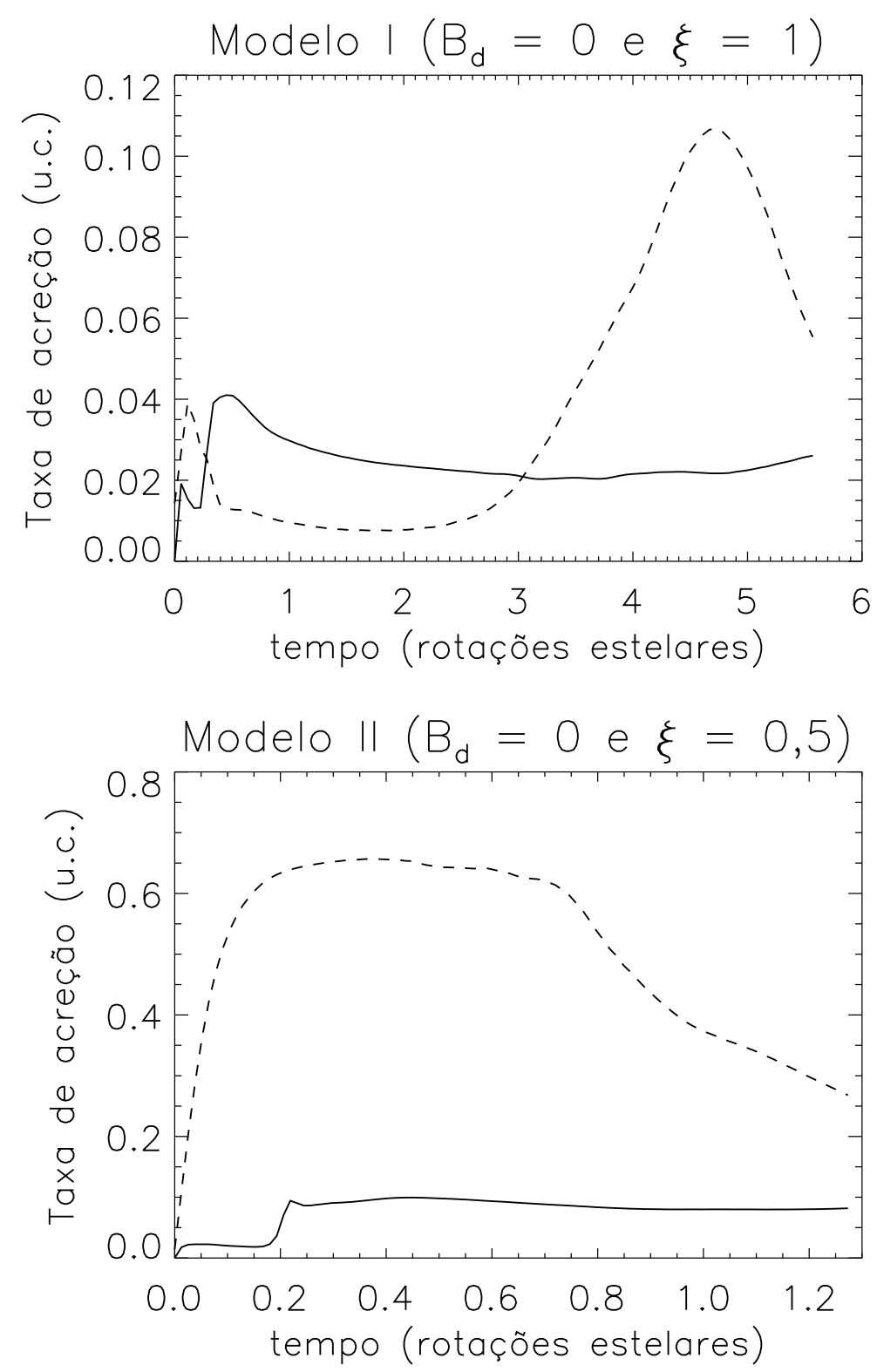

Figura 3.8: Evolução temporal da taxa de acreção medida na superfície da fonte central em $R=R_{*}$ (linha contínua) e no disco de acreção em um raio arbitrário $R=4 R_{*}$ (linha tracejada). O gráfico superior corresponde às taxas de acreção do modelo I e o gráfico inferior às taxas do modelo II. 
reconexão violenta (por curtos períodos de tempo) nas regiões mais internas dos discos de acreção dos OEJs, os quais são necessários para explicar os flares observados nas fontes COUP. Conforme descrito no capítulo 2, eventos de reconexão violenta somente ocorrerão quando as taxas de acreção tornarem-se da ordem de 100 a 1000 vezes maiores que os típicos inferidos das observações (veja Piovezan, 2009, de Gouveia Dal Pino et al., 2010a,b).

No caso do modelo II, é possível verificar que o sistema encontra-se submetido a taxas mais elevadas de acreção, em média dez vezes maiores que as encontradas no modelo I. Embora essas taxas sejam ainda insuficientes para produzir os flares, esses modelos dão uma ideia aproximada da evolução de tais eventos quase em "câmera lenta", o que nos permite segui-los passo a passo. Esses modelos mimetizam algumas características do cenário desenvolvido por de Gouveia Dal Pino e Lazarian (2005) como, por exemplo, a mudança no estado de acreção do sistema instantes antes da reconexão violenta.

No modelo I, observamos logo no início das simulações um pequeno aumento na taxa de acreção do disco (em $4 R_{*}$ ) causado pelo rearranjo inicial das forças nas regiões internas, entre os gradientes da pressão magnética da magnetosfera $\left(B^{2} / 8 \pi\right)$ e a pressão dinâmica do gás acretante $\left(\rho v_{R}^{2}\right)$. Este aumento é seguido de um aumento equivalente na acreção sobre a fonte central quando o funil de acreção é estabelecido em $t \simeq 0,3 P_{*}$ (veja também, o primeiro gráfico da figura 3.5). Após a formação do funil, é estabelecida uma acreção "quase" estacionária, acompanhada por uma compressão contínua das linhas magnéticas no disco e da expansão das mesmas na coroa, como explicado anteriormente. O pico que observamos na taxa de acreção do disco (por volta de $t \simeq 4,7 P_{*}$ ), com um valor 10 vezes maior que o da acreção estacionária, seguido de uma forte queda, está diretamente correlacionado a formação de um lençol de corrente. Em outras palavras, o aumento da taxa de acreção do disco e a maior compressão das linhas de campo leva à formação do lençol de corrente e, consequentemente, à perda de massa para a coroa e para o funil, fazendo diminuir a taxa de acreção logo em seguida.

Já no modelo II, o qual possui uma taxa de acreção em média dez vezes maior do que o modelo I, todo o processo desenvolve-se mais rapidamente. Do mesmo modo que no modelo I, o aumento inicial na acreção estelar (por volta de 0,2 $P_{*}$ ) dá-se com a formação do funil de acreção, que é bem maior e mais denso nesse caso. Depois disso, a acreção sobre a estrela (devido sobretudo ao funil de acreção) torna-se "quase" estacionária e é 
pouco influenciada pelo evento de reconexão coronal. Já a acreção no disco, em $4 R_{*}$, ao contrário do que vimos no modelo I, alcança o valor máximo logo no início da simulação. Sua atuação contínua e rápida, no sentido de comprimir as linhas na região do disco, na base do funil de acreção (por volta de $t=0,8 P_{*}$ ), ao mesmo tempo em que estas se expandem e esticam-se na coroa, causam a reconexão magnética por volta de $t=0,9 P_{*}$. Essa reconexão causa a perda de massa para a coroa e acarreta a diminuição da taxa de acreção, similar ao que vimos no modelo I (só que agora, a reconexão ocorre dentro do domínio computacional, por volta de $\left.t=0,9 P_{*}\right)$.

A queda súbita da acreção pode ser vista claramente nos gráficos com o campo de velocidades da figura 3.7. Nesses gráficos é possível observar o acúmulo de material do disco, na base do funil de acreção, e a mudança no campo de velocidades em $4 R_{*}$. No período compreendido entre $0,3 P_{*}$ e $1,3 P_{*}$, os vetores de velocidade nessa região diminuem, tornando-se menores que os vetores de velocidade do resto do disco. Em ambos os modelos, essa queda na taxa de acreção do disco pode representar episódios em que, num primeiro instante, há a acumulação do material próximo ao raio de truncamento do disco. Em seguida, o material acumulado é "suficiente"para novamente produzir um funil de acreção. Episódios como esses são observados por Romanova et al. (2011), em simulações cujos tempos de evolução são muito superiores aos realizados nessa dissertação.

As figuras 3.9 e 3.10 esquematizam a estrutura do funil, para os modelo I e II, em $t=0,9$ $P_{*}$. A figura 3.9 mostra a projeção $F=\boldsymbol{B}_{p} \cdot \boldsymbol{F} /\left|\boldsymbol{B}_{p}\right|$ das forças gravitacional e centrífuga, e do gradiente de pressão térmica ao longo da linha de campo magnético localizada no funil de acreção. A partir da orientação do campo magnético da fonte central (veja figura 3.3), é possível verificar que valores positivos correspondem à forças projetadas que empurram o material, ao longo da linha de campo, da estrela para o disco de acreção.

No gráfico à direita da figura 3.9, para o modelo II, é possível observar que na base do funil de acreção, o gradiente de pressão térmica (formado pela acumulação do material acretado e barrado pela pressão magnética no raio de truncamento do disco) levanta e empurra o material contra a ação das forças gravitacional e centrífuga, acelerando-o na direção da estrela. O gradiente de pressão térmica continuará dominante nas regiões logo acima do disco, porém, em uma determinada altura ( $D \sim 1,5$, veja figura 3.9), a força gravitacional passa a ser dominante e atuará sobre o material no sentido de empurrá-lo na 
direção da estrela (a força gravitacional projetada sobre a linha de campo é inicialmente positiva próxima ao disco, e passa a ser negativa próxima à estrela). Na superfície da fonte central, o gradiente de pressão térmica e a força centrífuga irão atuar contra a acreção do material, porém, não serão intensos o suficiente. Assim, a gravidade fará com que o material caia sobre a fonte central a uma velocidade de queda livre $\left(v_{p} \sim V_{K *}\right)$. Esse efeito pode ser observado no gráfico à direita da figura 3.10, que mostra o comportamento da velocidade poloidal $\left(v_{p}\right)$ ao longo da mesma linha de campo magnético, localizada no funil de acreção. A velocidade poloidal na linha de campo ancorada no disco $(D \sim 2,5)$ é quase nula e evolui para valores da ordem de 0,9 unidades do código na superfície da fonte central $(D \sim 0)$. Esse valor convertido em unidades físicas corresponde a aproximadamente 196 $\mathrm{km} \cdot \mathrm{s}^{-1}$ (veja equação 3.26 ).

Já para o caso do modelo I (gráfico à esquerda da figura 3.9), é possível verificar que o gradiente de pressão projetado ao longo da linha de campo, localizado no funil de acreção, não é alto o suficiente para levantar e empurrar o material do disco na direção da estrela, contra a ação da força centrífuga. De fato, ao observarmos os gráficos da figura 3.5, entre $0,3 P_{*}$ e $1,3 P_{*}$, verificamos que o funil de acreção torna-se menos intenso, de forma que o material do disco passa a ser acumulado na região mais interna do mesmo. Em contrapartida, na superfície da estrela, a força gravitacional ainda é dominante e atua da mesma forma que a descrita para o modelo II.

O comportamento da densidade $(\rho)$, da velocidade angular $(\Omega)$ e da temperatura $\left(T_{k}\right)$, ao longo da linha de campo no funil de acreção, também são apresentados na figura 3.10. Uma análise do gráfico à direita dessa figura, para o modelo II, mostra que a densidade mantém-se entre valores de 0,25, no disco, e 0,05 unidades do código, na superfície estelar ao longo do funil de acreção; em contraste com a densidade inicial da coroa da ordem de 0,01 unidades do código, caracterizando o acúmulo de gás na base do funil que vimos na figura 3.6 (veja também tabela 3.1). Já o perfil da velocidade angular, mostra que a linha de campo no funil de acreção mantém-se em corrotação, da fonte central ao disco de acreção. Por fim, o perfil de temperatura em Kelvin, mostra um aquecimento no funil de acreção que varia entre $10^{5}-10^{6} \mathrm{~K}$.

Para o modelo I, gráfico à esquerda da figura 3.9, o comportamento desses parâmetros são bem similares ao do modelo II em todos os aspectos, apesar de a temperatura do 

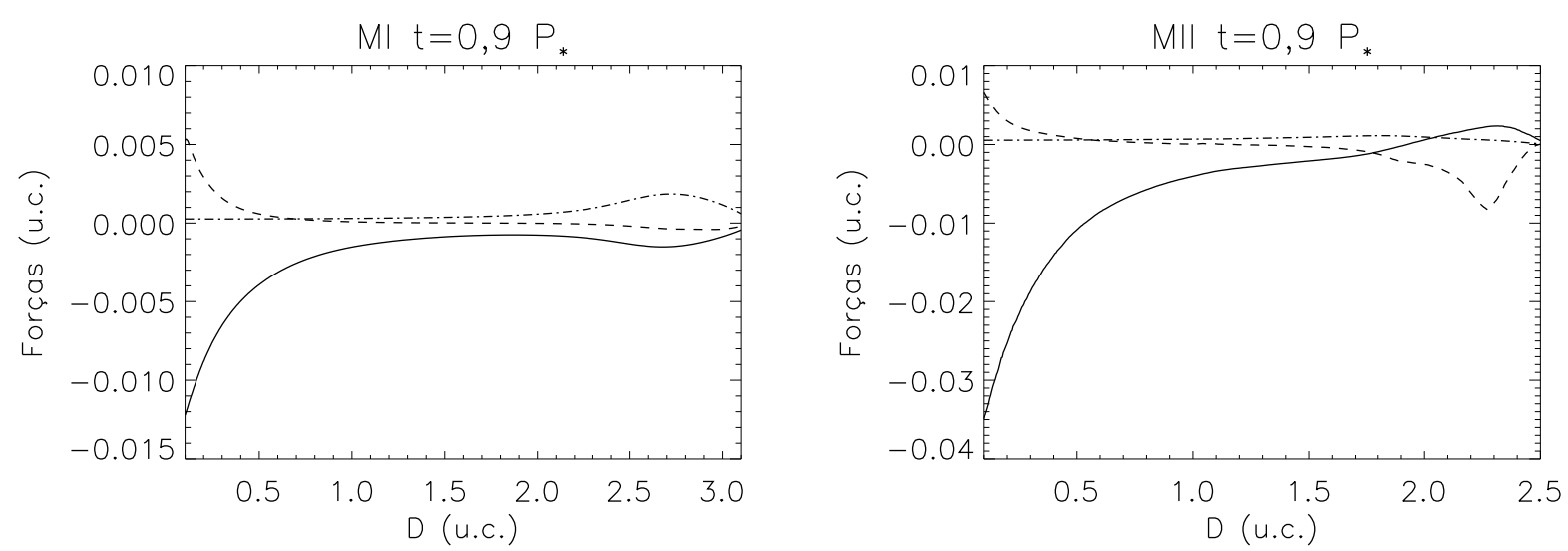

Figura 3.9: Forças projetadas, em $t=0,9 P_{*}$, ao longo da linha de campo localizada no funil de acreção. A figura à esquerda corresponde ao modelo I e à direita ao modelo II. O gradiente de pressão é representado pela linha tracejada, a força gravitacional pela linha contínua e a força centrífuga pela linha pontilhada e tracejada. Uma força positiva empurra o material ao longo da linha de campo, da estrela para o disco. $D$ corresponde ao comprimento da linha que vai da fonte central $(D=0)$ ao plano médio do disco.
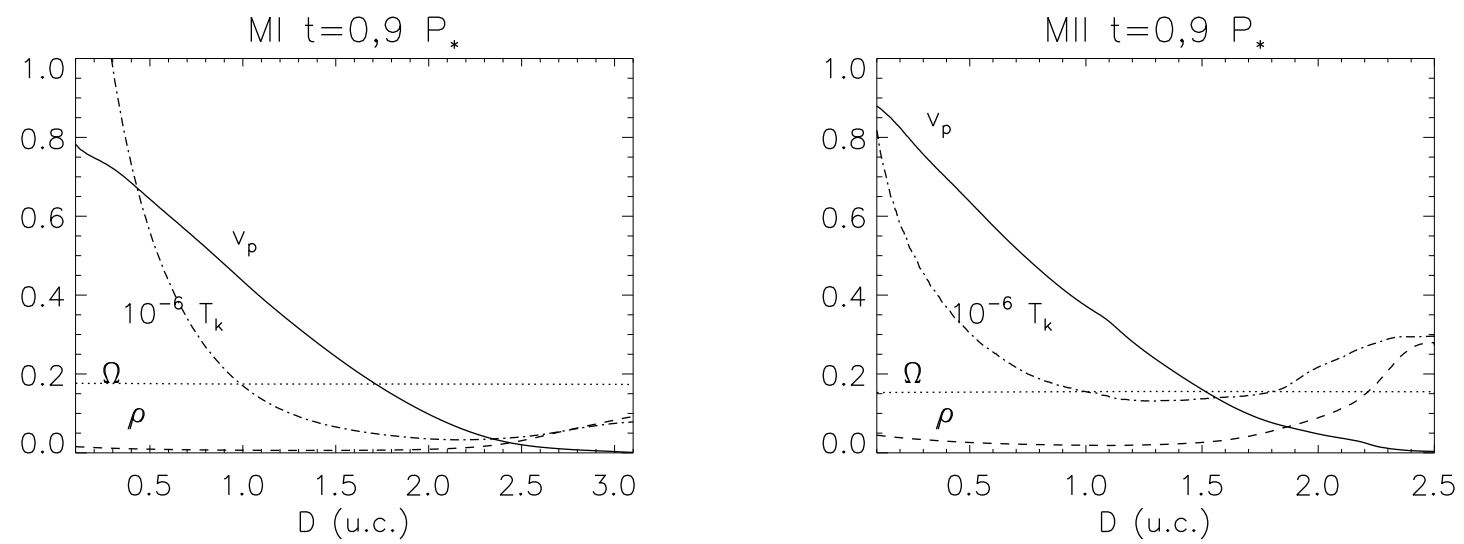

Figura 3.10: Comportamento da velocidade poloidal $\left(v_{p}\right)$, da densidade $(\rho)$, da velocidade angular $(\Omega)$ e da temperatura (em Kelvin), em $t=0,9 P_{*}$, ao longo da linha de campo localizada no funil de acreção. A figura à esquerda corresponde ao modelo I e à direita ao modelo II. $D$ corresponde ao comprimento da linha que vai da fonte central $(D=0)$ ao plano médio do disco. 
funil na superfície da estrela ser um pouco mais elevada $\left(2 \times 10^{6} \mathrm{~K}\right)$. Esses valores são importantes para comparação com as observações de magnetosferas de OEJs (veja adiante na discussão).

\subsubsection{Simulações com campo magnético dipolar da fonte central e campo poloidal do disco (modelos III e IV)}

A figura 3.11 corresponde à evolução do modelo III durante um período da ordem de 5, $6 P_{*}$, enquanto que a evolução do modelo IV é apresentada na figura 3.12 e corresponde a um período da ordem de $1,3 P_{*}$. Os perfis iniciais de ambos os modelos (em $\left.t=0\right)$ são ilustrados no gráfico inferior da figura 3.3; onde a configuração inicial do campo poloidal do disco é antiparalela ao campo dipolar inicial da fonte central na região equatorial do sistema.

Em primeiro lugar, notamos que a configuração inicial (por construção nesses modelos) já possui uma zona de descontinuidade entre os dois fluxos magnéticos, isto é, uma zona onde os campos aniquilam-se formando um lençol de corrente. É graças a essa reconexão inicial que as linhas de dipolo da estrela erguem-se "abertas" na direção poloidal e próximo ao fluxo magnético do disco, com a mesma orientação que estas últimas (veja em mais detalhes a orientação desses campos no gráfico inferior da figura 3.3). Nesse sentido, a configuração inicial dos modelos III e IV é, até certo ponto, similar à configuração final dos modelos I e II (veja figuras 3.5 e 3.6).

Embora a evolução numérica do modelo III corresponda a somente seis rotações da fonte central, esse período já é suficiente para a análise da formação de novos eventos de reconexão magnética. Durante esse intervalo de tempo, verificamos a deformação e acreção das linhas de campo na direção radial do sistema. Além disso, um evento de reconexão ocorre em 3,2 $P_{*}$, produzindo um pequeno arco magnético sobre o disco de acreção. Entre 3,2 $P_{*}$ e 5,6 $P_{*}$, linhas de campo que conectam a fonte central ao disco de acreção, logo acima do pequeno arco magnético, também sofrem reconexões. Essas, por sua vez, tornamse cada vez mais intensas com o aumento da compressão das linhas magnéticas no disco na direção das linhas da magnetosfera, causada pela acreção. Os eventos de reconexão, por sua vez, são acompanhados por um vento que ejeta material do disco (veja gráfico superior da figura 3.13), que poderia caracterizar a quase formação de um tênue plasmon, como 

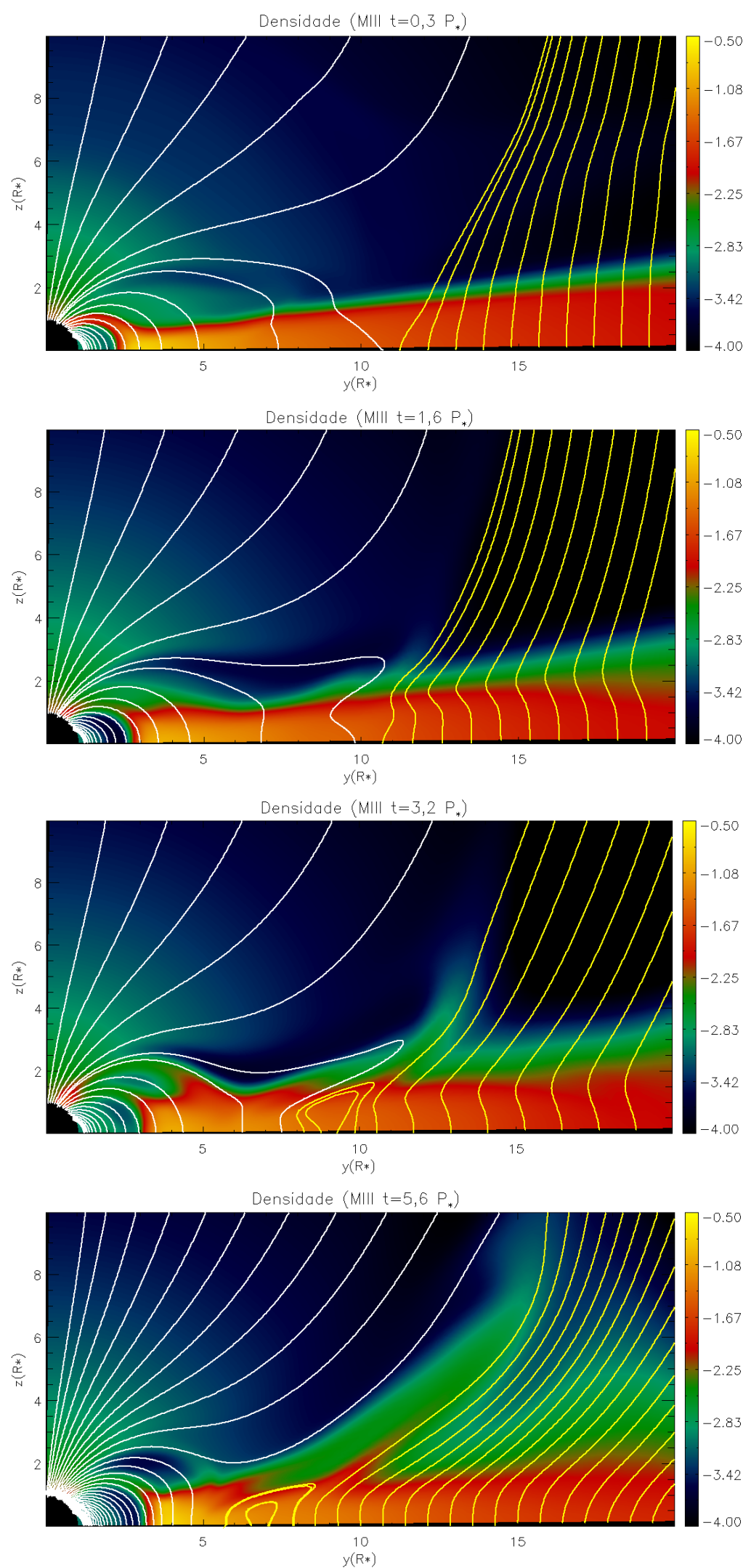

Figura 3.11: Perfil das simulações do modelo III $\left(B_{d}=0,002\right.$ e $\left.\xi=1\right)$ em $t=0,3 P_{*}, t=1,6 P_{*}, t=3,2$ $P_{*}$ e $t=5,6 P_{*}$. As linhas brancas correspondem ao campo magnético conectado à fonte central e as linhas amarelas ao campo poloidal do disco (desconectado da fonte central). As cores de fundo correspondem ao logaritmo da densidade em unidades do código. 

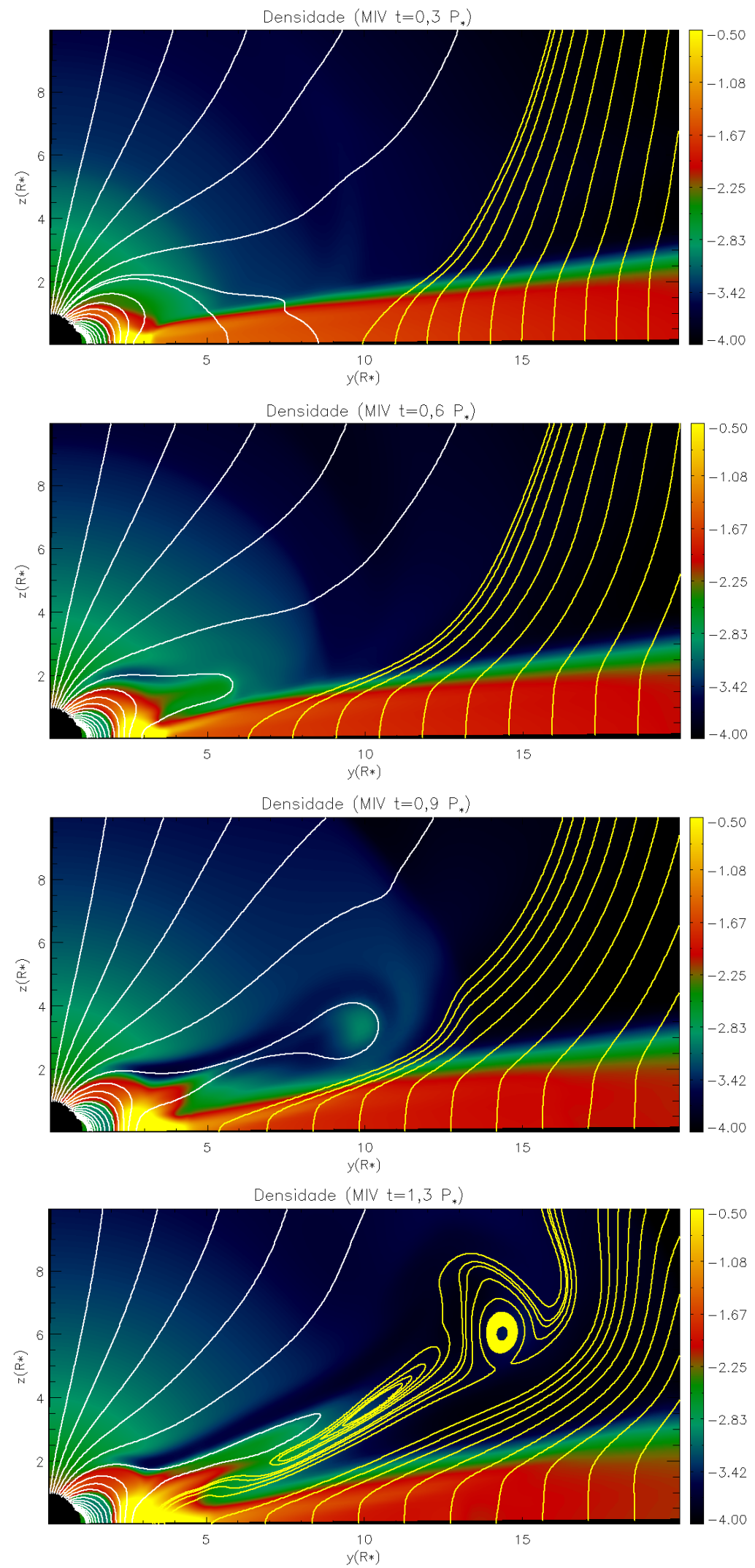

Figura 3.12: Perfil das simulações do modelo IV $\left(B_{d}=0,002\right.$ e $\left.\xi=0,5\right)$ em $t=0,3 P_{*}, t=0,6 P_{*}$, $t=0,9 P_{*}$ e $t=1,3 P_{*}$. As cores correspondem às mesmas da figura 3.11 . 
vimos no capítulo 2. O gráfico inferior da figura 3.13 mostra a distribuição da intensidade do campo magnético do sistema em escala logarítmica, onde é possível observar uma região de baixa magnetização, correspondente ao lençol de corrente onde ocorre a reconexão. Na verdade, uma inspeção mais cuidadosa revela dois, ao invés de um lençol de corrente, com várias diminutas ilhas magnéticas. Essa dupla estrutura de lençóis de corrente deve-se à formação do arco magnético que vemos no dois últimos gráficos da figura 3.11 (o qual separa o lençol em dois próximo à base).

No modelo IV, uma reconexão magnética entre as linhas "fechadas" que conectam a fonte central a região mais interna do disco de acreção desenvolve-se rapidamente em $t=0,9 P_{*}$. O evento de reconexão é acompanhado por um processo de acreção do fluxo magnético poloidal do disco e, também, por uma forte ejeção de matéria (veja o gráfico superior da figura 3.14). A ejeção, por sua vez, estica as linhas magnéticas "fechadas" (segundo e terceiro gráficos da figura 3.12) permitindo que mais reconexões ocorram na região coronal, logo acima do disco, provocando o rompimento de linhas de campo que antes ligavam a fonte central ao disco de acreção (quarto gráfico da figura 3.12). Nesse processo, notamos a formação de duas ilhas magnéticas, em $t=1,3 P_{*}$, onde uma delas termina sendo ejetada para fora do sistema. A estrutura de reconexão desenvolvida nesse modelo é facilmente identificada no gráfico inferior da figura 3.14. Aqui, novamente notamos a subdivisão do lençol de corrente próximo à superfície do disco devido à formação de uma segunda ilha magnética.

A figura 3.15 mostra o comportamento da acreção sobre a superfície da fonte central (linha contínua) e do disco de acreção (linha tracejada), ambas em função do tempo, para os modelos III e IV. Assim como no modelo I, as taxas de acreção do modelo III (veja o gráfico à esquerda da figura 3.15) variam entre $10^{-9}-10^{-8} M_{\odot} /$ ano, típicos de OEJs. Qualitativamente, a evolução das taxas de acreção sobre a estrela e no disco é similar em ambos os modelos. Porém, a formação do arco magnético no modelo III, devido à presença do campo magnético poloidal, parece influenciar o comportamento da acreção do disco em $R=4 R_{*}$. Durante a sua formação, identifica-se um segundo pico mais modesto de acreção no funil sobre a estrela, por volta de $t \simeq 3,5 P_{*}$. Além disso, a acreção no disco em $R=4 R_{*}$, apresenta forte crescimento por volta de $t \simeq 3,5 P_{*}$, o qual está correlacionado ao desenvolvimento do lençol de corrente entre $3,2 P_{*}$ e 5, $6 P_{*}$, tal como vimos no modelo 

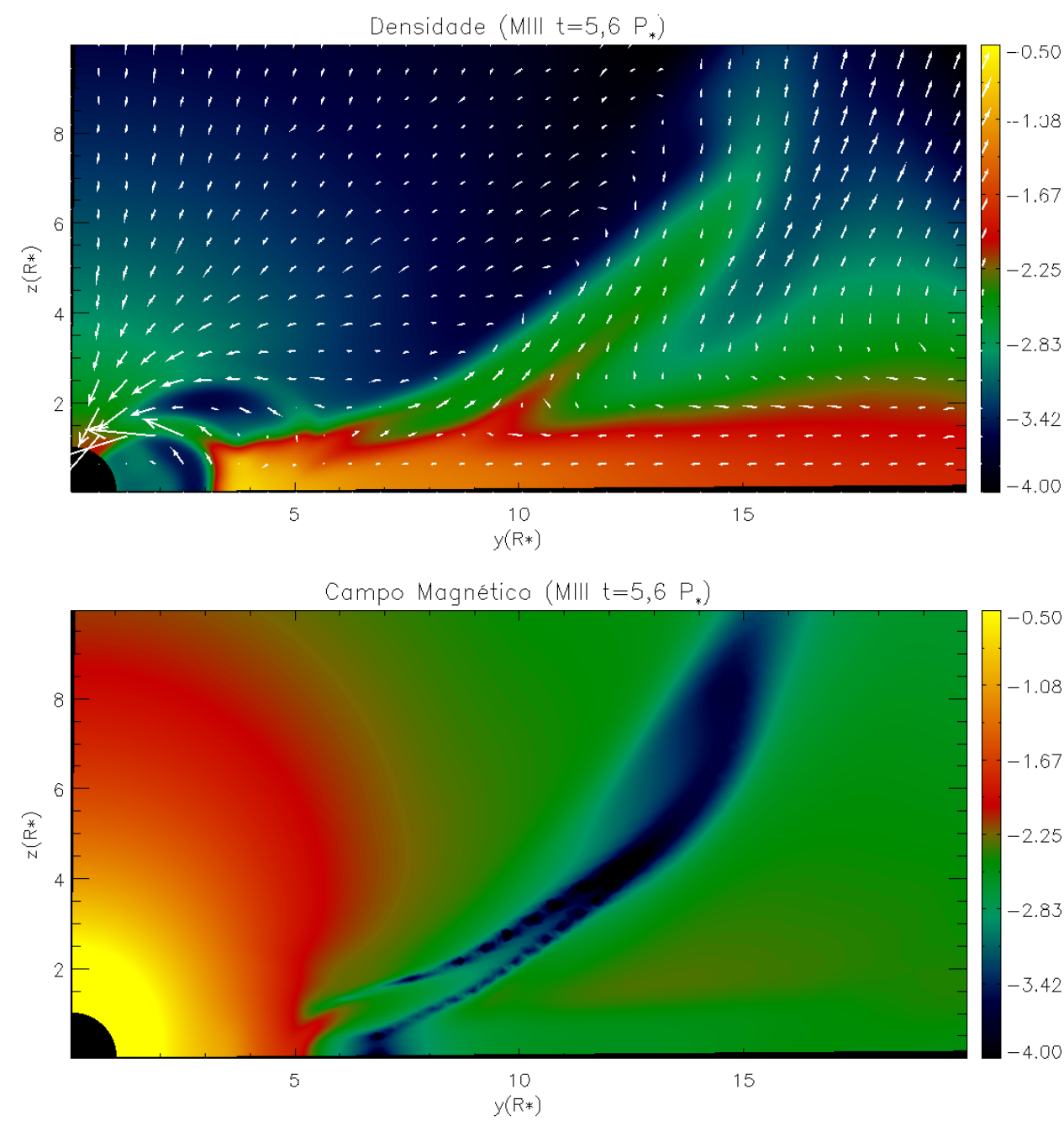

Figura 3.13: Perfil do modelo III em $t=5,6 P_{*}$. O painel superior apresenta o perfil de densidade, em escala logarítmica, sobreposta por vetores que correspondem à orientação do campo de velocidades. Esses vetores revelam a presença de um fraco vento que ejeta matéria do disco de acreção próximo à região de reconexão. No painel inferior é apresentada a distribuição da intensidade de campo magnético do sistema em escala logarítmica, onde é possível discernir uma superfície de baixa magnetização, correspondente à reconexão (ou ao lençol de corrente). 

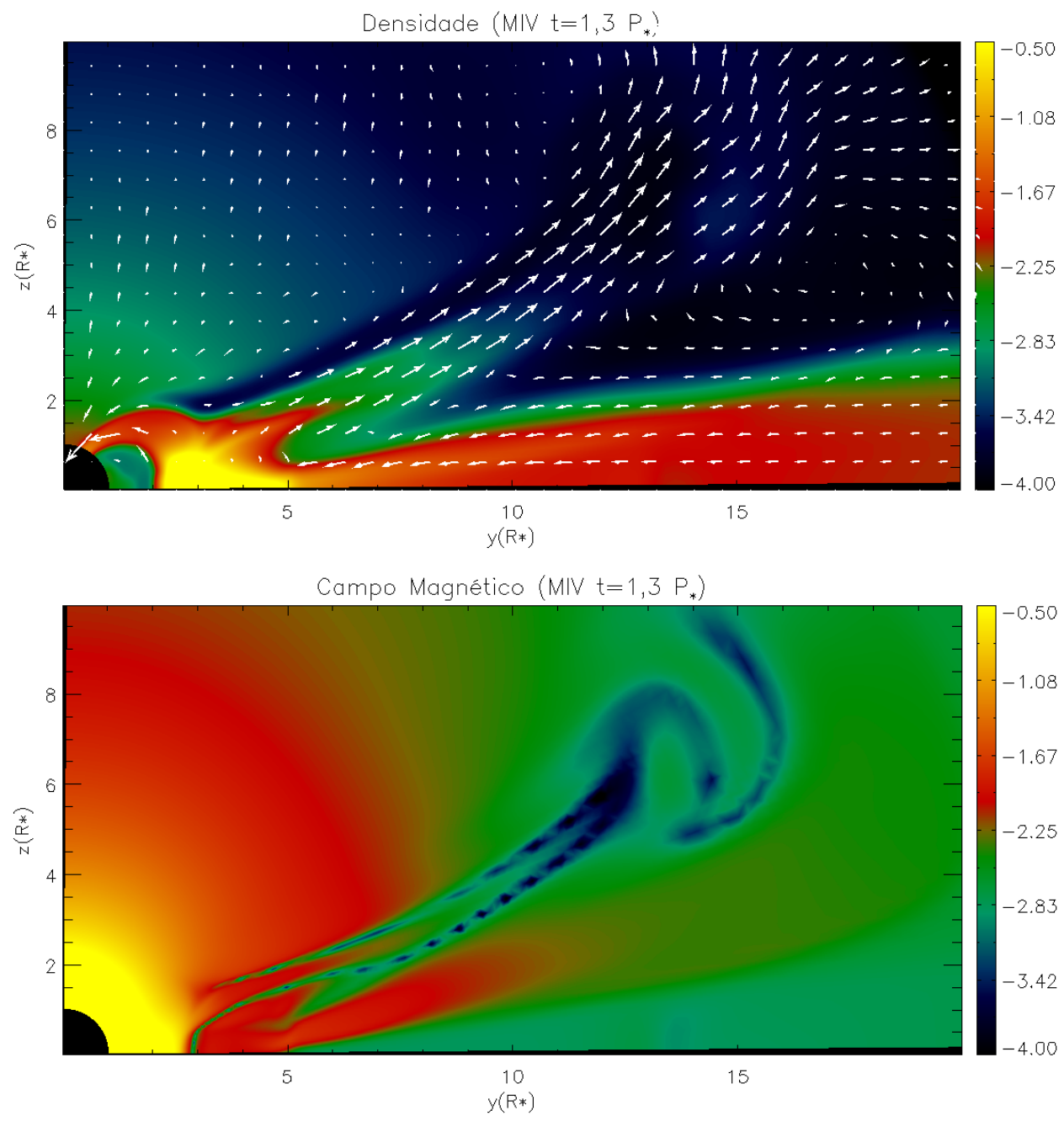

Figura 3.14: Perfil do modelo IV em $t=1,3 P_{*}$. O painel superior apresenta o perfil de densidade, em escala logarítmica, sobreposta por vetores que correspondem à orientação do campo de velocidades. No painel inferior é apresentada a distribuição da intensidade de campo magnético do sistema em escala logarítmica, onde é possível discernir a região de reconexão (ou ao lençol de corrente). Essa, por sua vez, apresenta um forte gradiente de $\boldsymbol{B}$, que se anula no lençol de corrente. 

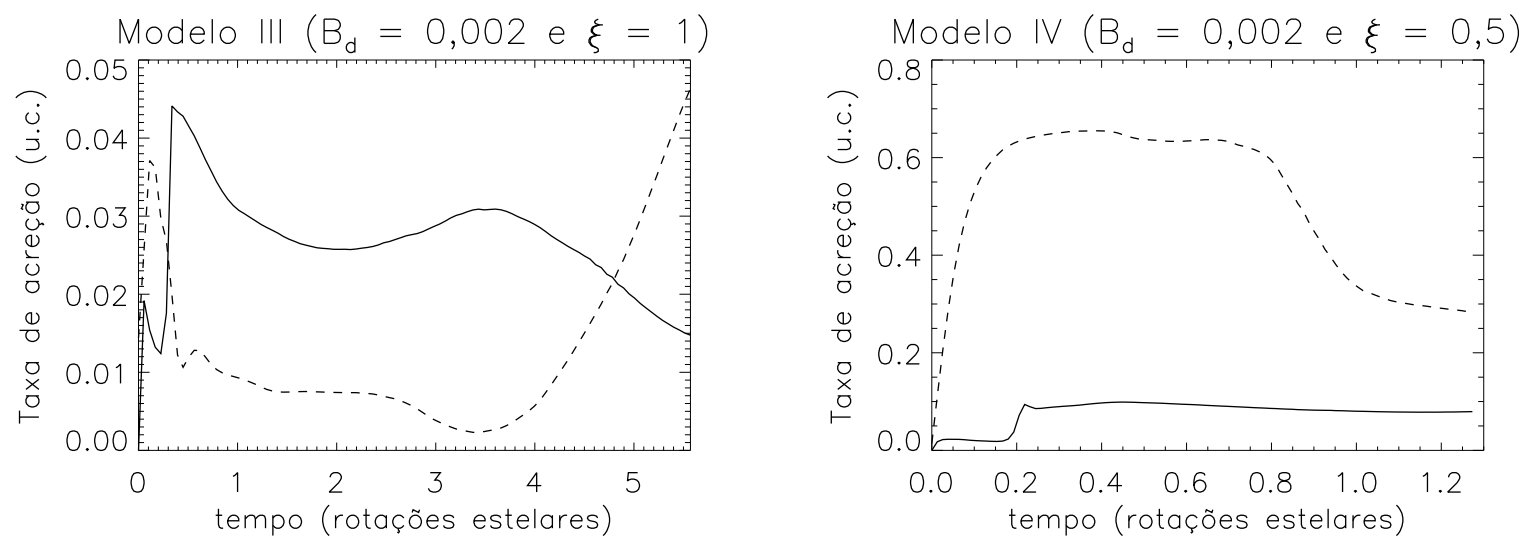

Figura 3.15: Evolução temporal da taxa de acreção medida na superfície da fonte central (linha contínua) e no disco de acreção (linha tracejada) em um raio arbitrário, $R=4 R_{*}$. O gráfico superior corresponde às taxas de acreção do modelo III e o gráfico inferior às taxas do modelo IV.

I. Porém, diferentemente do modelo I, não se verifica durante o período simulado de 5,6 rotações estelares, a queda na taxa de acreção do disco nesse ponto, sugerindo que o sistema não alcançou a máxima compressão das linhas de campo nessa região.

Já no modelo IV (veja o gráfico à direita da figura 3.15), é possível verificar que a inclusão do campo magnético poloidal do disco não parece influenciar significativamente o comportamento da acreção, tanto sobre a superfície da fonte central quanto do disco de acreção, pois apresenta um comportamento bem similar ao do modelo II (veja gráfico inferior da figura 3.8).

Por fim, as figuras 3.16 e 3.17 esquematizam a estrutura do funil de acreção, para os modelo III e IV em $t=0,9 P_{*}$. Essas, por sua vez, são bem similares aos dos casos I e II, de forma que a inclusão de um campo poloidal no disco não afeta a dinâmica de acreção no funil.

\subsection{Efeitos do termo de resfriamento nas simulações}

Esta seção tem como objetivo demonstrar brevemente a importância da presença do termo de resfriamento em simulações de um disco de acreção sob a ação de um processo viscoso (modelo padrão de Shakura e Sunyaev, 1973). Como descrito anteriormente, a viscosidade do disco é tratada através de uma versão dependente do tempo, desenvolvida por Zanni e Ferreira (2009), e é dada pela equação (3.14). Entretanto, esse processo 

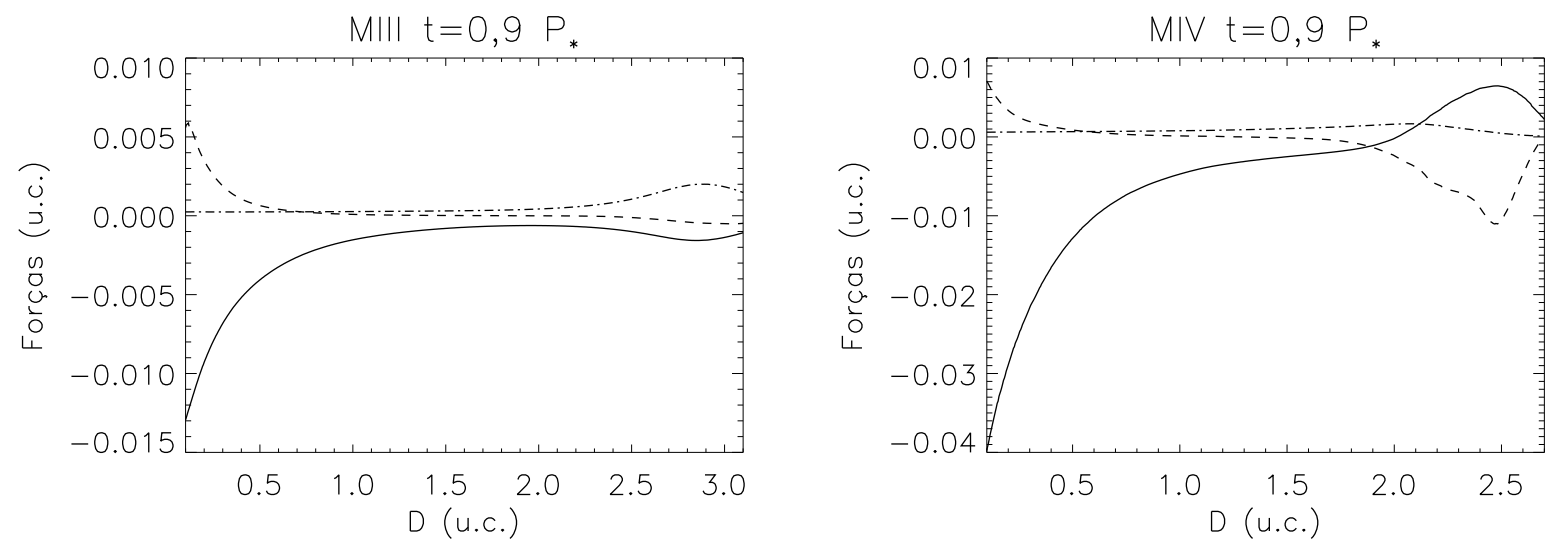

Figura 3.16: Forças projetadas, em $t=0,9 P_{*}$, ao longo da linha de campo localizada no funil de acreção. A figura à esquerda corresponde ao modelo III e à direita ao modelo IV. O gradiente de pressão é representado pela linha tracejada, a força gravitacional pela linha contínua e a força centrífuga pela linha pontilhada e tracejada. Uma força positiva empurra o material ao longo da linha de campo, da estrela para o disco. $D$ corresponde ao comprimento da linha que vai da fonte central $(D=0)$ ao plano médio do disco.
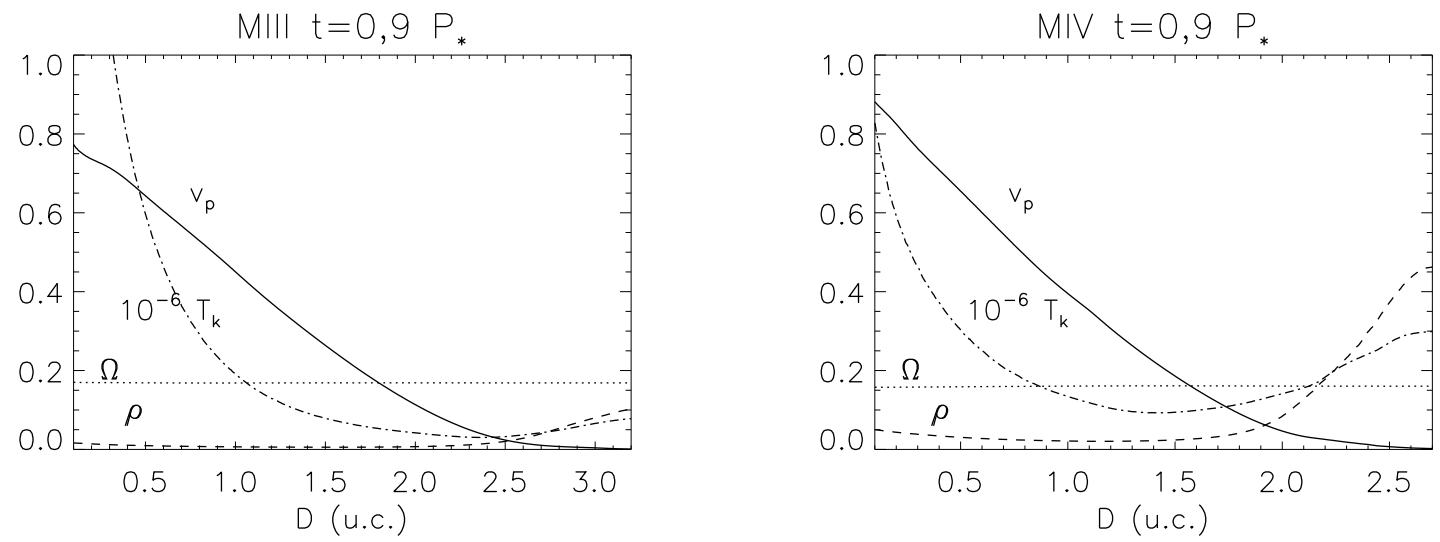

Figura 3.17: Comportamento da velocidade poloidal $\left(v_{p}\right)$, da densidade $(\rho)$, da velocidade angular $(\Omega)$ e da temperatura (em Kelvin), em $t=0,9 P_{*}$, ao longo da linha de campo localizada no funil de acreção. A figura à esquerda corresponde ao modelo III e à direita ao modelo IV. $D$ corresponde ao comprimento da linha que vai da fonte central $(D=0)$ ao plano médio do disco. 
provoca um aquecimento irreversível que, consequentemente, infla o disco de acreção nas regiões mais internas do sistema onde a viscosidade é mais relevante (veja figura 3.18).

Para evitar essa expansão, adicionamos no código um termo artificial de resfriamento (também usado por Zanni e Ferreira, 2009) dado pela equação (3.15). Como ressaltado anteriormente, esse termo remove somente o aquecimento provocado pela ação da viscosidade e não reflete o real mecanismo radiativo de resfriamento. A função de resfriamento passa a ser efetiva somente quando a entropia do disco torna-se $25 \%$ maior do que o seu valor inicial (veja Zanni e Ferreira, 2009) e, como consequência, torna o disco quase adiabático.

Na figura 3.18, mostramos a comparação entre os casos "com" e "sem" o termo de resfriamento artificial para as simulações do modelo $\mathrm{I}$, em $t=1,6 P_{*}$. Os gráficos correspondem à densidade e à temperatura do sistema em escala logarítmica, onde é possível observar uma expansão acentuada nas regiões mais internas do disco de acreção na ausência do termo de resfriamento. Além disso, para o mesmo modelo, as diferenças de temperatura são bem visíveis: enquanto no caso com resfriamento as temperaturas médias do disco são da ordem de $10^{3}-10^{4} \mathrm{~K}$; para o caso sem resfriamento, as temperaturas são da ordem de $10^{4}-10^{5} \mathrm{~K}$. Portanto, sem um mecanismo adequado de resfriamento, o disco não consegue manter uma estrutura fina; e caso a tendência de expansão continue, o disco será praticamente desfeito. Em todos os modelos apresentados nas seções precedentes, o termo de resfriamento foi aplicado ao disco.

\subsection{Discussões}

Neste capítulo, apresentamos resultados de um conjunto de simulações magnetohidrodinâmicas axissimétricas (2.5D-MHD) de um sistema contendo um disco de acreção viscoso e magnetizado ao redor de uma fonte central em rotação, com um campo magnético dipolar cujas características assemelham-se aos dos OEJs. Nosso objetivo foi examinar processos de reconexão magnética entre as linhas de campo ancoradas no disco e as linhas da magnetosfera da fonte central. A solução numérica das equações MHD na forma não ideal, onde foram incluídos os termos de viscosidade e resfriamento, foi obtida a partir de um conjunto de métodos reunidos no código numérico PLUTO (veja Mignone et al., 2007). Desenvolvemos modelos com a presença do campo puramente dipolar da fonte central, bem como, modelos com o campo dipolar associado a um campo magnético poloidal ancorado no disco 

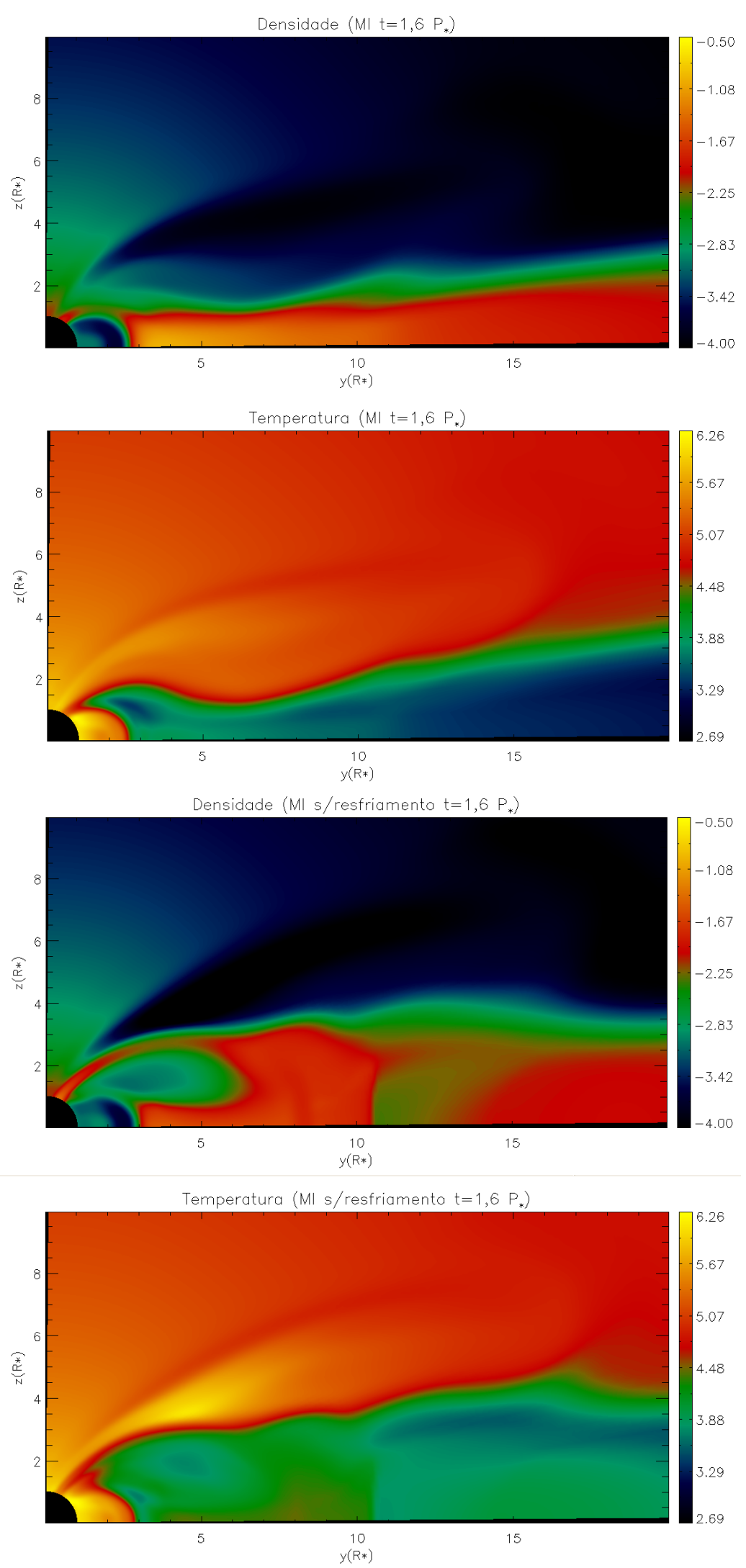

Figura 3.18: Perfil das simulações do modelo I em $t=1,6 P_{*}$. Os dois gráficos superiores correspondem ao caso com resfriamento e os dois últimos ao caso sem resfriamento, onde é visível o processo de expansão devido o aquecimento nas regiões mais internas do disco de acreção. A densidade encontra-se em unidades do código e a temperatura em Kelvin. Ambas são representadas em escala logarítmica. 
de acreção. Nesses modelos, consideramos diferentes rotações iniciais para o disco, com o objetivo de modificar o estado de acreção do sistema. Além disso, estudamos a formação de lençóis de corrente (ou eventos de reconexão magnética) em função da evolução das taxas de acreção para os diferentes modelos.

As simulações embora preliminares e limitadas a um pequeno espaço paramétrico, mostraram que eventos de reconexão magnética podem ocorrer de forma mais eficiente em regimes de alta acreção (modelos II e IV), que foram obtidos reduzindo-se em 50\% $(\xi=0,5)$ a rotação inicial de seus discos, em relação aos dos modelos I e III. Além disso, as simulações, de um modo geral, demonstraram que a dinâmica do sistema e a frequência com que eventos de reconexão magnética podem ocorrer, são sensíveis tanto às taxas de acreção (como previsto pelo modelo de de Gouveia Dal Pino e Lazarian, 2005) quanto à topologia inicial do campo magnético do sistema.

Notamos que no presente estudo, a reconexão das linhas, que só pode ocorrer em presença de uma resistividade magnética não nula, ocorre devido à presença de uma resistividade numérica. Essa, porém, não é intensa o bastante para determinar um processo de reconexão a taxas da ordem da velocidade de Alfvén, ou seja, ela é essencialmente não rápida, ou dita "lenta", conforme discutido no capítulo 2. Ainda assim, fomos capazes de capturar algumas das características essenciais previstas pelo modelo de de Gouveia Dal Pino e Lazarian (2005), como a rápida mudança de topologia do campo magnético e do estado de acreção do disco, assim como, a formação de lençóis de corrente e plasmons.

A análise da evolução das taxas de acreção, obtidas sobre a superfície da fonte central (em $R=R_{*}$ ) e sobre o disco de acreção em um raio arbitrário $R=4 R_{*}$, mostraram que a mudança de topologia magnética parece exercer pouca influencia na acreção entre os modelos cuja rotação do disco foi reduzida em $50 \%$ ( $\xi=0,5$, modelos II e IV). Isso se deve ao fato de que nesses dois modelos a taxa de acreção inicial no disco (a qual é aproximadamente 10 vezes maior que nos modelos I e III) já possui níveis tão altos que a mesma não é influenciada pela dragagem de novas linhas de campo magnético ao longo do disco (em direção ao raio de truncamento). Em contrapartida, as simulações dos modelos com uma rotação próxima à Kepleriana ( $\xi=1$, modelos I e III) revelaram que a acreção do disco pode ser alterada devido à presença e evolução de um campo magnético poloidal associado ao campo dipolar da estrela. Em particular, a presença do campo magnético 
no disco induz a formação de um segundo pico mais tênue de acreção sobre a superfície estelar (modelo IV), o qual não se verifica no modelo que possui apenas o campo magnético puramente dipolar (modelo I), para o mesmo período simulado.

A formação do funil de acreção foi brevemente descrita em função das forças projetadas que atuam sobre as linhas de campo que ligam a fonte central ao disco de acreção. Como observado nas seções anteriores, o funil é formado na região de truncamento do disco devido à presença da magnetosfera dipolar da fonte central. O material em acreção barrado pela pressão magnética é, então, levantado e empurrado pela pressão térmica e, em seguida, é escoado até a estrela ao longo das linhas de campo magnético devido à ação da força gravitacional. O material do disco alcança a superfície estelar com uma velocidade da ordem de $196 \mathrm{~km} . \mathrm{s}^{-1}$. De fato, estudos ja há mais de uma década dos espectros de estrelas $T$ Tauri mostram evidências de fluxos de matéria em acreção que podem alcançar velocidades próximas ao de queda livre (veja Hartmann et al., 1994; Muzerolle et al., 2001). Já o aumento da temperatura ao longo do funil de acreção, do disco para a estrela, é esperado, já que o material do disco ganha energia cinética e é cada vez mais comprimido à medida que se aproxima da superfície estelar, de modo que parte dessa energia transforma-se em energia interna e eventualmente é irradiada. De fato, nessa região, encontramos temperaturas no funil da ordem de $10^{6} \mathrm{~K}$, que são consistentes com os valores encontrados na literatura para os OEJs (veja, por exemplo, Lima et al., 2010, e referências lá contidas).

Por fim, verificamos a importância da presença de um mecanismo de resfriamento em simulações que envolvem a ação de um processo viscoso no disco de acreção. Sem esse mecanismo, a viscosidade gera um aquecimento nas regiões mais internas do disco (onde é mais relevante), que por sua vez, provoca a expansão do mesmo. Dessa forma, o disco deixa de ser fino e termina por se desfazer. 
Capítulo 4

\section{Conclusões e Perspectivas}

Nesta dissertação, estudamos o modelo originalmente desenvolvido por de Gouveia Dal Pino e Lazarian (2005) para explicar as ejeções superluminais e os flares em rádio associados ao microquasar GRS 1915 + 105, com o fim de estendê-lo a outras classes de fontes astrofísicas possuidoras de jatos e discos de acreção. Dentro desse cenário, a aceleração inicial do jato a velocidades superluminais ocorre devido a episódios de reconexão magnética rápida e violenta entre as linhas de campo magnético de polaridades opostas da região mais interna do disco de acreção (provavelmente produzidas através da ação de um processo de dínamo turbulento) e aquelas que estão ancoradas no horizonte de buracos negros. A reconexão violenta ocorre sempre que a relação entre a pressão efetiva do disco e a pressão magnética (fator $\beta$ ) diminui para valores menores ou da ordem de 1 e a taxa de acreção $(\dot{M})$ aproxima-se da taxa crítica de Eddington.

No capítulo 2, primeiramente descrevemos os estudos de Piovezan (2009) (veja também de Gouveia Dal Pino et al., 2010a,b), onde vimos que eventos de reconexão magnética violenta poderiam ser os responsáveis pela transição de uma fase "dura" para uma fase "mole" do SPLS (steep power law state). Estas fases são observadas partir dos espectros em rádio e raios-X do microquasar GRS 1915+105 e também de outros microquasares (veja Dhawan et al., 2000). Além disso, vimos também, que antes de um flare em rádio, as taxas elevadas de acreção produzem uma emissão em raios-X "mole" com uma luminosidade em torno de $10^{39} \mathrm{erg} / \mathrm{s}$. Já a potência magnética liberada em eventos de reconexão violenta é, principalmente, utilizada para aquecer o gás tanto da coroa (a temperaturas da ordem de $10^{9}$ K) quanto do disco de acreção através da condução térmica ao longo das linhas de campo (provocando o aumento e a variabilidade da emissão em raios-X "mole" observadas nessas 
fontes). Acredita-se, também, que uma parte da energia magnética liberada nesses eventos pode ser usada para acelerar partículas através de um processo de Fermi de primeira ordem na zona de reconexão que, por sua vez, produz ejeções relativísticas (ou "plasmons") acompanhadas pela emissão rádio sincrotrônica com índice espectral $\alpha_{R} \simeq-0,75$. Esse valor é consistente com a faixa de índices espectrais em rádio observadas durante os flares do microquasar GRS $1915+105\left(-0,2<\alpha_{R}<-1\right.$, 0; veja, Dhawan et al., 2000; Hannikainen et al., 2001).

No mesmo capítulo, apresentamos uma generalização do modelo acima descrito para o caso dos OEJs (objetos estelares jovens) e dos NAGs (núcleos ativos de galáxias). Parte dessa análise foi iniciada na dissertação de mestrado de Piovezan (2009) e complementada nesta dissertação, onde construímos um diagrama "log-log" da potência liberada em eventos de reconexão magnética violenta em função das massas dos buracos negros centrais, dos microquasares aos NAGs. Esse diagrama foi comparado com os limites superiores para as luminosidades em rádio observadas de jatos nucleares que emergem das regiões centrais de galáxias Seyfert, de LINERs e de quasares (e.g., Kellermann et al., 1998; Nagar et al., 2005); e das luminosidades observadas em rádio durante os flares dos microquasares GRS 1915 + 105, XTE J1859 + 226 e XTE J1550 - 564 (e.g., Merloni et al., 2003; Mirabel e Rodríguez, 1998). A partir de uma análise desse diagrama, constatamos que a atividade de reconexão magnética na região coronal, na base de lançamento do jato, pode explicar a emissão rádio das ejeções relativísticas dos microquasares aos NAGs de menor luminosidade. A potência liberada em eventos de reconexão magnética em função das massas dos buracos negros dessas fontes, de $5 M_{\odot}$ a $10^{10} M_{\odot}$, obedece a uma correlação que se mantém por todo esse intervalo, abrangendo $10^{9}$ ordens de magnitude. Essa correlação implica em uma dependência quase linear $\left(\dot{W}_{B} \propto M^{1 / 2}\right)$, aproximadamente independente das características físicas locais dessas fontes e de seus discos de acreção. Além disso, ela é compatível com o chamado "plano fundamental", obtido empiricamente, que correlaciona a emissão rádio e raios-X dos microquasares e NAGs às massas dos seu buracos negros (veja Merloni et al., 2003). Esse bom ajuste do modelo às observações dos microquasares e NAGs de baixa luminosidade, é uma indicação de que o modelo de atividade magnética aqui descrito parece apropriado, apesar de sua simplicidade, e oferece uma explicação física natural para a correlação observada entre as massas das fontes e sua emissão rádio. Já os 
quasares e NAGs mais luminosos não satisfazem à mesma correlação, possivelmente porque a densidade ao redor da região coronal nessas fontes é tão alta que "mascara" a emissão devida à atividade magnética. A emissão rádio nesses casos deve-se, possivelmente, a regiões mais externas do jato supersônico, onde ele já expandiu o suficiente para tornar-se opticamente fino e visível, e onde os elétrons relativísticos são possivelmente produzidos em choques. Esses resultados foram também publicados em dois artigos (veja de Gouveia Dal Pino et al., 2010a,b).

No capítulo 3, investigamos a formação de eventos de reconexão magnética através de simulações magnetohidrodinâmicas axissimétricas (2.5D-MHD), da interação entre o campo magnético poloidal ancorado em um disco de acreção viscoso (satisfazendo ao modelo padrão de Shakura e Sunyaev, 1973) e a magnetosfera dipolar de uma fonte central em rotação. Por simplicidade, as simulações foram realizadas considerando-se condições que se assemelham às dos OEJs (e.g., Zanni e Ferreira, 2009; Bessolaz et al., 2008; Romanova et al., 2002). Nos testes preliminares aqui realizados, notamos que a reconexão magnética das linhas ocorre em presença de uma resistividade numérica, que não é intensa o bastante para determinar um processo de reconexão a taxas da ordem da velocidade de Alfvén, ou seja, ela é essencialmente "lenta". Ainda assim, fomos capazes de capturar algumas das características essenciais previstas pelo modelo de de Gouveia Dal Pino e Lazarian (2005), como a rápida mudança de topologia do campo magnético e do estado de acreção do disco, assim como, a formação de lençóis de corrente e plasmons. Por exemplo, verificamos que a frequência e a intensidade com que eventos de reconexão magnética podem ocorrer é sensível tanto à topologia inicial do campo magnético do sistema quanto às taxas de acreção do disco, de modo que tais eventos ocorrem de forma mais eficiente em regimes de altas taxas de acreção.

Analisamos também no capítulo 3, a formação do funil de acreção em função das forças projetadas que atuam sobre as linhas de campo que ligam a fonte central ao disco de acreção. Assim como observado por Zanni e Ferreira (2009) e Romanova et al. (2002), verificamos que o funil é formado na região de truncamento do disco devido à presença da magnetosfera dipolar da fonte central. O material em acreção barrado pela pressão magnética é levantado e empurrado pela pressão térmica que, em seguida, é escoado até a estrela ao longo das linhas de campo magnético devido à ação da força gravitacional. O 
material do disco alcança a superfície estelar, próximo às regiões de latitude intermediária da fonte, com uma velocidade de queda livre da ordem de $196 \mathrm{~km} \cdot \mathrm{s}^{-1}$, para todos o modelos simulados.

Futuramente, pretende-se melhorar as condições das simulações numéricas para obtermos tempos de evolução maiores, sem que instabilidades numéricas interfiram nos mesmos, particularmente nas regiões de fronteira. Além disso, a inclusão de uma resistividade finita anômala e grande, e mesmo de turbulência na região de reconexão magnética estão previstas, a fim de aumentar a eficiência de reconexão nas simulações, tornando-a "rápida", conforme descrito no capítulo 2. Particularmente, a extensão destas para um caso relativístico será avaliada, com a intensão de reproduzirmos as condições próximas ao horizonte de eventos de um buraco negro e, consequentemente, para aplicações mais realistas ao caso dos microquasares e quasares. Um estudo numérico mais detalhado da região de reconexão e a sua atuação na aceleração de partículas, a partir do processo de Fermi de primeira ordem, será também feito em complementação aos estudos já iniciados por Kowal et al. (2011), onde simulações numéricas vêm demonstrando que esse processo é altamente eficiente. Em particular, esse estudo de aceleração em zonas de reconexão será aplicado a várias classes de fontes astrofísicas, da coroa solar, aos discos de acreção e jatos associados a microquasares, NAGs e GRBs, incluindo-se também os efeitos das perdas radiativas sobre as partículas aceleradas. Isso permitirá a construção das curvas de luz dessas fontes e comparações com o crescente volume de observações multibandas oferecidas pelos instrumentos atuais (como os satélites FERMI e SWIFT e os observatórios VERITAS, MAGIC e HESS) e os que estão por vir (como o ALMA, LLAMA e CTA). 


\section{Referências Bibliográficas}

Alencar S. H. P., Time variable funnel flows, In Star-Disk Interaction in Young Stars, Proceedings of the International Astronomical Union, IAU Symposium, 2007, vol. 243, p. 71

Aschwanden M. J., Poland A. I., Rabin D. M., The New Solar Corona, ARA\&A, 2001, vol. 39 , p. 175

Bacciotti F., Ray T. P., Mundt R., Eislöffel J., Solf J., Hubble Space Telescope/STIS Spectroscopy of the Optical Outflow from DG Tauri: Indications for Rotation in the Initial Jet Channel, ApJ, 2002, vol. 576, p. 222

Balbus S. A., Gammie C. F., Hawley J. F., Fluctuations, dissipation and turbulence in accretion discs, MNRAS, 1994, vol. 271, p. 197

Balbus S. A., Hawley J. F., A powerful local shear instability in weakly magnetized disks. I - Linear analysis. II - Nonlinear evolution, ApJ, 1991, vol. 376, p. 214

Balbus S. A., Hawley J. F., Instability, turbulence, and enhanced transport in accretion disks, Reviews of Modern Physics, 1998, vol. 70, p. 1

Balsara D. S., Spicer D. S., A Staggered Mesh Algorithm Using High Order Godunov Fluxes to Ensure Solenoidal Magnetic Fields in Magnetohydrodynamic Simulations, Journal of Computational Physics, 1999, vol. 149, p. 270

Beckwith K., Hawley J. F., Krolik H. J., Transport of Large-Scale Poloidal Flux in Black Hole Accretion, ApJ, 2009, vol. 707, p. 428 
Beckwith S. V. W., Sargent A. I., Chini R. S., Guesten R., A survey for circumstellar disks around young stellar objects, AJ, 1990, vol. 99, p. 924

Bell A. R., The acceleration of cosmic rays in shock fronts. I, MNRAS, 1978a, vol. 182, p. 147

Bell A. R., The acceleration of cosmic rays in shock fronts. II, MNRAS, 1978b, vol. 182, p. 443

Bessolaz N., Zanni C., Ferreira J., Keppens R., Bouvier J., Accretion funnels onto weakly magnetized young stars, A\&A, 2008, vol. 478, p. 155

Blandford R. D., Payne D. G., Hydromagnetic flows from accretion discs and the production of radio jets, A\&A, 1982, vol. 199, p. 883

Blandford R. D., Znajek R. L., Electromagnetic extraction of energy from Kerr black holes, MNRAS, 1977, vol. 179, p. 433

Bolton C. T., Dimensions of the Binary System HDE 226868 = Cygnus X-1, Nature, 1972, vol. 240 , p. 124

Bouvier J., Alencar S. H. P., Boutelier T., Dougados C., Balog Z., Grankin K., Hodgkin S. T., Ibrahimov M. A., Kun M., Magakian T. Y., Pinte C., Magnetospheric accretionejection processes in the classical T Tauri star AA Tauri, A\&A, 2007, vol. 463, p. 1017

Bridle A. H., Perley R. A., Extragalactic Radio Jets, ARA\&A, 1984, vol. 22, p. 319

Brocksopp C., Fender R. P., McCollough M., Pooley G. G., Rupen M. P., Hjellming R. M., de la Force C. J., Spencer R. E., Muxlow T. W. B., Garrington S. T., Trushkin S., Initial low/hard state, multiple jet ejections and X-ray/radio correlations during the outburst of XTE J1859+226, MNRAS, 2002, vol. 331, p. 765

Camenzind M., Magnetized Disk-Winds and the Origin of Bipolar Outflows., Reviews in Modern Astronomy, 1990, vol. 3, p. 234

Cerqueira A. H., de Gouveia Dal Pino E. M., 3-D numerical simulations of rotating jets. The case of DG Tau microjet, A\&A, 2004, vol. 426, p. L25 
Cowley A. P., Crampton D., Hutchings J. B., Remillard R., Penfold J. E., Discovery of a massive unseen star in LMC X-3, ApJ, 1983, vol. 272, p. 118

de Gouveia Dal Pino E. M., Astrophysical jets and outflows, Advances in Space Research, 2005, vol. 35, p. 908

de Gouveia Dal Pino E. M., Kowal G., Kadowaki L. H. S., Piovezan P., Lazarian A., Magnetic Field Effects Near the Launching Region of Astrophysical Jets, International Journal of Modern Physics D, 2010, vol. 19, p. 729

de Gouveia Dal Pino E. M., Lazarian A., Ultra-High-Energy Cosmic-Ray Acceleration by Magnetic Reconnection in Newborn Accretion-induced Collapse Pulsars, ApJ, 2000, vol. 536 , p. 31

de Gouveia Dal Pino E. M., Lazarian A., Constraints on the Acceleration of Ultra-HighEnergy Cosmic Rays in Accretion-induced Collapse Pulsars, ApJ, 2001, vol. 560, p. 358

de Gouveia Dal Pino E. M., Lazarian A., Production of the large scale superluminal ejections of the microquasar GRS 1915+105 by violent magnetic reconnection, A\&A, 2005, vol. 441, p. 845

de Gouveia Dal Pino E. M., Piovezan P. P., Kadowaki L. H. S., The role of magnetic reconnection on jet/accretion disk systems, A\&A, 2010, vol. 518, p. 5

del Valle M. V., Romero G. E., Luque-Escamilla P. L., Martí J., Ramón Sánchez-Sutil J., Are T Tauri Stars Gamma-Ray Emitters?, ApJ, 2011, vol. 738, p. 115

Dhawan V., Mirabel I. F., Rodríguez L. F., AU-Scale Synchrotron Jets and Superluminal Ejecta in GRS 1915+105, ApJ, 2000, vol. 543, p. 373

Done C., Nayakshin S., Testing models of X-ray reflection from irradiated discs, MNRAS, 2001, vol. 328 , p. 616

Falcke H., Körding E., Markoff S., A scheme to unify low-power accreting black holes. Jet-dominated accretion flows and the radio/X-ray correlation, A\&A, 2004, vol. 414, p. 895 
Fanaroff B. L., Riley J. M., The morphology of extragalactic radio sources of high and low luminosity, MNRAS, 1974, vol. 167, p. 31

Favata F., Flaccomio E., Reale F., Micela G., Sciortino S., Shang H., Stassun K. G., Feigelson E. D., Bright X-Ray Flares in Orion Young Stars from COUP: Evidence for Star-Disk Magnetic Fields?, ApJ, 2005, vol. 160, p. 469

Feigelson E. D., Montmerle T., High-Energy Processes in Young Stellar Objects, ARA\&A, 1999, vol. 37 , p. 363

Fender R. P., Belloni T. M., Gallo E., Towards a unified model for black hole X-ray binary jets, MNRAS, 2004, vol. 335, p. 110

Frank J., King A., Raine D., Accretion power in astrophysics. 3rd ed., Cambridge: Cambridge University Press, 1992

Gammie C. F., Menou K., On the Origin of Episodic Accretion in Dwarf Novae, ApJ, 1998, vol. 492, p. 75

Ghosh P., Lamb F. K., Accretion by rotating magnetic neutron stars. III - Accretion torques and period changes in pulsating X-ray sources, ApJ, 1979a, vol. 234, p. 296

Ghosh P., Lamb F. K., Accretion by rotating magnetic neutron stars. II - Radial and vertical structure of the transition zone in disk accretion, ApJ, 1979b, vol. 232, p. 259

Goedbloed H., Poedts S., Principles of magnetohydrodynamics: with applications to laboratory and astrophysical plasmas. 1st ed. Cambridge: Cambridge University Press, 2004

Goodson A. P., Böhm K., Winglee R. M., Jets from Accreting Magnetic Young Stellar Objects. I. Comparison of Observations and High-Resolution Simulation Results, ApJ, 1999, vol. 524, p. 142

Goodson A. P., Winglee R. M., Jets from Accreting Magnetic Young Stellar Objects. II. Mechanism Physics, ApJ, 1999, vol. 524, p. 159

Hannikainen D., Wu K., Campbell-Wilson D., Hunstead R., Lovell J., McIntyre V., Reynolds J., Soria R., Tzioumis T., Radio emission from the X-ray transient XTE J1550-564, ESA Special Publication, 2001, vol. 459, p. 291 
Hartmann L., Hewett R., Calvet N., Magnetospheric accretion models for T Tauri stars. 1: Balmer line profiles without rotation, ApJ, 1994, vol. 426, p. 669

Kellermann K. I., Vermeulen R. C., Zensus J. A., Cohen M. H., Sub-Milliarcsecond Imaging of Quasars and Active Galactic Nuclei, AJ, 1998, vol. 115, p. 1295

King A. R., Pringle J. E., West R. G., Livio M., Variability in black hole accretion discs, MNRAS, 2004, vol. 348, p. 111

Kippenhahn R., Weigert A., Stellar Structure and Evolution. Springer-Verlag Berlin Heidelberg New York, 1994, 468

Kluźniak W., Kita D., Three-dimensional structure of an alpha accretion disk, ARXIV, 2000

Koldoba A. V., Lovelace R. V. E., Ustyugova G. V., Romanova M. M., Funnel Flows from Disks to Magnetized Stars, AJ, 2002, vol. 123, p. 2019

Kotera K., Olinto A. V., The Astrophysics of Ultrahigh-Energy Cosmic Rays, ARA\&A, 2011, vol. 49, p. 119

Kowal G., de Gouveia Dal Pino E. M., Lazarian A., Magnetohydrodynamic Simulations of Reconnection and Particle Acceleration: Three-dimensional Effects, ApJ, 2011, vol. 735, p. 102

Kowal G., Lazarian A., Vishniac E. T., Otmianowska-Mazur K., Numerical Tests of Fast Reconnection in Weakly Stochastic Magnetic Fields, ApJ, 2009, vol. 700, p. 63

Kudoh T., Matsumoto R., Shibata K., Are Jets Ejected from Locally Magnetized Accretion Disks?, Publ. Astron. Soc. Japan, 2002, vol. 54, p. 267

Königl A., Disk accretion onto magnetic T Tauri stars, ApJ, 1991, vol. 370, p. 39

Lada C. J., Star formation - From OB associations to protostars, In Star forming regions, Proceedings of the Symposium, Tokyo, Japan., 1987, vol. 115, p. 1

Laor A., Behar E., On the origin of radio emission in radio-quiet quasars, MNRAS, 2008, vol. 390, p. 847 
Lazarian A., Opher M., A Model of Acceleration of Anomalous Cosmic Rays by Reconnection in the Heliosheath, ApJ, 2009, vol. 703, p. 8

Lazarian A., Vishniac E. T., Reconnection in a Weakly Stochastic Field, ApJ, 1999, vol. 517, p. 700

Lima G. H. R. A., Alencar S. H. P., Calvet N., Hartmann L., Muzerolle J., Modeling the Ho line emission around classical T Tauri stars using magnetospheric accretion and disk wind models, A\&A, 2010, vol. 522, p. 104

Liu B. F., Mineshige S., Shibata K., A Simple Model for a Magnetic Reconnection-heated Corona, ApJ, 2002, vol. 572, p. 173

Livio M., Pringle J. E., King A. R., The Disk-Jet Connection in Microquasars and Active Galactic Nuclei, ApJ, 2003, vol. 593, p. 184

Longair M. S., High energy astrophysics. Vol.1: Particles, photons and their detection. Cambridge: Cambridge University Press, 1992

Lovelace R. V. E., Dynamo model of double radio sources, Nature, 1976, vol. 262, p. 649

MacDonald D. A., Thorne K. S., Zhang X., Price R. H., Astrophysical applications of black-hole electrodynamics. New Haven, CT: Yale University Press, 1986, 121

Maciel W. J., Introdução à estrutura e evolução estelar. São Paulo, Brasil: EDUSP Editora da Universidade de São Paulo, 1999

Malzac J., Models for microquasars, ARXIV, 2007

Marchesini D., Celotti A., Ferrarese L., A transition in the accretion properties of radioloud active nuclei, MNRAS, 2004, vol. 351, p. 733

Matt S., Goodson A. P., Winglee R. M., Böhm K., Simulation-based Investigation of a Model for the Interaction between Stellar Magnetospheres and Circumstellar Accretion Disks, ApJ, 2002, vol. 574, p. 232

McClintock J. E., Horne K., Remillard R. A., The DIM inner accretion disk of the quiescent black hole A0620-00, ApJ, 1995, vol. 442, p. 358 
McClintock J. E., Remillard R. A., The black hole binary A0620-00, ApJ, 1986, vol. 308, p. 110

Merloni A., Beyond the standard accretion disc model: coupled magnetic disc-corona solutions with a physically motivated viscosity law, MNRAS, 2003, vol. 341, p. 1051

Merloni A., Heinz S., di Matteo T., A Fundamental Plane of black hole activity, MNRAS, 2003, vol. 345, p. 1057

Mignone A., Bodo G., Massaglia S., Matsakos T., Tesileanu O., Zanni C., Ferrari A., PLUTO: A Numerical Code for Computational Astrophysics, ApJS, 2007, vol. 170, p. 228

Mirabel I. F., Rodríguez L. F., A superluminal source in the Galaxy, Nature, 1994, vol. 371, p. 46

Mirabel I. F., Rodríguez L. F., Microquasars in our Galaxy, Nature, 1998, vol. 392, p. 673

Miyoshi T., Kusano K., A multi-state HLL approximate Riemann solver for ideal magnetohydrodynamics, Journal of Computational Physics, 2005, vol. 208, p. 305

Muzerolle J., Calvet N., Hartmann L., Emission-Line Diagnostics of T Tauri Magnetospheric Accretion. II. Improved Model Tests and Insights into Accretion Physics, ApJ, 2001, vol. 550, p. 944

Nagar N. M., Falcke H., Wilson A. S., Radio sources in low-luminosity active galactic nuclei. IV. Radio luminosity function, importance of jet power, and radio properties of the complete Palomar sample, A\&A, 2005, vol. 435, p. 521

Nakamura F., Formation of an Infalling Disklike Envelope around a Protostar, ApJ, 2000, vol. 543 , p. 291

Pesenti N., Dougados C., Cabrit S., O'Brien D., Garcia P., Ferreira J., Near-IR [Fe II] emission diagnostics applied to cold disk winds in young stars, A\&A, 2003, vol. 410, p. 155

Peterson B. M., An introduction to active galactic nuclei. Cambridge, New York: Cambridge University Press, 1997 
Piovezan P. P., O papel da reconexão magnética em sistemas astrfísicos com discos de acreção: dos AGNs aos YSOs, São Paulo: Universidade de São Paulo, 2009, Dissertação de Mestrado, $164 \mathrm{p}$.

Powell K. G., Roe P. L., Linde T. J., Gombosi T. I., De Zeeuw D. L., A Solution-Adaptive Upwind Scheme for Ideal Magnetohydrodynamics, Journal of Computational Physics, 1999, vol. 154, p. 284

Ray T., Dougados C., Bacciotti F., Eislöffel J., Chrysostomou A., Toward Resolving the Outflow Engine: An Observational Perspective, In Protostars and Planets V, 2007

Regev O., Gitelman L., Asymptotic models of meridional flows in thin viscous accretion disks, A\&A, 2002, vol. 396, p. 623

Reig P., Belloni T., van der Klis M., Does GRS 1915+105 exhibit "canonical" black-hole states?, A\&A, 2003, vol. 412, p. 229

Remillard R. A., McClintock J. E., X-Ray Properties of Black-Hole Binaries, ARA\&A, 2006, vol. 44 , p. 49

Reynoso M. M., Romero G. E., Magnetic field effects on neutrino production in microquasars, A\&A, 2009, vol. 493, p. 1

Romanova M. M., Ustyugova G. V., Koldoba A. V., Lovelace R. V. E., Magnetohydrodynamic Simulations of Disk-Magnetized Star Interactions in the Quiescent Regime: Funnel Flows and Angular Momentum Transport, ApJ, 2002, vol. 578, p. 420

Romanova M. M., Ustyugova G. V., Koldoba A. V., Lovelace R. V. E., The Propeller Regime of Disk Accretion to a Rapidly Rotating Magnetized Star, ApJ, 2004, vol. 616, p. 151

Romanova M. M., Ustyugova G. V., Koldoba A. V., Lovelace R. V. E., MRI-driven accretion on to magnetized stars: axisymmetric MHD simulations, MNRAS, 2011, vol. 416, p. 416

Rybicki G. B., Lightman A. P., Radiative Processes in Astrophysics. Wiley-VCH, 1986, 400 
Schulz N. S., From Dust To Stars Studies of the Formation and Early Evolution of Stars. From Dust To Stars Studies of the Formation and Early Evolution of Stars, by N.S. Schulz. Springer-Praxis books in astrophysics and astronomy. Praxis Publishing Ltd, 2005

Shakura N. I., Sunyaev R. A., Black holes in binary systems. Observational appearance, A\&A, 1973, vol. 24, p. 337

Shu F., Najita J., Ostriker E., Wilkin F., Ruden S., Lizano S., Magnetocentrifugally driven flows from young stars and disks. 1: A generalized model, ApJ, 1994, vol. 429, p. 781

Shu F. H., Self-similar collapse of isothermal spheres and star formation, ApJ, 1977, vol. 214 , p. 488

Soker N., Vrtilek S., Interpreting a Dwarf Nova Eruption as Magnetic Flare Activity, ARXIV, 2009

Spruit H. C., Magnetohydrodynamic winds and jets from accretion disks, ARXIV, 1996

Stone J. M., Pringle J. E., Magnetohydrodynamical non-radiative accretion flows in two dimensions, MNRAS, 2001, vol. 322, p. 461

Tagger M., Varnière P., Rodriguez J., Pellat R., Magnetic Floods: A Scenario for the Variability of the Microquasar GRS 1915+105, ApJ, 2004, vol. 607, p. 410

Takasaki H., Asai A., Kiyohara J., Shimojo M., Terasawa T., Takei Y., Shibata K., A Quantitative Study of the Homologous Flares on 2000 November 24, ApJ, 2004, vol. 613, p. 592

Tananbaum H., Gursky H., Kellogg E., Giacconi R., Jones C., Observation of a Correlated X-Ray Transition in Cygnus X-1, ApJ, 1972, vol. 177, p. 5

Toro E. F., Riemann Solvers and Numerical Methods for Fluid Dynamics: A Practical Introduction. 3rd ed. Springer, 2009, 724

Tremaine S., Gebhardt K., Bender R., Bower G., Dressler A., Faber S. M., Filippenko A. V., Green R., Grillmair C., Ho L. C., Kormendy J., Lauer T. R., Magorrian J., 
Pinkney J., Richstone D., The Slope of the Black Hole Mass versus Velocity Dispersion Correlation, ApJ, 2002, vol. 574, p. 740

Umurhan O. M., Nemirovsky A., Regev O., Shaviv G., Global axisymmetric dynamics of thin viscous accretion disks, A\&A, 2006, vol. 446, p. 1

Ustyugova G. V., Koldoba A. V., Romanova M. M., Chechetkin V. M., Lovelace R. V. E., Magnetocentrifugally Driven Winds: Comparison of MHD Simulations with Theory, ApJ, 1999, vol. 516, p. 221

Uzdensky D. A., Goodman J., Statistical Description of a Magnetized Corona above a Turbulent Accretion Disk, ApJ, 2008, vol. 682, p. 608

Uzdensky D. A., Königl A., Litwin C., Magnetically Linked Star-Disk Systems. I. Force-free Magnetospheres and Effects of Disk Resistivity, ApJ, 2002, vol. 565, p. 1191

von Rekowski B., Brandenburg A., Outflows and accretion in a star-disc system with stellar magnetosphere and disc dynamo, A\&A, 2004, vol. 420, p. 17

Wang D. X., H. L. W., Ma R. Y., Transfer of energy and angular momentum in the magnetic coupling between a rotating black hole and the surrounding accretion disc, MNRAS, 2003, vol. 342, p. 851

Wang D. X., Xiao K., Lei W. H., Evolution characteristics of the central black hole of a magnetized accretion disc, MNRAS, 2002, vol. 335, p. 655

Webster B. L., Murdin P., Cygnus X-1-a Spectroscopic Binary with a Heavy Companion?, Nature, 1972, vol. 235, p. 37

Zanni C., Ferreira J., MHD simulations of accretion onto a dipolar magnetosphere. I. Accretion curtains and the disk-locking paradigm, A\&A, 2009, vol. 508, p. 1117

Zdziarski A. A., Radiative Processes and Geometry of Spectral States of Black-hole Binaries, In Highly Energetic Physical Processes and Mechanisms for Emission from Astrophysical Plasmas, IAU Symposium, 2000, vol. 195, p. 153 
Apêndice 

Apêndice A

\section{Alguns conceitos e equações fundamentais de discos de}

\section{acreção}

O processo de acreção está relacionado com a concentração de matéria em torno de uma massa central devido à atração gravitacional. Em contrapartida, em sistemas do tipo disco onde o material está em rotação, esse processo é fortemente limitado pela ação de uma barreira centrífuga. Logo, um processo intrínseco ao disco deve agir para levar a uma remoção do momento angular e possibilitar que o gás seja deslocado radialmente em direção à fonte central. Esses sistemas são conhecidos como discos de acreção, e são observados em vários sistemas astrofísicos, desde núcleos ativos de galáxias, até sistemas binários, e protoestrelas. Apesar da sua diversidade, a estrutura e a dinâmica desses objetos podem ser entendidas por uma teoria que combina cisalhamento, viscosidade e turbulência. Nos últimos trinta anos, o problema central foi compreender quais são os processos intrínsecos ao disco que possibilitam que os mesmos acretem matéria. Em princípio, a presença de uma viscosidade de cisalhamento permite transferir momento angular de um elemento de fluído para o outro, mas não é suficiente para explicar as altas taxas de acreção que são ordens de grandeza superiores àquelas que a viscosidade microscópica pode oferecer. Por outro lado, os discos são, por vários motivos, turbulentos. Assim, a viscosidade turbulenta pode ser grande o suficiente para manter a acreção desses sistemas.

\section{A.1 Instabilidade magneto-rotacional}

Porém, uma grande questão deve ser feita: qual o fenômeno físico que poderia dar origem a turbulência no disco? Há cerca de duas décadas, Balbus e Hawley (1991) pro- 
puseram que discos de acreção, e outros sistemas com rotação diferencial, estão sujeitos a uma poderosa instabilidade mediada por um fraco campo magnético e conhecida como instabilidade magneto-rotacional (IMR). Segundo essa instabilidade o fraco campo magnético do disco exercerá uma força do tipo mola entre dois elementos de fluído muito próximos. Por exemplo, consideremos a situação mostrada na figura (A.1). Duas massas pontuais, inicialmente na mesma órbita, são deslocadas para duas novas órbitas muito próximas. A massa pontual $m_{i}$ é deslocada para uma órbita interna $r_{i}$, enquanto que a massa pontual $m_{o}$ é deslocada para uma órbita externa $r_{o}$. É fácil percebermos que em um disco Kepleriano $\left(\Omega^{2}(r)=G M / r^{3}\right)$, onde a velocidade azimutal e o momento angular são dados por:

$$
|\vec{v}|=r \Omega \propto r^{-1 / 2}
$$

e

$$
|\vec{L}|=|\vec{r} \times m \vec{v}|=m r^{2} \Omega \propto r^{1 / 2}
$$

a massa $m_{i}$ gira mais rápido que $m_{o}$. Neste processo a mola é esticada produzindo uma tensão $\vec{T}$ cujo torque exercido sobre $m_{i}$ fará com que esta massa perca continuamente momento angular, o oposto ocorre com $m_{o}$. Assim, $m_{i}$ não permanecerá mais em sua órbita $r_{i}$, deslocando-se para um raio menor. De forma similar, $m_{o}$, que ganha momento angular, será deslocado para um raio maior. Este efeito faz com que a mola se estique ainda

mais e o processo se repete, transportando momento angular para fora do disco. É crucial a existência de um campo magnético fraco, de maneira que a constante da mola não seja forte suficiente para permitir que ocorram várias vibrações dentro de um período orbital. Caso acontecesse, o cenário em que a mola é continuamente esticada não ocorreria e, consequentemente, interromperia o transporte de momento angular por essa instabilidade.

\section{A.2 Potência de acreção do disco}

A potência de acreção é um dos principais parâmetros físicos dos discos e, através dela, é possível estimar a taxa de acreção $(\dot{M})$ destes sistemas. É fácil demonstrar que (veja Frank et al., 1992):

$$
L_{a c c}=\frac{G M \dot{M}}{r},
$$




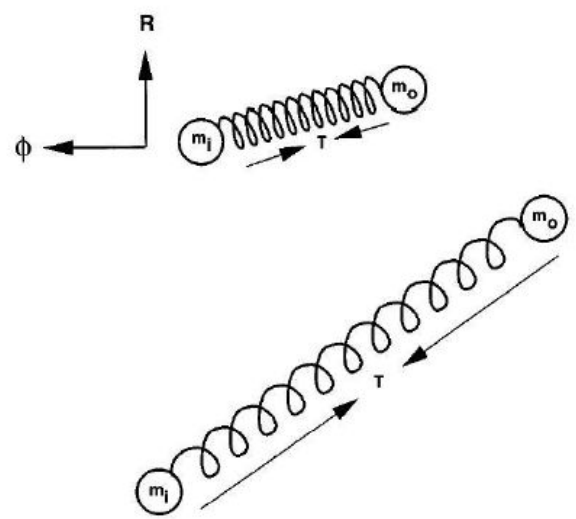

Figura A.1: Dois elementos de fluído em órbitas vizinhas conectadas por uma mola fraca. A mola exerce uma força de tensão restauradora sobre o sistema resultando em um transporte de momento angular para fora do disco Balbus e Hawley (1998).

onde $L_{a c c}$ é a potência de acreção, $G$ a constante gravitacional, $M$ a massa da fonte central, e $r$ a distância ao centro do sistema.

A interpretação da equação acima é simples: essa potência corresponde à liberação de energia gravitacional à medida que a matéria é espiralada para fonte central, porém, somente parte dessa energia será irradiada. Argumentos simples de virialização (veja dedução completa em Frank et al., 1992) sugerem que metade é convertida em energia cinética orbital e, eventualmente, pode ser transformada em radiação quando o material alcançar a superfície da fonte. Assim, é necessário incluir um fator de eficiência $\eta$ na equação (A.3).

A luminosidade bolométrica também é caracterizada, e até limitada, por uma quantidade denominada luminosidade de Eddington $\left(L_{E}\right)$. Essa quantidade é a luminosidade na qual o fluxo de momento da radiação de uma fonte esfericamente simétrica equilibra a pela força gravitacional do objeto central (Frank et al., 1992):

$$
L_{E}=\frac{4 \pi G m_{p} M c}{\sigma_{T}} \simeq 1.3 \times 10^{38} \frac{M}{M_{\odot}} \text { erg.s }^{-1},
$$

onde $m_{p}$ é a massa do próton, $c$ a velocidade da luz, e $\sigma_{T}$ a seção de choque de espalhamento Thompson.

Quando a luminosidade da fonte esférica excede $L_{E}$, a acreção é interrompida, já que a força devido à pressão de radiação excede a força gravitacional. Em discos, sob certas circunstâncias, a luminosidade pode exceder este valor por curtos períodos de tempo. Mesmo assim, este cenário reforça a ideia de que estes sistemas devem perder momento 
angular para voltarem a um regime sub-Eddington e, assim, voltarem a acretar matéria. No regime de Eddington, ou super-Eddington, a matéria impedida de acretar terá que escapar para fora do sistema na forma de um vento ou jato, já que não pode cair no objeto central.

\section{A.3 Discos Keplerianos}

Vamos considerar um disco em torno de uma massa $M$ localizada no centro de um sistema de coordenadas cilíndricas $(r, \phi, z)$. Vamos admitir que a massa central é a única responsável pela força gravitacional e vamos desprezar a auto gravidade do disco devido à sua baixa densidade. No estado de equilíbrio, a velocidade do fluido é caracterizada por uma componente azimutal $v_{\phi}$, chamada de velocidade Kepleriana, e uma pequena componente radial $v_{r}$, correspondente à acreção do material, onde $v_{r} \ll v_{\phi}$.

A velocidade Kepleriana é obtida, na direção radial, pelo balanceamento entre as forças gravitacional e centrífuga, de maneira que:

$$
\frac{v_{\phi}^{2}}{r}=\Omega^{2} r=\frac{G M}{r^{2}}
$$

Já a estrutura vertical do disco é definida pelo equilíbrio hidrostático, na direção z, dado por:

$$
\partial_{z} P=-\frac{G M \rho}{r^{3}} z=-\rho \Omega^{2} z
$$

onde $\rho$ é o perfil de densidade do disco. Para o caso de um disco isotérmico a equação (A.6) possui solução dada por:

$$
\rho=\rho_{0} e^{-\Omega^{2} z^{2} / 2 c_{s}^{2}} \equiv \rho_{0} e^{-z^{2} / H^{2}}
$$

onde $\rho_{0}$ é a densidade no plano médio do disco, $c_{s}^{2}=P / \rho$ é a velocidade do som isotérmica, e $H=\sqrt{2} c_{s} / \Omega$ é a escala de altura característica do disco. A razão $H / r$ é claramente uma medida da razão entre a velocidade do som e a velocidade de rotação local do sistema. Quando a velocidade de rotação $r \Omega$ excede a velocidade do som isotérmica do meio, o que ocorre frequentemente em casos astrofísicos, podemos dizer que o disco é fino, ou seja, a escala de altura $H$ satisfaz a condição de $H \ll r$. 
A pressão total do disco $P$ corresponde à soma entre a pressão térmica e a de radiação:

$$
P=\frac{\rho k_{B} T}{\bar{m}}+\frac{4}{3 c} \sigma T^{4}
$$

onde $\bar{m}$ é a massa média do gás.

Aqui vale destacar que as temperaturas do disco não são necessariamente constantes. Entretanto, a variação de temperatura entre a superfície e o plano médio do sistema é muito pequena se comparada à variação de densidade e, portanto, é comum definirmos a velocidade do som em termos somente da temperatura no plano médio.

Para o caso de um disco fino, onde $H / r$ é um parâmetro pequeno, podemos usar técnicas perturbativas mesmo quando a turbulência no disco está totalmente desenvolvida. Vamos definir a velocidade $\mathbf{u}$ como sendo a diferença entre a velocidade do fluído $\mathbf{v}$ e a velocidade circular na direção azimutal $r \Omega$, de maneira que:

$$
u_{r}=v_{r} \quad, \quad u_{\phi}=v_{\phi}-r \Omega, u_{z}=v_{z} .
$$

O campo de velocidades u será, no máximo, da ordem da velocidade térmica do sistema (assumindo que o disco não está sujeito à ação de um campo magnético intenso), já que flutuações supersônicas formarão choques e serão rapidamente dissipadas. A consequência prática de tomarmos $u / r \Omega \ll 1$ é que é possível analisar as correlações da velocidade turbulenta considerando apenas termos de segunda ordem.

Considerando um estado estacionário $\left(\partial_{t}=0\right)$, a componente radial do fluxo de momento angular (equação 3.2) a partir do campo de velocidades perturbadas (u) será dado por:

$$
F_{r}=r\left[\rho u_{r}\left(r \Omega+u_{\phi}\right)-\frac{B_{\phi} B_{r}}{4 \pi}\right],
$$

onde desprezamos os termos viscosos. Agora, tomando a média sobre $\phi$, integrando sobre a altura do disco em $z$ e tomando novamente a média sobre um pequeno intervalo radial $\Delta r$ (grande o suficiente para suavizar as rápidas flutuações associadas à estrutura radial detalhada) obtemos que:

$$
\left\langle F_{r}\right\rangle=\Sigma R\left[R \Omega\left\langle u_{r}\right\rangle_{\rho}+\left\langle u_{r} u_{\phi}-u_{A r} u_{A \phi}\right\rangle_{\rho}\right],
$$

onde $\Sigma=\int_{-\infty}^{\infty} \rho d z$ é a densidade superficial do disco. Assim, para qualquer quantidade $X$ temos que:

$$
\langle X\rangle_{\rho}=\frac{1}{2 \pi \Sigma \Delta r} \int X \rho d \phi d r d z
$$


As notações $u_{A r}, u_{A \phi}$ e $u_{A z}$ às componentes do campo de velocidades relacionado às flutuações do campo magnético $(\boldsymbol{B})$ :

$$
\mathbf{u}_{A}=\frac{\mathbf{B}}{\sqrt{4 \pi \rho}}
$$

É importante ressaltar que neste caso, esse campo de velocidade está sendo adotado mais como uma normalização do campo magnético flutuante e não deve ser confundido com a velocidade Alfvén $\left(v_{A}\right)$ que foi vista durante essa dissertação. A equação (A.13) refere-se à velocidade característica das ondas transversais que surgem num fluído magnetizado, denominadas de ondas Alfvén, para as quais o campo magnético na mesma equação corresponde ao campo em larga escala de primeira ordem (e não um campo flutuante).

O primeiro termo da equação (A.11) corresponde à uma parte do fluxo de momento angular, acoplado ao fluxo de acreção, que será carregada para dentro do disco. Já o segundo termo, corresponde ao o fluxo de momento angular que será carregado para fora do sistema, e representa a componente $r \phi$ do tensor de stress turbulento (Balbus e Hawley, 1998):

$$
W_{r \phi} \equiv\left\langle u_{r} u_{\phi}-u_{A r} u_{A \phi}\right\rangle_{\rho}
$$

A existência de um valor não-nulo para esse tensor implicará numa extração de momento angular de um elemento de fluido do disco que, consequentemente, levará o fluido a espiralar em direção ao centro do sistema. Portanto, a taxa de acreção de massa gerada por esse processo será dada por:

$$
\dot{M}=-2 \pi r \Sigma\left\langle u_{r}\right\rangle_{\rho}
$$

Agora, se admitirmos que a taxa de acreção não varia radialmente sob condições estacionárias e definindo uma fronteira interna onde o tensor de stress é nulo, que pode ser tomada como a superfície de uma estrela em $r_{*}$ com uma velocidade angular $\Omega_{*}$, temos que:

$$
-\frac{\dot{M}}{2 \pi} r \Omega+\Sigma r W_{r \phi}=-\frac{\dot{M}}{2 \pi r} r_{*} \Omega_{*} .
$$

Portanto, $W_{r \phi}$ pode ser definida como:

$$
W_{r \phi}=\frac{\dot{M} \Omega}{2 \pi \Sigma}\left[1-\left(\frac{r_{*}}{r}\right)^{1 / 2}\right] .
$$


Até agora, esta análise está sendo exata, pois o fluxo de momento angular não envolve correções maiores do que a de segunda ordem. O fluxo de energia, entretanto, contém momentos de ordem superior e, portanto, é nesse caso que técnicas de perturbação são mais úteis. Se considerarmos somente os termos dominantes da componente radial do fluxo de energia da equação (3.3) (tais como o das energias cinética, gravitacional e magnética), e adotando o campo de velocidades perturbadas (equação A.9), teremos que:

$$
F_{r}^{E}=\rho u_{r}\left(\Phi+\frac{1}{2} r^{2} \Omega^{2}+r \Omega u_{\phi}\right)-\frac{r \Omega}{4 \pi} B_{r} B_{\phi} .
$$

Usando o resultado virial Kepleriano $\Phi=-r^{2} \Omega^{2}$, encontramos que depois de integrar e tomar as médias, o fluxo de energia será:

$$
\left\langle F_{r}^{E}\right\rangle=\frac{\dot{M} r \Omega^{2}}{4 \pi}+\Sigma r \Omega W_{r \phi}
$$

Da equação (A.17) podemos reescrever a equação acima como:

$$
\left\langle F_{r}^{E}\right\rangle=\frac{3 G M \dot{M}}{4 \pi r^{2}}\left[1-\frac{2}{3}\left(\frac{r_{*}}{r}\right)^{1 / 2}\right] .
$$

Sabendo que a divergência do fluxo de energia fornece a emissividade superficial $Q$, temos que:

$$
Q=\frac{1}{r} \partial_{r} r\left\langle F_{r}^{E}\right\rangle=\frac{3 G M \dot{M}}{8 \pi r^{3}}\left[1-\left(\frac{r_{*}}{r}\right)^{1 / 2}\right] .
$$

Note que o tensor de stress não aparece nessa relação. Isso não é uma surpresa, já que a relação $Q-\dot{M}$ depende apenas da conservação local da energia e deve ser obtida independentemente da forma do tensor de stress (Shakura e Sunyaev, 1973). A abordagem que estamos usando aqui, no entanto, leva a uma relação entre $Q$ e as flutuações de primeira ordem do disco, que não são obtidas por outros métodos. Eliminando $\dot{M}$ das equações (A.17) e (A.21) teremos que:

$$
Q=\frac{3}{4} \Sigma \Omega W_{r \phi}=\frac{3}{4} \Sigma \Omega\left\langle u_{r} u_{\phi}-u_{A r} u_{A \phi}\right\rangle_{\rho},
$$

que é uma espécie de mecanismo dissipação flutuante associado à acreção nos discos (Balbus et al., 1994).

Podemos tomar a integral de $Q$ sobre toda a superfície do disco obtendo, assim, a sua luminosidade:

$$
L=2 \int_{r_{*}}^{\infty} Q(r) 2 \pi r d r=2 \pi r_{*}\left\langle F_{r}^{E}\right\rangle=\frac{G M \dot{M}}{2 r_{*}},
$$


onde o fator 2 de $2 \pi r_{*}\left\langle F_{r}^{E}\right\rangle$, corresponde aos dois lados disco. A equação (A.23) é justamente metade da potência de acreção definida na seção anterior pela equação (A.3). A outra metade, como já citado, é transformada em energia cinética orbital que, eventualmente, pode ser transformada em radiação quando o material alcança a superfície estelar.

Das equações acima é possível concluir que a luminosidade do disco de acreção tem origem na emissão do material nas regiões mais internas do sistema, já que a emissividade decai rapidamente com o raio $\left(Q \propto r^{-3}\right)$. Finalmente, de $Q=\sigma T^{4}$, obtém-se o perfil radial da temperatura $T \propto r^{-3 / 4}$.

\section{A.4 Parametrização $\alpha$ do disco}

Embora a relação entre a emissividade superficial do disco estacionário $Q$ e a taxa de acreção $\dot{M}$ seja independente das propriedades detalhadas do transporte do momento angular e da energia, a maior parte das grandezas do disco, tais como a temperatura $T(r)$, a densidade superficial $\Sigma(r)$, e a escala de altura do disco $H(r)$ dependem do tensor de stress $W_{r \phi}$. Reconhecendo a importância central de $W_{r \phi}$ e a sua inacessibilidade computacional na década de 70, Shakura e Sunyaev (1973) sugeriram que uma escala natural para o tensor de stress é $W_{r \phi} \sim c_{s}^{2}$ e introduziram o parâmetro $\alpha$, agora clássico:

$$
W_{r \phi}=\alpha c_{s}^{2}
$$

A ideia é que as velocidades turbulentas, cuja correlação determina $W_{r \phi}$, seriam limitadas pela velocidade do som local: velocidades em excesso a essa desenvolveriam choques e rapidamente atingiriam valores abaixo de $c_{s}$ devido à dissipação da energia cinética. Assim, é razoável admitir que $\alpha$ pode assumir valores da ordem ou menores do que 1, já que não há outro limite óbvio ou natural para que as velocidades turbulentas possam se desenvolver.

A partir desse simples modelo de parametrização, somos capazes de avaliar as condições físicas do disco de acreção sem que se faça qualquer suposição a respeito da origem física do processo turbulento que gera a remoção de momento angular do sistema. Além disso, como vimos na seção anterior, grandezas físicas, tais como a temperatura e densidade do disco mantem, uma correlação com $W_{r \phi}$ que, a partir desse modelo, pode ser determinada. Portanto, o conjunto de parâmetros que descreve um disco geometricamente fino e 
estacionário pode ser resumido nas seguintes equações:

$$
\begin{aligned}
& \rho_{d}=\Sigma / 2 H_{d}, \\
& H_{d}=\sqrt{2} c_{s} / \Omega, \\
& c_{s}^{2}=P_{d} / \rho d, \\
& P_{d}=\frac{\rho_{d} k_{B} T_{d}}{\bar{m}}+\frac{4 \sigma T_{d}^{4}}{3 c}, \\
& Q=\frac{3 G M \dot{M}}{8 \pi r^{3}}\left[1-\left(\frac{r_{*}}{r}\right)^{1 / 2}\right], \\
& Q=\frac{3}{4} \Sigma \Omega W_{r \phi} \\
& \tau\left(\Sigma, \rho_{d}, T_{d}\right)=\left(\rho_{d}, T_{d}\right) \Sigma \\
& W_{r \phi}=\alpha c_{s}^{2} .
\end{aligned}
$$

onde $\tau$ corresponde à profundidade óptica integrada do sistema. Se definirmos uma relação para a opacidade $\kappa$ e mantivermos como parâmetros livres $\dot{M}, M, r$ e $\alpha$, o conjunto de equações acima pode ser resolvido para as incógnitas $\rho_{d}, \Sigma, P$ e $T_{d}$.

Como descrito nesta dissertação (veja capítulo 2), ao considerarmos discos de acreção que giram em torno de microquasares ou NAGs, podemos considerar que a principal fonte de opacidade é o espalhamento Thomson, devido às altas temperaturas desses sistemas. 
Apêndice B

\section{Método Numérico e o código PLUTO}

O PLUTO é um código numérico multidimensional de rede adaptativa baseado no método de Godunov e é empregado tanto para resolver as equações da hidrodinâmica quanto da magnetohidrodinâmica, nos regimes clássico (HD e MHD) e relativístico (RHD e RMHD), em um sistema de coordenadas cartesianas, cilíndricas ou esféricas (veja Mignone et al., 2007). A evolução temporal é obtida através de métodos explícitos e os fluxos entre as células da grade computacional (geralmente identificados como problemas de Riemann, veja Toro, 2009) são computados através de uma entre as diferentes "Soluções de Riemann" (ou $\mathcal{R S}$, do inglês Riemann Solvers) disponíveis no código; desde o mais difusivo (e menos acurado), ao menos difusivo (e mais acurado). Nesta dissertação, em particular, utilizamos o módulo MHD do PLUTO, para um sistema de coordenadas esféricas $(r, \theta, \phi)$ com simetria axissimétrica $\left(\partial_{\phi}=0\right)$ em torno do eixo de rotação do sistema disco de acreção-fonte central. Configuramos o módulo MHD para utilizar um $\mathcal{R} \mathcal{S}$ do tipo HLL (solução aproximada de Harten, Lax, Van Leer; veja Miyoshi e Kusano, 2005), enquanto um esquema Runge-Kutta de segunda ordem foi usado para resolver a parte temporal das equações.

Este anexo tem como objetivo descrever, em linhas gerais, os principais passos para a resolução numérica das equações da magnetohidrodinâmica, realizadas nesta dissertação através do PLUTO. Uma descrição mais detalhada do código pode ser encontrada em Mignone et al. (2007) e um estudo mais profundo dos métodos numéricos em Toro (2009). 


\section{B.1 Estrutura do código}

O código PLUTO foi desenvolvido para integrar um conjunto de leis de conservação que pode ser escrito como:

$$
\frac{\partial \boldsymbol{U}}{\partial t}=-\nabla \cdot \boldsymbol{T}(\boldsymbol{U})+\boldsymbol{S}(\boldsymbol{U})
$$

onde $\boldsymbol{U}$ corresponde ao conjunto de variáveis conservativas; e $\boldsymbol{T}(\boldsymbol{U})$ e $\boldsymbol{S}(\boldsymbol{U})$ correspondem, respectivamente, aos fluxos e termos fontes de cada componente $\boldsymbol{U}$.

Para as equações da magnetohidrodinâmica na forma ideal (MHD), a equação (B.1) pode ser reescrita como:

$$
\frac{\partial}{\partial t}\left(\begin{array}{c}
\rho \\
\rho \boldsymbol{v} \\
\boldsymbol{B} \\
E
\end{array}\right)=-\boldsymbol{\nabla} \cdot\left(\begin{array}{c}
\rho \boldsymbol{v} \\
\rho \boldsymbol{v} \boldsymbol{v}+\left(p+\frac{\boldsymbol{B}^{2}}{8 \pi}\right) \boldsymbol{I}-\frac{\boldsymbol{B} \boldsymbol{B}}{4 \pi} \\
\boldsymbol{v} \boldsymbol{B}-\boldsymbol{B} \boldsymbol{v} \\
\left(E+p+\frac{\boldsymbol{B}^{2}}{8 \pi}\right) \boldsymbol{v}-\frac{(\boldsymbol{v} \cdot \boldsymbol{B}) \boldsymbol{B}}{4 \pi}
\end{array}\right)^{T}+\left(\begin{array}{c}
0 \\
\rho \boldsymbol{a} \\
0 \\
\rho \boldsymbol{v} \cdot \boldsymbol{a}
\end{array}\right)
$$

onde $\rho$ é a densidade; $p$ é a pressão térmica do gás; e os vetores $\boldsymbol{v}$ e $\boldsymbol{B}$ são, respectivamente, a velocidade e o campo magnético. Já o vetor $\boldsymbol{a}$, no termo fonte $\boldsymbol{S}(\boldsymbol{U})$, corresponde tanto ao vetor aceleração gravitacional quanto à soma deste com outras forças externas, tais como, a força de Coriolis. Por fim, E corresponde à densidade de energia total do gás, que é dada por:

$$
E=\frac{p}{\Gamma-1}+\frac{\rho \boldsymbol{v}^{2}}{2}+\frac{\boldsymbol{B}^{2}}{8 \pi}
$$

onde $\Gamma$ é definido como a razão entre os calores específicos para uma equação de estado ideal.

A divergência de $\boldsymbol{B}$ é mantida a partir de um conjunto de técnicas, à escolha do usuário. Em nossas simulações, utilizamos uma formulação denominada de constrained transport (veja Balsara e Spicer, 1999), que será descrita com mais detalhes na seção B.5.

A integração numérica da equação (B.1) é obtida através de um formalismo de volumes finitos e um algoritmo do tipo Godunov (veja Toro, 2009). Esse algoritmo é composto por três etapas: (a) uma rotina de interpolação; (b) a solução dos problemas de Riemann para os fluxos nas interfaces de cada célula da grade computacional; (c) e por um avanço temporal. 
É importante ressaltar que embora sejam as componentes das variáveis conservativas $\boldsymbol{U}$ que serão atualizadas na integração numérica da equação (B.1), os fluxos entre as células da grade computacional serão calculados a partir de suas variáveis primitivas, definidas pelo vetor $\boldsymbol{V}$. Essa escolha é apoiada, por exemplo, no fato de que a interpolação das variáveis primitivas evita com maior facilidade o surgimento de valores negativos para a pressão ou a densidade durante a integração numérica (Mignone et al., 2007). Assim, para o módulo MHD, teremos que:

$$
\boldsymbol{U}=(\rho, \rho \boldsymbol{v}, \boldsymbol{B}, E)^{T} \longrightarrow \boldsymbol{V}=(\rho, \boldsymbol{v}, \boldsymbol{B}, p)^{T}
$$

\section{B.2 Solução numérica}

A discretização da equação (B.1) é realizada a partir de uma grade retangular em um sistema genérico de coordenadas ortogonais $\left(x^{1}, x^{2}, x^{3}\right)$ (veja tabela B.1). Assim, se $N_{1}$, $N_{2}$ e $N_{3}$ correspondem ao número de pontos nas três direções, de maneira que $1 \leq i \leq N_{1}$, $1 \leq j \leq N_{2}$ e $1 \leq k \leq N_{3}$, a posição central de cada célula da grade computacional corresponderá a $\left(x_{i}^{1}, x_{j}^{2}, x_{k}^{3}\right)$.

A reconstrução das variáveis primitivas dentro das células da grade computacional, a partir dos valores centrais ou das faces (ou, ainda, de ambos), é obtida através de uma entre as diferentes rotinas de interpolação contidas no PLUTO (e.g., flat, linear, ceno3, parabolic e weno5; veja Mignone et al., 2007), e corresponde ao primeiro passo da resolução numérica segundo o método de Godunov. Os métodos de reconstrução devem satisfazer condições de monotonicidade, a fim de evitar oscilações espúrias nas proximidades das descontinuidades (i.e., nas interfaces entre as células; veja Toro, 2009, e referências lá contidas).

A forma discretizada dos termos do lado direito da equação (B.1), em um sistema genérico de coordenadas ortogonais $\left(x^{1}, x^{2}, x^{3}\right)$ (veja tabela B.1), é dada pelo operador $\mathcal{L}$, de maneira que:

$$
\mathcal{L}^{d}(\boldsymbol{V})=-\frac{1}{\Delta \mathcal{V}^{d}}\left(A_{+}^{d} \boldsymbol{F}_{+}^{d}-A_{-}^{d} \boldsymbol{F}_{-}^{d}\right)+\boldsymbol{S}^{d}
$$

onde $d=1,2$ e 3 define uma direção da grade computacional; $A_{ \pm}^{d}$ e $\Delta \mathcal{V}^{d}$ correspondem, respectivamente, às componentes das áreas da interface esquerda (-) e direita (+) e do volume da célula numa dada direção (veja tabela B.1); e a notação " \pm " em $d=1,2$ e 3 
corresponde, respectivamente, a:

$$
(i \pm 1 / 2, j, k),(i, j \pm 1 / 2, k) \text { e }(i, j, k \pm 1 / 2) .
$$

Tabela B.1 - Sistemas de coordenadas (i.e., coordenadas, volumes e áreas) adotadas pelo PLUTO. $r$ corresponde ao raio cilíndrico ou esférico, $\phi$ é o ângulo na direção azimutal $(0 \leq \phi \leq$ $2 \pi)$ e $\theta$ é o ângulo na direção polar $(0 \leq \theta \leq \pi)$. Aqui $\Delta^{n} r=\left(r_{+}^{n}-r_{-}^{n}\right) / n, \Delta \mu=\cos \theta_{+}-\cos \theta_{-}$, e $s_{+}=\operatorname{sen} \theta_{+}$.A notação " \pm " corresponde às interfaces esquerda e direita de uma dada célula da grade computacional.

\begin{tabular}{lccccccc}
\hline \hline Coordenadas & $\left(\mathrm{x}^{1}, x^{2}, x^{3}\right)$ & $\Delta \mathcal{V}^{1}$ & $\Delta \mathcal{V}^{2}$ & $\Delta \mathcal{V}^{3}$ & $\mathrm{~A}_{+}^{1}$ & $\mathrm{~A}_{+}^{2}$ & $\mathrm{~A}_{+}^{3}$ \\
\hline Cartesiana & $(\mathrm{x}, \mathrm{y}, \mathrm{z})$ & $\Delta x$ & $\Delta y$ & $\Delta z$ & 1 & 1 & 1 \\
Polar & $(\mathrm{r}, \phi, z)$ & $\Delta^{2} r$ & $\mathrm{r} \Delta \phi$ & $\Delta z$ & $\mathrm{r}_{+}$ & 1 & 1 \\
Esférica & $(\mathrm{r}, \theta, \phi)$ & $\Delta^{3} r$ & $\Delta^{3} r \Delta \mu$ & $\Delta^{3} r \Delta \mu \Delta \phi$ & $\mathrm{r}_{+}^{2}$ & $\Delta^{2} r s_{+}$ & $\Delta^{2} r \Delta \theta$ \\
& & & & & & & \\
\hline
\end{tabular}

Os fluxos $F_{ \pm}$correspondem, por sua vez, às soluções unidimensionais dos problemas de Riemann nas interfaces das células da grade computacional numa dada direção. Essas são computadas através de uma entre as diferentes "Soluções de Riemann" ( $\mathcal{R S}$ ) disponíveis no PLUTO (veja adiante), de maneira que:

$$
F_{+}=\mathcal{R S}\left(V_{+, L}, V_{+, R}\right)
$$

onde $V_{+, L}$ e $V_{+, R}$ correspondem, respectivamente, às variáveis primitivas à esquerda e à direita da interface da célula, em $x_{+}^{d}$, onde o Riemann solver é aplicado.

Por exemplo, para um sistema de coordenadas cartesianas na direção $d=1$, a equação (B.5) será escrita como:

$$
\mathcal{L}(\boldsymbol{V})=-\frac{1}{\Delta x}\left(\boldsymbol{F}_{i+1 / 2, j, k}-\boldsymbol{F}_{i-1 / 2, j, k}\right)+\boldsymbol{S},
$$

Já para um sistema de coordenadas esféricas (utilizadas em nossas simulações), também na direção $d=1$, teremos que:

$$
\mathcal{L}(\boldsymbol{V})=-\frac{1}{\Delta^{3} r}\left(r_{i+1 / 2, j, k}^{2} \boldsymbol{F}_{i+1 / 2, j, k}-r_{i-1 / 2, j, k}^{2} \boldsymbol{F}_{i-1 / 2, j, k}\right)+\boldsymbol{S}
$$

onde $\Delta^{3} r=\left(r_{i+1 / 2, j, k}^{3}-r_{i-1 / 2, j, k}^{3}\right) / 3$. 
Resolvido o problema de Riemann, partimos para a evolução temporal da equação (B.1). Para tanto, usamos um esquema Runge-Kutta de segunda ordem, onde a solução espacial é considerada separada da evolução temporal. Assim, conhecida a solução de $\boldsymbol{U}^{n}$ para uma dada célula em $t=t^{n}$, a evolução temporal será dada por:

$$
\begin{aligned}
& \boldsymbol{U}^{*}=\boldsymbol{U}^{n}+\Delta t \mathcal{L}^{n} e \\
& \boldsymbol{U}^{n+1}=\frac{1}{2}\left[\boldsymbol{U}^{n}+\boldsymbol{U}^{*}+\Delta t \mathcal{L}^{*}\right],
\end{aligned}
$$

onde o índice “*” corresponde a valores intermediários entre $t^{n}$ e $t^{n+1}$. Já para um esquema onde as contribuições do fluxo são calculadas simultaneamente para todas as direções (unsplit scheme), temos que $\mathcal{L}^{n}=\Sigma_{d} \mathcal{L}^{d}\left(\boldsymbol{V}^{n}\right)$, o qual foi usado em nossas simulações.

O passo temporal, por sua vez, é limitado pela condição de Courant-Friedrich-Lewy (veja Mignone et al., 2007) dada pela equação:

$$
\Delta t=C_{a} \frac{\min \left(\Delta x_{d}\right)}{\max \left(\left|\lambda_{\max }^{d}\right|\right)}, \quad C_{a}<1
$$

onde $\lambda_{\max }^{d}$ é o valor máximo da velocidade característica do sistema na região de descontinuidade em uma dada direção "d".

\section{B.3 Soluções de Riemann}

Em um caso unidimensional simples, em que $\boldsymbol{S}(\boldsymbol{U})=0$, resolver a equação (B.1) numa região separada do resto do domínio por uma descontinuidade e com uma condição inicial $\boldsymbol{V}(x, t=0)=V_{0}(x)$, é chamado de problema de Riemann. A solução desse problema, por sua vez, é obtida considerando-se os valores das variáveis primitivas à esquerda $\left(V_{+, L}\right)$ e à direita $\left(V_{+, R}\right)$ da região de descontinuidade, em $x_{+}$. Já que a equação (B.1) é do tipo hiperbólica, a sua solução é um conjunto de $m$ ondas (uma para cada variável), que se propagam no plano $x$-t.

Já no caso de uma grade unidimensional abrangendo o intervalo $[0, L]$, é necessário resolver o problema de Riemann $(\mathcal{R S})$ localmente para cada par de arestas. Por exemplo, para os pontos $i-1$ e $i$, resolve-se $\mathcal{R} \mathcal{S}\left(V_{i-1}, V_{i}\right)$ e para os pontos $i$ e $i+1$, resolve-se $\mathcal{R S}\left(V_{i}, V_{i+1}\right)$, o qual gera um padrão de ondas como o apresentado na figura B.1, emergindo dos pontos intermediários da grade computacional, $i-1 / 2$ e $i+1 / 2$, correspondente à região de descontinuidade. 


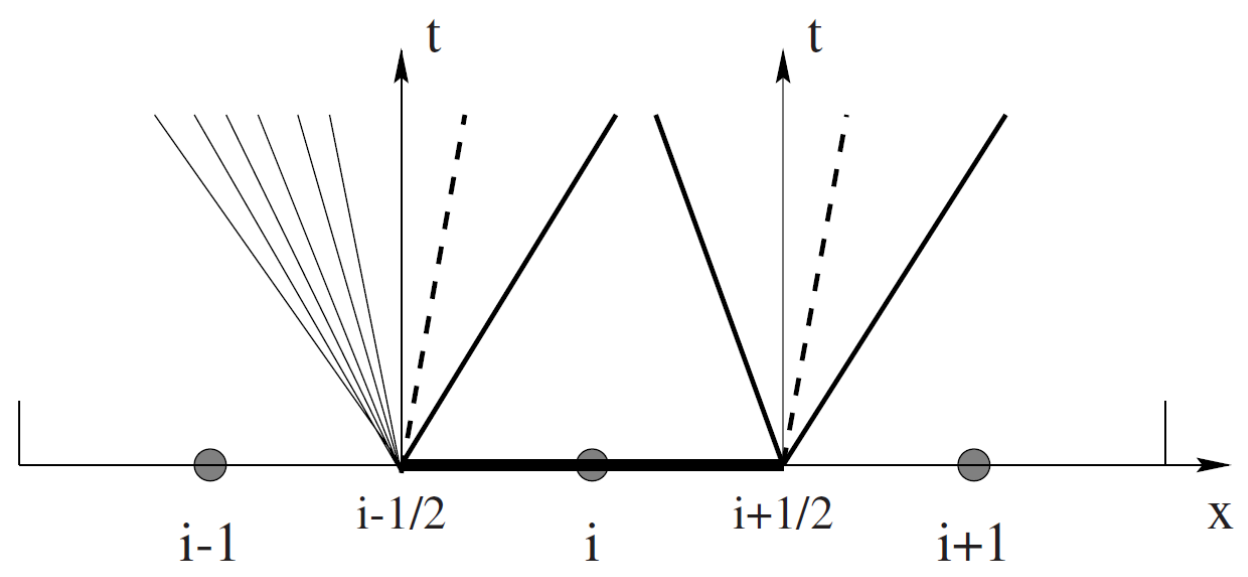

Figura B.1: Padrão de ondas gerado pela solução local do problema de Riemann nas interfaces das células em $i-1 / 2$ e $i+1 / 2$. Figura obtida de Toro (2009).

Como citado no início deste capítulo, configuramos o módulo MHD para utilizar um $\mathcal{R S}$ do tipo HLL (solução aproximada de Harten, Lax, Van Leer). Esse esquema calcula a solução do problema de Riemann a partir das estimativas das velocidades características à esquerda e à direita da descontinuidade, de forma que (Mignone et al., 2007; Toro, 2009; Miyoshi e Kusano, 2005)

$$
\boldsymbol{F}_{+}=\left\{\begin{array}{lc}
\boldsymbol{F}_{L} & \text { se } \lambda_{L}>0, \\
\boldsymbol{F}_{*} & \text { se } \lambda_{L} \leq 0 \leq \lambda_{R}, \\
\boldsymbol{F}_{R} & \text { se } \lambda_{R}<0
\end{array}\right.
$$

onde

$$
\boldsymbol{F}_{*}=\frac{\lambda_{L} \lambda_{R}\left(\boldsymbol{V}_{R}-\boldsymbol{V}_{L}\right)+\lambda_{R} \boldsymbol{F}_{L}-\lambda_{L} \boldsymbol{F}_{R}}{\lambda_{R}-\lambda_{L}}
$$

Nas equações acima $\lambda_{L}=\min \left(\lambda_{L}, 0\right)$ e $\lambda_{R}=\max \left(\lambda_{R}, 0\right)$ correspondem, respectivamente, à menor velocidade à esquerda e à maior velocidade à direita da descontinuidade. Além disso, omitimos o índice "+" por motivos de simplicidade.

Uma descrição mais completa desse esquema pode ser encontrada em Toro (2009), e a sua aplicação para o caso magnetohidrodinâmico, na forma ideal, em Miyoshi e Kusano (2005). 


\section{B.4 Termos fontes e termos dissipativos}

Para as simulações apresentadas nesta dissertação, onde incluímos os efeitos de viscosidade e um termo de resfriamento, o PLUTO usa uma versão modificada da equação (B.1), que é reescrita como:

$$
\frac{\partial \boldsymbol{U}}{\partial t}+\nabla \cdot \boldsymbol{T}(\boldsymbol{U})=\boldsymbol{\nabla} \cdot \boldsymbol{\tau}+\boldsymbol{S}(\boldsymbol{U})
$$

para a equação de momento $(\boldsymbol{U}=\rho \boldsymbol{v})$ e

$$
\frac{\partial \boldsymbol{U}}{\partial t}+\nabla \cdot \boldsymbol{T}(\boldsymbol{U})=\boldsymbol{\nabla} \cdot(\boldsymbol{v} \cdot \boldsymbol{\tau})+\boldsymbol{S}(\boldsymbol{U})
$$

para a equação de energia $(\boldsymbol{U}=E)$; onde $\boldsymbol{\tau}$ representa o tensor de "estresse" viscoso definido como:

$$
\boldsymbol{\tau}=\eta_{v}\left[(\boldsymbol{\nabla} \boldsymbol{v})+(\boldsymbol{\nabla} \boldsymbol{v})^{T}-2 / 3(\boldsymbol{\nabla} \cdot \boldsymbol{v}) \boldsymbol{I}\right]
$$

Na equação acima, $\eta_{v}$ corresponde à chamada viscosidade dinâmica.

Nesse caso, os termos fontes (que incluem todos os termos do lado direito não incluídos termo de divergência) são dados por:

$$
\boldsymbol{S}(\boldsymbol{U})=\left(\begin{array}{c}
0 \\
\rho \boldsymbol{g} \\
0 \\
\rho \boldsymbol{g} \cdot \boldsymbol{v}-\boldsymbol{\Lambda}_{\text {cool }}
\end{array}\right)
$$

onde $\boldsymbol{g}$ é o vetor aceleração gravitacional; e $\boldsymbol{\Lambda}_{\text {cool }}$ é o termo de resfriamento. Apesar de o código PLUTO conter um conjunto de diferentes funções de resfriamento, nós adotamos a função dada pela equação (3.15), que foi por nós implementada baseando-se nas simulações realizadas por Zanni e Ferreira (2009).

\section{B.5 Divergência de $\boldsymbol{B}$ e a técnica de divisão de campo}

Para manter a divergência do campo magnético nula $(\boldsymbol{\nabla} \cdot \boldsymbol{B}=0)$, utilizamos uma formulação denominada de constrained transport (CT, veja Balsara e Spicer, 1999), onde os valores do campo magnético são tratados tanto no centro $(\boldsymbol{B})$ quanto nas faces $(\boldsymbol{b})$ de 

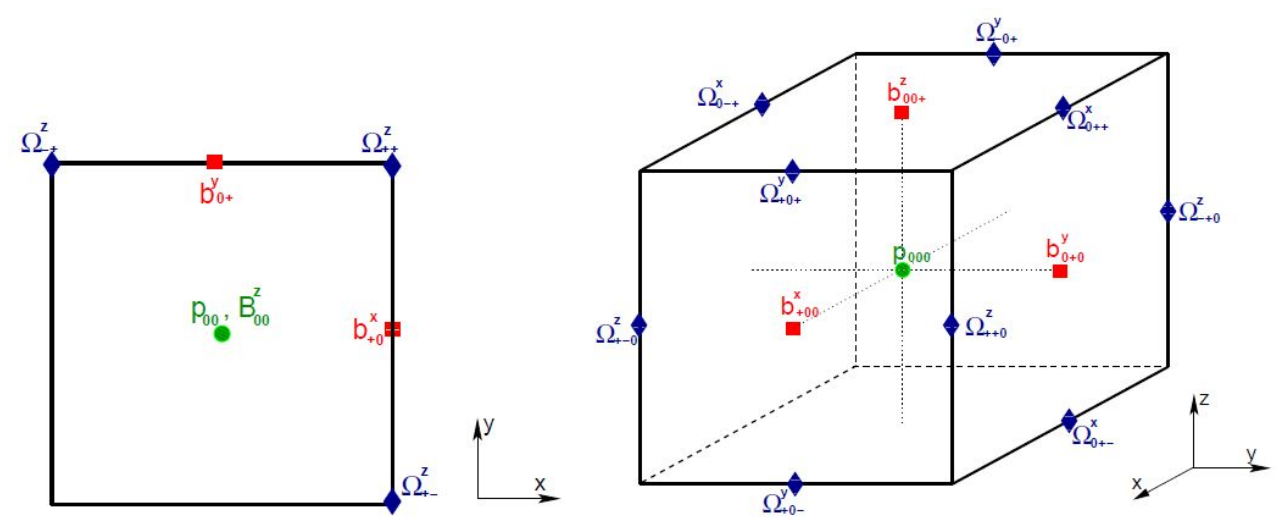

Figura B.2: Posição das componentes do campo magnético $(B$ e $b)$ e das demais variáveis $(p)$ no espaço bidimensional e tridimensional. As quantidades centrais são representadas pelos círculos verdes e as quantidades localizadas nas faces pelos quadrados vermelhos. Na formulação CT, a força eletromotriz $(\Omega)$ é definida nas bordas da célula, representada pelos losangos azuis. Figura obtida do manual do usuário do código PLUTO (http://plutocode.to.astro.it).

cada célula da grade computacional. As componentes do campo nas faces são posicionadas em diferentes pontos espaciais da célula (ver figura B.2), ou seja:

$$
b_{i+1 / 2, j, k}^{x, R} \quad, \quad b_{i, j+1 / 2, k}^{y, \theta} \quad, \quad b_{i, j, k+1 / 2}^{z, \phi} .
$$

Nesse método, as demais variáveis (densidade, pressão e velocidade) são definidas no centro das células e as condições iniciais do campo podem ser definidas a partir de seu potencial vetor $(\boldsymbol{B}=\boldsymbol{\nabla} \times \boldsymbol{A})$.

Associado à formulação CT, utilizamos uma técnica de divisão de campo (field-splitting technique; veja Powell et al., 1999) para tratarmos de forma adequada o intenso campo magnético de geometria dipolar, próximo à fronteira interna do domínio computacional. Essa é uma técnica empregada em problemas onde um campo magnético intrínseco e livre de forças (force-free, veja capítulo 2) está presente, de forma que o campo total é separado em uma componente estática $\left(\boldsymbol{B}_{0}\left(x^{d}\right)\right)$ e uma componente residual dependente do tempo $\left(\boldsymbol{B}_{1}\left(x^{d}, t\right)\right)$. Isso é possível no código PLUTO considerando-se as seguintes suposições:

$$
\boldsymbol{B}\left(x^{d}, t\right)=\boldsymbol{B}_{0}\left(x^{d}\right)+\boldsymbol{B}_{1}\left(x^{d}, t\right), \frac{\partial \boldsymbol{B}_{0}}{\partial t}=0, \quad \boldsymbol{\nabla} \cdot \boldsymbol{B}_{0}=0 \quad, \quad \boldsymbol{\nabla} \times \boldsymbol{B}_{0}=0 .
$$


Apêndice $\mathrm{C}$

\section{Tabela da emissão rádio observada em NAGs}

Tabela C.1 - Medidas da emissão em rádio para os jatos nucleares, na escala de parsecs, para galáxias Seyfert e LINERs obtidas por Nagar et al. (2005). As massas dos respectivos buracos negros centrais $\left(M / M_{\odot}\right)$ foram estimadas a partir dos valores de velocidade de dispersão das estrelas dessas galáxias $\left(v_{\sigma}\right)$, obtidos a partir do catálogo HYPERLEDA. Já a relação entre $M / M_{\odot}$ e $v_{\sigma}$ foi obtida do trabalho de Tremaine et al. (2002)

\begin{tabular}{|c|c|c|c|c|}
\hline Fontes (NGC) & NAG & Distância (Mpc) & $\log _{10}\left(M / M_{\odot}\right)$ & $L_{R}(\mathrm{erg} / \mathrm{s})$ \\
\hline 185 & Seyfert & 0,70 & 4,11 & $9,68 \times 10^{33}$ \\
\hline 315 & LINER & 65,80 & 9,10 & $3,68 \times 10^{40}$ \\
\hline 404 & LINER & 2,40 & 5,23 & $1,34 \times 10^{35}$ \\
\hline 474 & LINER & 32,50 & 7,77 & $2,86 \times 10^{37}$ \\
\hline 718 & LINER & 21,40 & 7,28 & $1,22 \times 10^{37}$ \\
\hline 1058 & Seyfert & 9,10 & 4,70 & $1,34 \times 10^{36}$ \\
\hline 1167 & Seyfert & 65,30 & 7,86 & $3,44 \times 10^{39}$ \\
\hline 1169 & LINER & 33,70 & 7,66 & $3,06 \times 10^{37}$ \\
\hline 1275 & Seyfert & 70,10 & 8,64 & $2,61 \times 10^{41}$ \\
\hline 1961 & LINER & 53,10 & 8,67 & $7,52 \times 10^{37}$ \\
\hline 2273 & Seyfert & 28,40 & 7,27 & $5,97 \times 10^{37}$ \\
\hline 2655 & Seyfert & 24,40 & 7,77 & $6,40 \times 10^{37}$ \\
\hline 2681 & LINER & 13,30 & 7,07 & $4,53 \times 10^{36}$ \\
\hline 2768 & LINER & 23,70 & 7,97 & $8,06 \times 10^{37}$ \\
\hline 2787 & LINER & 13,00 & 7,59 & $2,12 \times 10^{37}$ \\
\hline 2832 & LINER & 91,60 & 9,03 & $2,27 \times 10^{38}$ \\
\hline 2841 & LINER & 12,00 & 8,42 & $2,86 \times 10^{36}$ \\
\hline 2911 & LINER & 42,20 & 8,27 & $5,57 \times 10^{38}$ \\
\hline 3031 & Seyfert & 3,60 & 7,79 & $3,86 \times 10^{37}$ \\
\hline 3079 & Seyfert & 20,40 & 7,65 & $3,60 \times 10^{38}$ \\
\hline 3147 & Seyfert & 40,90 & 8,79 & $2,38 \times 10^{38}$ \\
\hline 3166 & LINER & 22,00 & 7,12 & $1,31 \times 10^{37}$ \\
\hline 3169 & LINER & 19,70 & 7,91 & $4,74 \times 10^{37}$ \\
\hline 3193 & LINER & 23,20 & 8,08 & $1,47 \times 10^{37}$ \\
\hline
\end{tabular}

Continua na próxima página... 
Tabela C.1 - Continuação

\begin{tabular}{|c|c|c|c|c|}
\hline Fontes (NGC) & NAG & Distância (Mpc) & $\log _{10}\left(M / M_{\odot}\right)$ & $L_{R}(\mathrm{erg} / \mathrm{s})$ \\
\hline 3226 & LINER & 23,40 & 8,23 & $4,97 \times 10^{37}$ \\
\hline 3227 & Seyfert & 20,60 & 7,59 & $2,67 \times 10^{37}$ \\
\hline 3254 & Seyfert & 23,60 & 7,21 & $1,50 \times 10^{37}$ \\
\hline 3301 & LINER & 23,30 & 7,25 & $1,47 \times 10^{37}$ \\
\hline 3368 & LINER & 8,10 & 7,35 & $1,16 \times 10^{36}$ \\
\hline 3414 & LINER & 24,90 & 8,43 & $2,55 \times 10^{37}$ \\
\hline 3486 & Seyfert & 7,40 & 5,97 & $9,91 \times 10^{35}$ \\
\hline 3516 & Seyfert & 38,90 & 7,36 & $3,52 \times 10^{37}$ \\
\hline 3607 & LINER & 19,90 & 8,34 & $1,14 \times 10^{37}$ \\
\hline 3623 & LINER & 7,30 & 7,54 & $8,63 \times 10^{35}$ \\
\hline 3626 & LINER & 26,30 & 7,53 & $1,85 \times 10^{37}$ \\
\hline 3642 & LINER & 27,50 & 7,72 & $1,72 \times 10^{37}$ \\
\hline 3718 & LINER & 17,00 & 7,85 & $5,45 \times 10^{37}$ \\
\hline 3900 & LINER & 29,40 & 7,56 & $2,32 \times 10^{37}$ \\
\hline 3941 & Seyfert & 18,90 & 7,54 & $7,02 \times 10^{36}$ \\
\hline 3945 & LINER & 22,50 & 7,89 & $1,64 \times 10^{37}$ \\
\hline 3982 & Seyfert & 17,00 & 6,22 & $5,20 \times 10^{36}$ \\
\hline 3998 & LINER & 21,60 & 8,75 & $4,74 \times 10^{38}$ \\
\hline 4036 & LINER & 24,60 & 7,96 & $1,64 \times 10^{37}$ \\
\hline 4051 & Seyfert & 17,00 & 6,11 & $5,20 \times 10^{36}$ \\
\hline 4111 & LINER & 17,00 & 7,60 & $6,55 \times 10^{36}$ \\
\hline 4138 & Seyfert & 17,00 & 7,51 & $7,69 \times 10^{36}$ \\
\hline 4143 & LINER & 17,00 & 8,32 & $1,72 \times 10^{37}$ \\
\hline 4151 & Seyfert & 20,30 & 7,17 & $9,25 \times 10^{37}$ \\
\hline 4168 & Seyfert & 16,80 & 7,98 & $1,53 \times 10^{37}$ \\
\hline 4169 & Seyfert & 50,40 & 8,26 & $5,45 \times 10^{37}$ \\
\hline 4203 & LINER & 9,70 & 7,90 & $1,61 \times 10^{37}$ \\
\hline 4258 & Seyfert & 6,80 & 7,60 & $2,17 \times 10^{36}$ \\
\hline 4261 & LINER & 35,10 & 8,72 & $6,70 \times 10^{39}$ \\
\hline 4278 & LINER & 9,70 & 9,20 & $1,50 \times 10^{38}$ \\
\hline 4293 & LINER & 17,00 & 7,62 & $3,60 \times 10^{36}$ \\
\hline 4314 & LINER & 9,70 & 7,04 & $1,68 \times 10^{36}$ \\
\hline 4374 & LINER & 16,80 & 9,20 & $9,25 \times 10^{38}$ \\
\hline 4378 & Seyfert & 35,10 & 8,11 & $3,28 \times 10^{37}$ \\
\hline 4388 & Seyfert & 16,80 & 6,80 & $1,11 \times 10^{37}$ \\
\hline 4394 & LINER & 16,80 & 7,48 & $4,53 \times 10^{36}$ \\
\hline 4395 & Seyfert & 3,60 & 5,04 & $2,07 \times 10^{35}$ \\
\hline 4450 & LINER & 16,80 & 7,30 & $1,01 \times 10^{37}$ \\
\hline 4457 & LINER & 17,40 & 6,86 & $5,45 \times 10^{36}$ \\
\hline 4472 & Seyfert & 16,80 & 8,80 & $1,89 \times 10^{37}$ \\
\hline 4477 & Seyfert & 16,80 & 8,00 & $5,08 \times 10^{36}$ \\
\hline 4486 & LINER & 16,80 & 9,48 & $1,37 \times 10^{40}$ \\
\hline 4494 & LINER & 9,70 & 7,65 & $1,34 \times 10^{36}$ \\
\hline
\end{tabular}

Continua na próxima página... 
Tabela C.1 - Continuação

\begin{tabular}{|c|c|c|c|c|}
\hline Fontes (NGC) & NAG & Distância (Mpc) & $\log _{10}\left(M / M_{\odot}\right)$ & $L_{R}(\mathrm{erg} / \mathrm{s})$ \\
\hline 4501 & Seyfert & 16,80 & 7,90 & $5,57 \times 10^{36}$ \\
\hline 4548 & LINER & 16,80 & 7,40 & $6,11 \times 10^{36}$ \\
\hline 4550 & LINER & 16,80 & 6,77 & $3,52 \times 10^{36}$ \\
\hline 4565 & Seyfert & 9,70 & 7,70 & $6,25 \times 10^{36}$ \\
\hline 4589 & LINER & 30,00 & 8,33 & $1,89 \times 10^{38}$ \\
\hline 4596 & LINER & 16,80 & 7,62 & $5,57 \times 10^{36}$ \\
\hline 4636 & LINER & 17,00 & 7,90 & $8,24 \times 10^{36}$ \\
\hline 4639 & Seyfert & 16,80 & 6,68 & $5,57 \times 10^{36}$ \\
\hline 4698 & Seyfert & 16,80 & 7,42 & $5,08 \times 10^{36}$ \\
\hline 4725 & Seyfert & 12,40 & 7,49 & $2,49 \times 10^{36}$ \\
\hline 4736 & LINER & 4,30 & 7,30 & $6,25 \times 10^{35}$ \\
\hline 4762 & LINER & 16,80 & 7,59 & $4,53 \times 10^{36}$ \\
\hline 4866 & LINER & 16,00 & 8,16 & $5,08 \times 10^{36}$ \\
\hline 5033 & Seyfert & 18,70 & 7,30 & $8,83 \times 10^{36}$ \\
\hline 5194 & Seyfert & 7,70 & 6,90 & $1,16 \times 10^{36}$ \\
\hline 5195 & LINER & 9,30 & 7,59 & $1,72 \times 10^{36}$ \\
\hline 5273 & Seyfert & 21,30 & 6,37 & $9,04 \times 10^{36}$ \\
\hline 5297 & LINER & 37,80 & 7,22 & $3,86 \times 10^{37}$ \\
\hline 5322 & LINER & 31,60 & 8,39 & $2,27 \times 10^{38}$ \\
\hline 5363 & LINER & 22,40 & 8,09 & $3,44 \times 10^{38}$ \\
\hline 5485 & LINER & 32,80 & 7,73 & $2,92 \times 10^{37}$ \\
\hline 5813 & LINER & 28,50 & 8,43 & $3,21 \times 10^{37}$ \\
\hline 6340 & LINER & 22,00 & 7,56 & $1,31 \times 10^{37}$ \\
\hline 6500 & LINER & 39,70 & 8,28 & $2,38 \times 10^{39}$ \\
\hline 6703 & LINER & 35,90 & 7,94 & $3,44 \times 10^{37}$ \\
\hline 6951 & Seyfert & 24,10 & 6,88 & $1,57 \times 10^{37}$ \\
\hline 7217 & LINER & 16,00 & 7,34 & $2,55 \times 10^{36}$ \\
\hline 7479 & Seyfert & 32,40 & 7,16 & $4,53 \times 10^{37}$ \\
\hline 7626 & LINER & 45,60 & 8,66 & $1,50 \times 10^{39}$ \\
\hline 7743 & Seyfert & 24,40 & 6,47 & $1,06 \times 10^{37}$ \\
\hline 7814 & LINER & 15,10 & 7,84 & $4,53 \times 10^{36}$ \\
\hline
\end{tabular}

